\title{
$\circlearrowleft$
}

UNIVERSIDAD PERUANA DE CIENCIAS APLICADAS

FACULTAD DE NEGOCIOS

PROGRAMA ACADEMICO DE ADMINISTRACIÓN DE EMPRESAS

PROGRAMA ACADEMICO DE MARKETING

PROGRAMA ACADEMICO DE ADMINISTRACIÓN DE BANCA Y FINANZAS

\section{Mi Bodeguita}

\section{TRABAJO DE INVESTIGACIÓN}

Para optar al grado académico de bachiller en Administración de Empresas

Para optar al grado académico de bachiller en Marketing

Para optar al grado académico de bachiller en Administración de Banca y Finanzas

\section{AUTORES}

Condori Cerón, Abel Alcides (0000-0002-0766-6724)

Chávez Lamilla, Enrique Oliverio (0000-0001-8450-9389)

Domínguez Melgarejo, Tania Joaquina (0000-0002-3897-886X)

Orosco Calero, Karina Edith (0000-0002-3048-0135)

\section{ASESOR}

Solís Pellanne, Pedro Martin (0000-0003-3272-337X)

Lima, 17 de julio de 2018 
A nuestras queridas familias, quienes nos apoyaron desde el inicio de nuestros estudios, y ahora ven cumplir las metas profesionales que cada uno se planteó en la vida. 


\section{RESUMEN}

Este proyecto denominado $\mathrm{Mi}$ bodeguita es el resultado de la experiencia profesional de sus integrantes que viendo la coyuntura actual, donde el tiempo es un factor importante en la vida de las personas, es que presentamos esta propuesta nueva y diferente que pensamos ayudará a los ciudadanos de Lima a abastecer su hogar de productos de primera necesidad.

Este proyecto estará dividido en dos partes, una dirigida a los clientes directos (bodegueros) y, por otro lado, los usuarios de la aplicación que realizarán sus compras.

Con Mi bodeguita, se plantea brindar a los bodegueros, el servicio de inventarios (manejos de stocks), orientarlos a la bancarización mediante pagos virtuales a elección del usuario, facilidad de pago de facturas de sus proveedores, etc. Adicionalmente, se le brindará apoyo a la captación de nuevos clientes.

Inicialmente abarcaremos los distritos de Miraflores, San Isidro y Surco que cumplen con los requisitos necesarios para poder emprender un negocio de este tipo, y según se vaya avanzando y cumpliendo con lo proyectado, se podría ingresar a distritos aledaños.

Actualmente no hay competencia directa en el mercado local. Esto, debido a que es un proyecto que nace de cero, con muchos obstáculos y trabas. Sin embargo, contamos con múltiples factores de éxito en los que se basará el siguiente trabajo: Equipo competitivo y motivado, atención personalizada al cliente, alianzas estratégicas con proveedores de tecnología certificados, etc.

Palabras clave : aplicación, ventas, mercado y tiendas. 


\begin{abstract}
This project called 'Mi Bodeguita' is the result of the professional experience of its members that seeing the current situation, where time is an important factor in the lives of people, present this new and different proposal because they think it will help citizens of Lima to supply their homes with essential products.

This project will be divided into two parts, one aimed at direct customers (the store owner) and, on the other hand, the users of the application that will make their purchases.

With 'Mi Bodeguita', it is proposed to provide the store owners the stocklists service (stocklist management), guide them to the bankarization through virtual payments at the user's choice, ease of payment of bills from their suppliers, etc. Additionally, support will be provided to attract new clients.

Initially we will cover the districts of Miraflores, San Isidro and Surco that since they meet the necessary requirements to start a business of this type, and as progress is made and the goal is reached, we could expand to neighboring districts.

Currently there is no direct competition in the local market. This, because it is a project that is born from scratch, with many obstacles. However, we have multiple success factors on which the following work will be based: Competitive and motivated team, personalized customer service, strategic alliances with certified technology suppliers, etc.
\end{abstract}

Key words : app, sales, market and stores. 


\section{Tabla de Contenidos}

RESUMEN EJECUTIVO .................................................................................

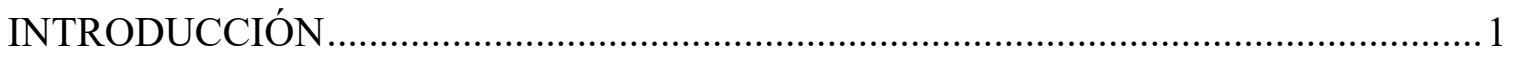

CAPÍTULO 1. ASPECTOS GENERALES DEL NEGOCIO .......................................... 3

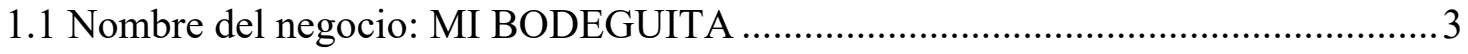

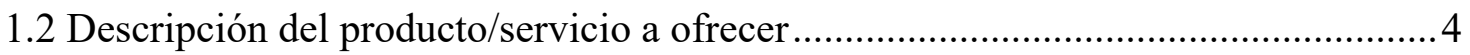

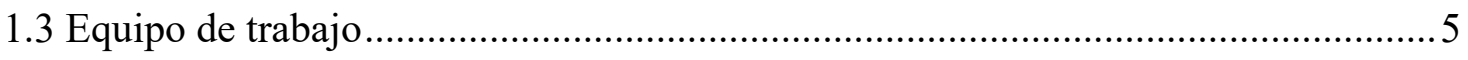

CAPÍTULO 2. PLANEAMIENTO ESTRATÉGICO ................................................... 7

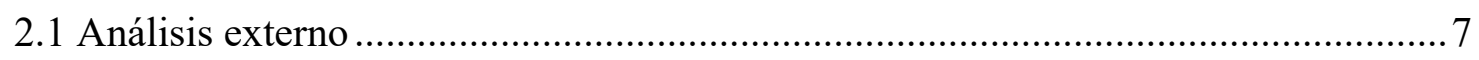

2.1.1 Análisis PESTEL: político-legal, social-cultural, demográfico, global, económico, medioambiental y tecnológico. ............................................................ 7

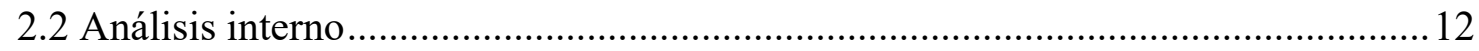

2.2.1 Análisis de las 5 fuerzas de Porter: Competidores, clientes, proveedores, productos sustitutos, competidores potenciales....................................................... 12

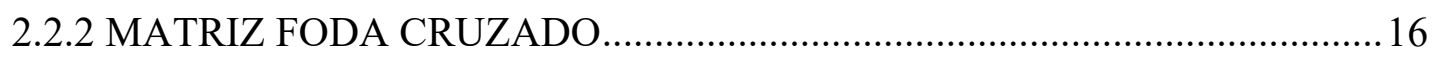

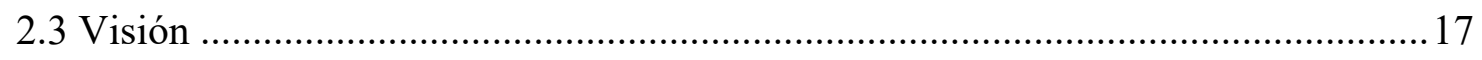

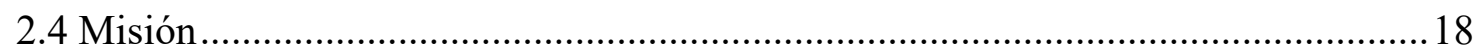

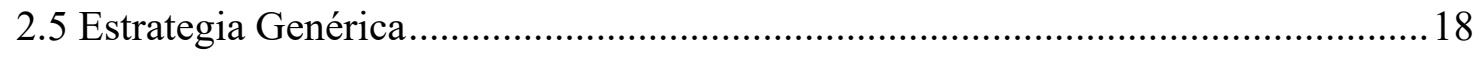

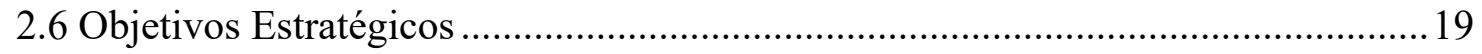

CAPITULO 3. INVESTIGACIÓN / VALIDACIÓN DE MERCADO............................20

3.1 Diseño metodológico de la investigación / metodología de validación de hipótesis

(n)

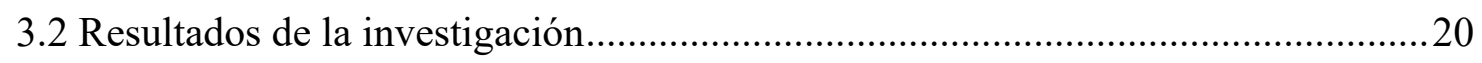

3.3 Informe final: Elaboración de tendencias, patrones y conclusiones........................26

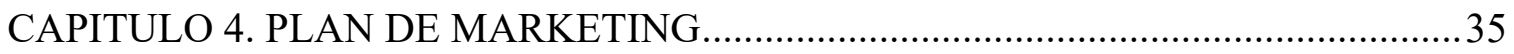

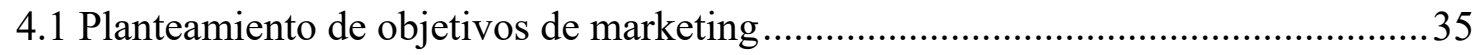

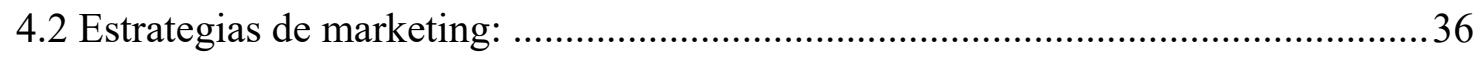

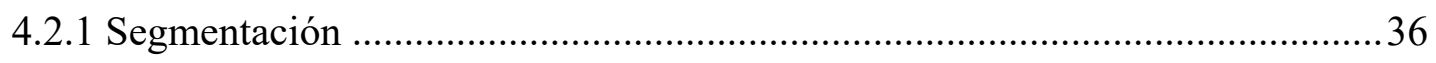

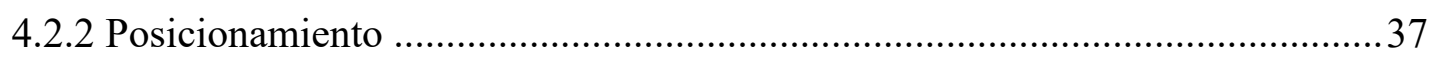

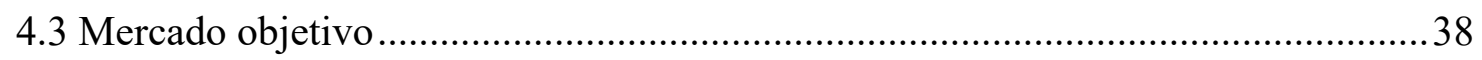

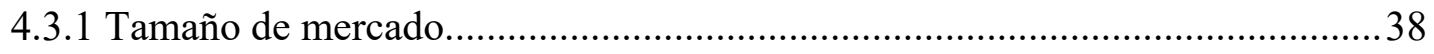




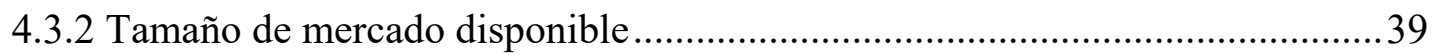

4.3.3 Tamaño de mercado operativo (target).........................................................40

4.3.4 Potencial de crecimiento del mercado ............................................................. 41

4.4 Desarrollo y estrategia del marketing mix.......................................................... 42

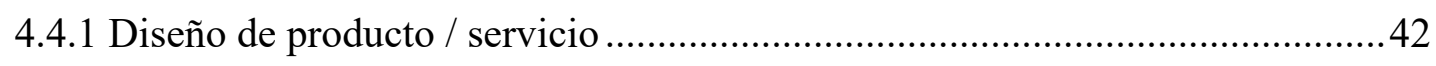

4.4.2 Estrategia de precios (Análisis de costos, precios de mercado) .......................43

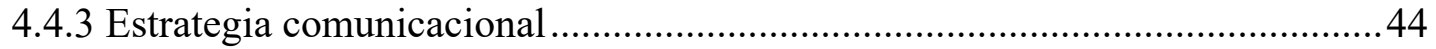

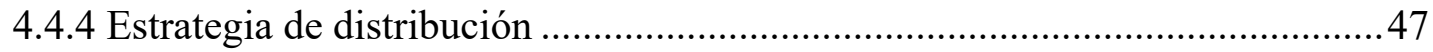

4.5 Plan de Ventas y proyección de la Demanda ...........................................................48

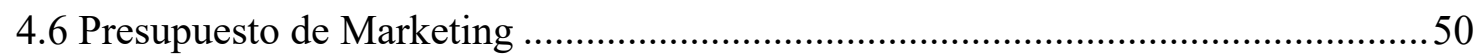

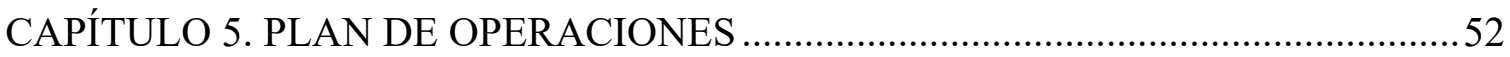

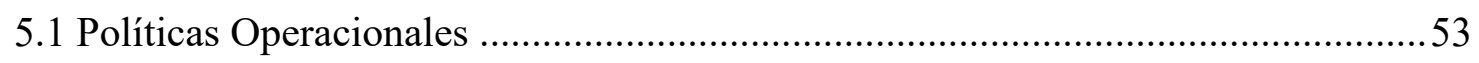

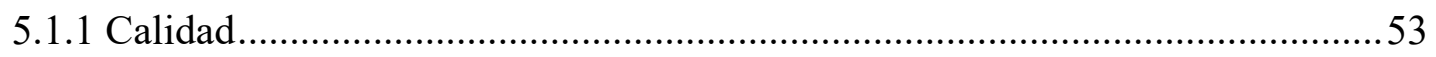

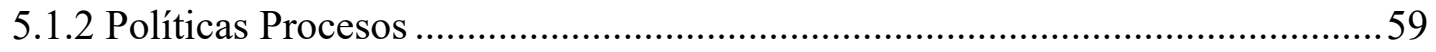

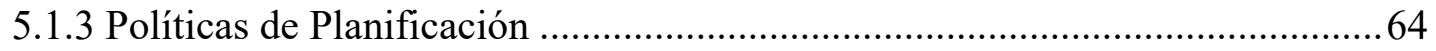

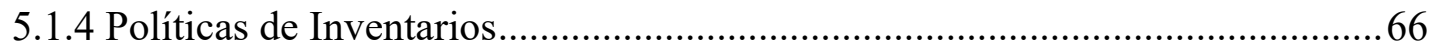

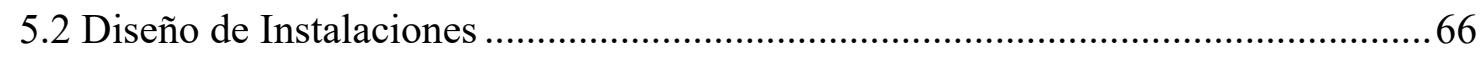

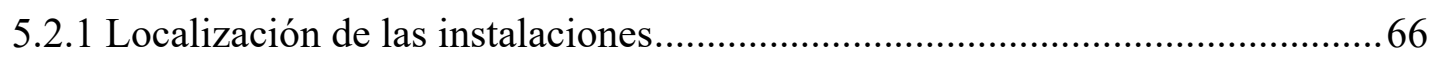

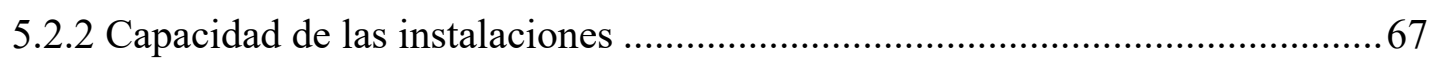

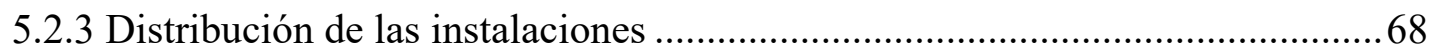

5.3 Especificaciones Técnicas del Producto / servicio ....................................................68

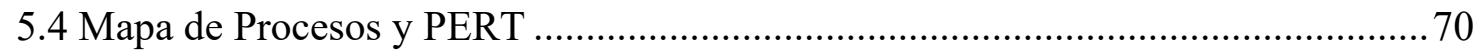

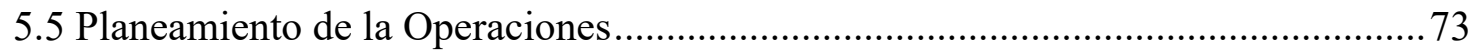

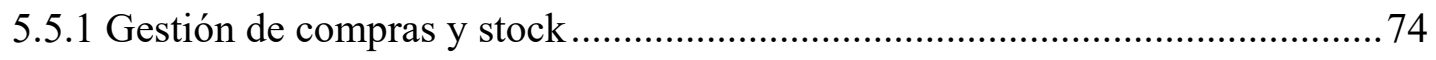

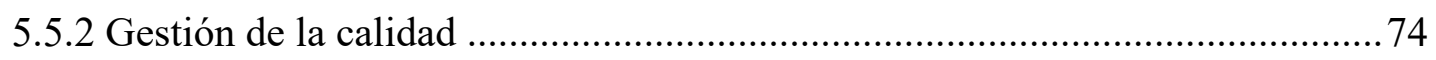

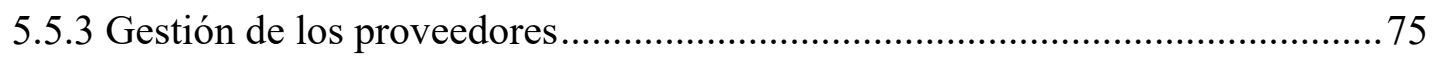

5.6 Inversión en activos fijos vinculados al proceso productivo..................................76

5.7 Estructura de costos de producción y gastos operativos........................................... 77

CAPÍTULO 6. Estructura organizacional y recursos humanos......................................... 78

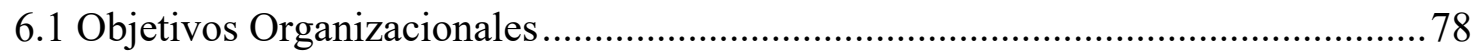

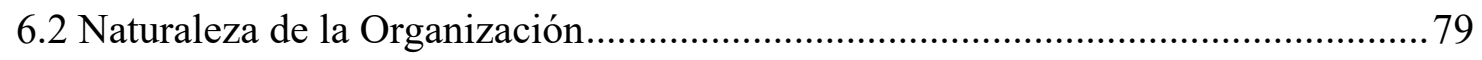

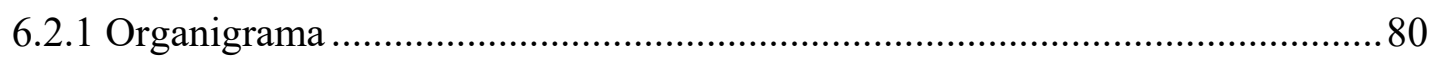

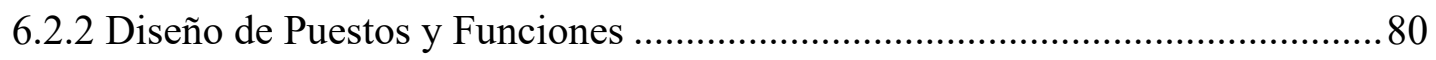

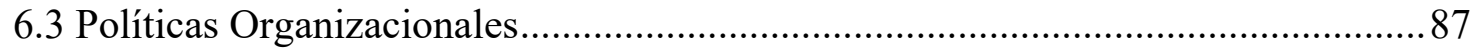




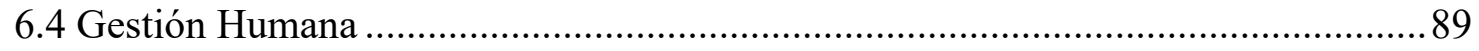

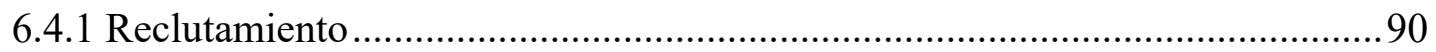

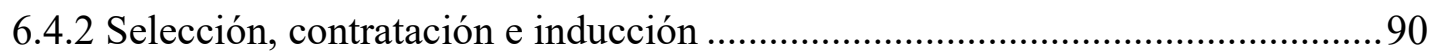

6.4.3 Capacitación, desarrollo y evaluación del desempeño ................................... 91

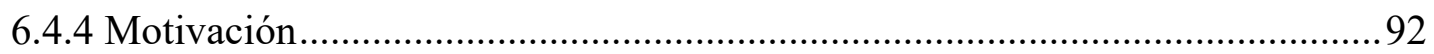

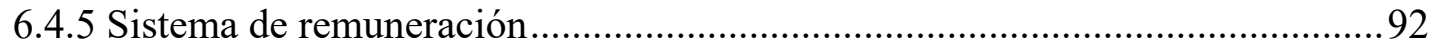

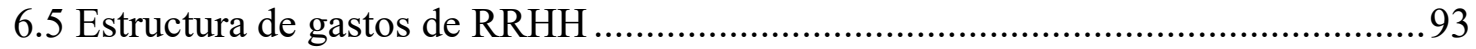

CAPÍTULO 7. PLAN ECONÓMICO - FINANCIERO ................................................ 95

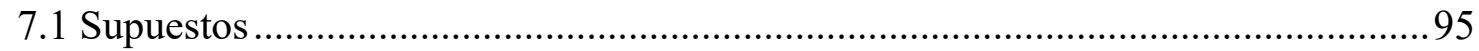

7.2 Inversión en activos (fijos, costos y gastos) …................................................... 97

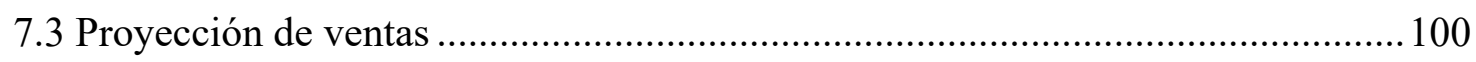

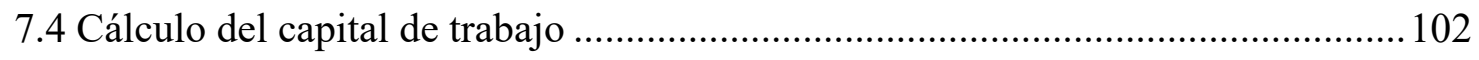

7.5 Estructura de financiamiento: Tradicional y no tradicional ................................. 103

7.6 Estados Financieros (Balance General, Estado de GGPP, Flujo de Caja) ............. 105

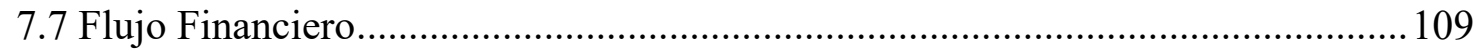

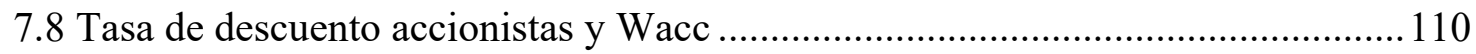

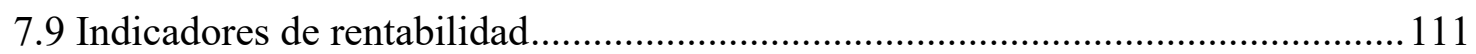

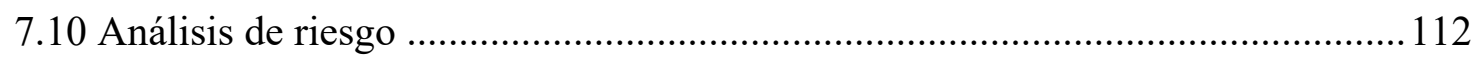

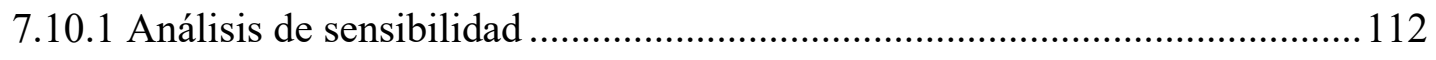

7.10.2 Análisis por escenarios (por variables) ...................................................... 113

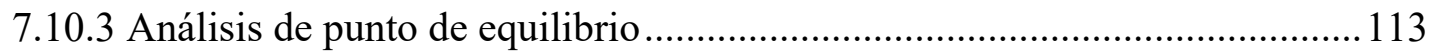

7.10.4 Principales riesgos del proyecto (cualitativos) ........................................... 114

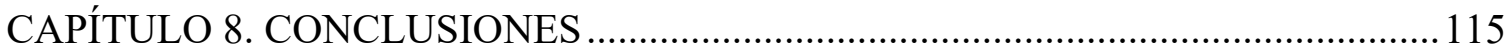

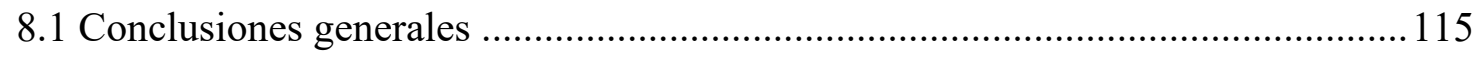

8.2 Conclusión Individual: Administración de Empresas Gestión Operativa................128

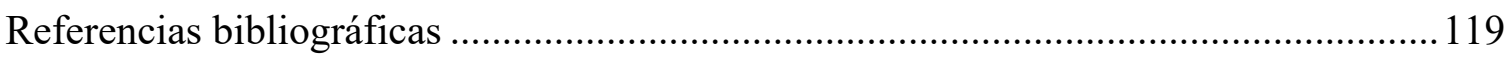

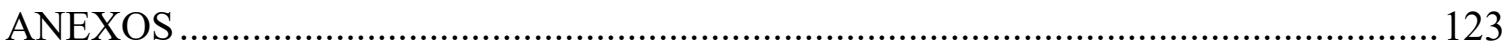




\section{Índice de Tablas}

Tabla 1 Puntaje de análisis de las 5 fuerzas de Porter sobre Mi Bodeguita ...................... 15

Tabla 2 Canvas de Mi Bodeguita - Elaboración propia.................................................. 33

Tabla 3: Basada en datos recopilados por la empresa; encuestas y datos de la Municipalidad

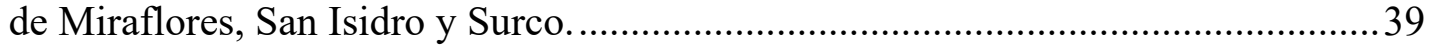




\section{Índice de Figuras}

Figura 1. Evolución oficial del tipo de cambio de dólar americano en el Perú - 2017 por

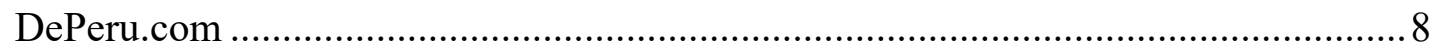

Figura 2. Cuadro de la evolución del PBI hasta mediados del 2017 por INEI..................9

Figura 3. Inflación peruana del 2012-2017 por Banco Central de Reserva del Perú........ 10

Figura 4. FODA cruzado de Mi Bodeguita - Elaboración propia.................................... 16

Figura 5. Estrategias genéricas de Porter por Wikipedia ................................................ 18

Figura 6. Número de visitas de la página de Facebook de M4rk3t (Negocios 1) - Base de la investigación de mercado .29

Figura 7. Mapa de empatía elaborado por ex M4rk3t (Mi Bodeguita) ..............................30

Figura 8. Experiment Board elaborado por ex M4rk3t (Mi Bodeguita) ............................ 31

Figura 9. Experiment Board por ex M4rk3t (Mi Bodeguita)............................................ 32

Figura 10. Ejemplo de bodega en Lima, elaborado por RPP Noticias ..............................38

Figura 11. Proyecciones de población por sexo, edad, elaborado por INEI- Perú ............41

Figura 12. Ejemplo de percepción de valor y sensibilidad al precio, elaborado por Prexus

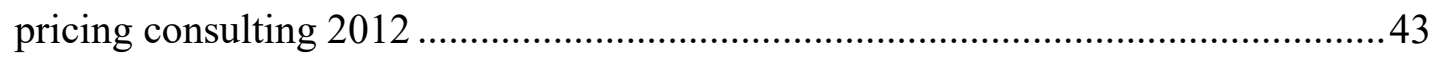

Figura 13. Ejemplo de promoción, elaborado por JPFitness ..........................................45

Figura 14. Ejemplo de formulario para ubicación de la bodega, elaborado por AlóBodega

Figura 15. Ejemplo de formulario para inscripción de distribuidores, elaborado por AlóBodega .46

Figura 16. Contacto con bodegueros, elaborado por El Comercio ..................................46

Figura 17. Ejemplo de inscripción de bodega, elaborado por AlóBodega .......................4 47

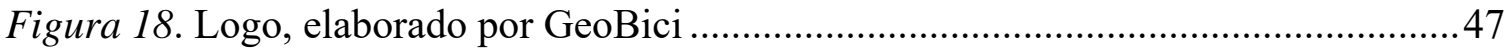

Figura 19. Ejemplo de proceso de negocios, elaborado por UPC Curso Desarrollo de

Negocios 2 BlackBoard (Ciclo 2018-1) ...................................................................59

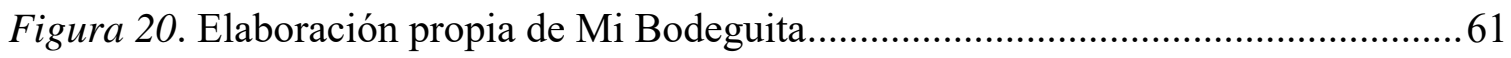

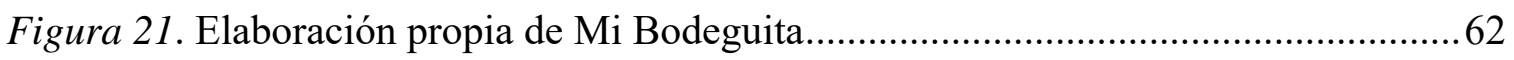

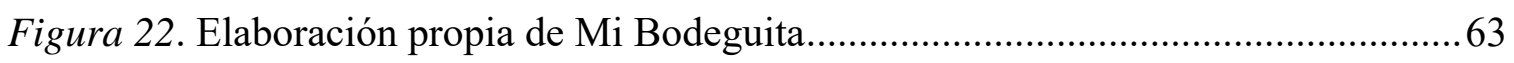

Figura 23. Mapa de ubicación de oficinas, elaborado por Comunal Coworking .............67

Figura 24. Modelo de oficina, elaborado por Comunal Coworking .................................6 68

Figura 25. Modelo de oficina, elaborado por ComScore - CNN Expansión .....................69

Figura 26. Elaboración propia de Mi Bodeguita.............................................................. 70 
Figura 27. Elaboración propia de Mi Bodeguita.......................................................... 76

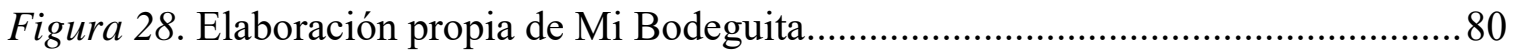




\section{Índice de Gráficas}

Gráfica 1. Distribución por edades de los dueños de bodegas encuestados - Elaboración propia.

Gráfica 2. Distribución por sexo de los dueños de bodegas encuestados - Elaboración propia

Gráfica 3. Distribución por uso de smartphones de los dueños de bodegas encuestados Elaboración propia.

Gráfica 4. Distribución por uso de aplicaciones de los dueños de bodegas encuestados Elaboración propia.

Gráfica 5. Distribución de compras por internet de los dueños de bodegas encuestados Elaboración propia.

Gráfica 6. Distribución de disposición de pago por servicio de los dueños de bodegas encuestados - Elaboración propia

Gráfica 7. Distribución de manejo de stocks con sistema virtual de los dueños de bodegas encuestados - Elaboración propia

Gráfica 8. Distribución de manejo directo de exhibición de productos de los dueños de bodegas encuestados - Elaboración propia

Gráfica 9. Distribución de manejo de servicio delivery de los dueños de bodegas encuestados - Elaboración propia .25

Gráfica 10. Distribución de uso de POS de los dueños de bodegas encuestados Elaboración propia. .25

Gráfica 11. Objetivos de marketing - Elaboración propia. 36

Gráfica 13. Elaboración propia de Mi Bodeguita .79 


\section{INTRODUCCIÓN}

En el día a día, las personas viven de manera acelerada por el trabajo, estudios, atención de sus familias, etc. Por ello, les falta tiempo para realizar sus actividades cotidianas, entre ellas las compras simples para sus hogares. Asimismo, con la masificación y uso de las aplicaciones, a través de los smartphones, se hace de fácil acceso la conexión de millones de usuarios y negocios. Cabe señalar que a pesar que existen supermercados que ofrecen distintos productos de primera necesidad y otros en general, las personas no desean invertir tiempo en acercarse a estos comercios para compras pequeñas, o tener que invertir importes económicos tan altos como los que realizan de manera semanal. Asimismo, estos negocios no están tan accesibles como una tienda cercana, de confianza, que les brinde precios adecuados y que le pueda brindar el valor agregado de ahorro de tiempo.

Por otro lado, se encuentran las bodegas de los distritos de Miraflores, San Isidro y Surco que son negocios familiares con aspiraciones, metas de crecimiento y que buscan la manera de generar más ingresos para sus negocios, aparte del canal tradicional que atienden.

Por ello, ante una necesidad no satisfecha de bodegueros para expansión, mejora económica, y supervivencia competitiva contra tiendas de conveniencia y supermercados, surge el proyecto empresarial Mi Bodeguita que plantea ser el nexo o convertirse en el intermediario entre las personas y las bodegas de los distritos de Miraflores, San Isidro y Surco. Con ello, se consigue conectar a las bodegas a nuevos nichos de mercados no atendidos (personas que no desean invertir tiempo en realizar pequeñas compras y que estarían dispuestos a pagar un porcentaje mínimo de comisión que se aplicarían a los productos de manera directa). Por ello, Mi Bodeguita se muestra como una aplicación de smartphones que permita a los usuarios acceder a una plataforma en donde puede escoger la bodega que lo atienda, cercana a su domicilio, hacer su pedido de productos de una lista virtual que la puede ver en línea (en el celular). Luego la bodega elegida, prepara el pedido, y se lo envía a la dirección del usuario (por medio de la geolocalización de la aplicación). El usuario puede elegir el pago de sus compras, a través de efectivo y tarjeta. Esta aplicación permite la posibilidad de desarrollar nuevas líneas de negocios para los clientes a quienes se dirige este proyecto (bodegueros). 
Finalmente, las principales limitaciones del proyecto es que solo se dirige, en un inicio, a tres distritos (Lima Moderna). Lo ideal es que a corto plazo, la aplicación Mi Bodeguita se expanda a los distritos aledaños o conos para una mayor cobertura de usuarios que permita afiliar más bodegas al proyecto (cliente principal). 


\section{CAPÍTULO 1. ASPECTOS GENERALES DEL NEGOCIO}

El grupo actualmente se encuentra conformado por un profesional en marketing, dos administradores y una financista. Con la participación de todo el equipo se propuso desarrollar una aplicación para smartphone, con la finalidad que se pueda realizar compras básicas en una bodega, además de programar su entrega por delivery o recojo en tienda. De esta manera, el cliente del bodeguero podrá optimizar su tiempo. Adicionalmente, el bodeguero podría ordenar sus inventarios y pagos a proveedores. Cabe señalar que, esta idea satisface la necesidad de los bodegueros que buscan generar mayores ingresos para sus negocios y la necesidad de sus usuarios para ahorrar tiempo en las compras.

La idea de este negocio está basada en usuarios potenciales e interesados en realizar compras sin tener que acercarse a las bodegas (nuevo nicho de mercado para los bodegueros) y en los bodegueros que se encuentran interesados en este nuevo público para aumentar sus utilidades.

Mi Bodeguita plantea atender de manera inicial a los distritos de Miraflores, San Isidro y Surco (Lima Moderna) dirigido a usuarios habituados al uso de celulares y aplicaciones. Posteriormente, se abarcará a distritos aledaños y a los conos de Lima Metropolitana.

\subsection{Nombre del negocio: MI BODEGUITA}

$$
\text { Mi Bodeguita }
$$




\subsection{Descripción del producto/servicio a ofrecer}

Se creó una aplicación para celulares que permita por medio de dos clics, realizar compras según la demanda de los clientes. Esto permitirá que el cliente del bodeguero ahorre tiempo, y como beneficio el bodeguero incremente los ingresos de su negocio.

En la aplicación Mi Bodeguita, se mostrará la ubicación de las bodegas más cercanas al lugar de origen del cliente, las opciones de productos, precios y formas de pago. Luego, el usuario realizará el pedido de los productos a elección y seleccionará la forma de pago (virtual, contra entrega, efectivo, etc.). Inmediatamente, la bodega seleccionada recibirá una alerta del pedido, procederá a prepararlo y enviarlo (delivery a pie, bicicleta o según decida el bodeguero utilizar) a la dirección indicada (dirección exacta desde donde se realizó el pedido). Cabe señalar que el pedido deberá llegar en un promedio de 30 minutos, aproximadamente, como parte de su eficiencia en la atención al cliente. En general, cuando se termina este proceso se estará generando un nuevo canal de atención para nuestros clientes (bodegueros), como efecto positivo incrementaran sus ventas por día (tickets), y tal vez decidan extender su negocio con nuevos locales.

La aplicación Mi Bodeguita es una idea de negocio que proporciona a los bodegueros una nueva opción de conectarse con millones de usuarios no atendidos, o por el contrario no desean invertir tiempo en acercarse a las bodegas. Esta nueva forma de comprar es un nuevo segmento fuera del canal tradicional y con herramientas actuales, a través del celular para el manejo adecuado de sus stocks, formas de cobro y ser atractivos a entidades financieras que les podrían otorgar créditos para su expansión. 


\subsection{Equipo de trabajo}

\section{Abel Alcides Condori Cerón}

Egresado de la carrera de Farmacia y Bioquímica, con más de 10 años de experiencia en áreas comerciales (Marketing \& Ventas). Posee experiencia en rubros como: salud, educación, comercio exterior, publicidad. En los últimos 5 años se ha especializado en la consultoría de RRHH (selección/capacitación).

$\mathrm{Su}$ aporte al trabajo estará relacionado a la parte estratégica del modelo de negocio, así mismo como al diseño del plan comercial

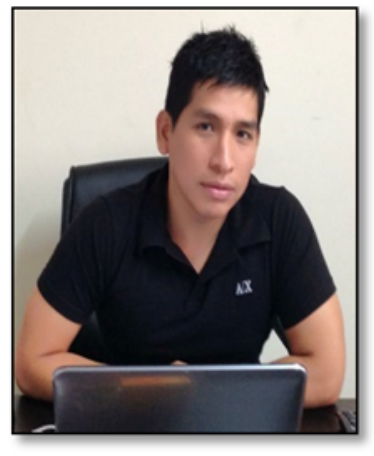
(Marketing \& Ventas).

\section{Enrique Chávez Lamilla}

Cuenta con estudios en informática y se ha desempeñado 10 años en ventas y marketing (Grupo El Comercio), su aporte será todo lo referente en la parte tecnológica para sacar este proyecto adelante.

\section{Tania Domínguez Melgarejo}

Profesional técnica titulada en Administración de Banca del Instituto de Formación Bancaria IFB (Certus), próxima egresada de la carrera de Administración de Banca y Finanzas de la Universidad Peruana de Ciencias Aplicadas UPC. Con tres años de experiencia en el rubro financiero con seminarios de Atención al Cliente.

Como aporte al trabajo brindaré mis conocimientos de finanzas y principales fuentes de financiamiento, reconociendo el mejor mercado para invertir que genere un mejor ingreso en un corto tiempo de

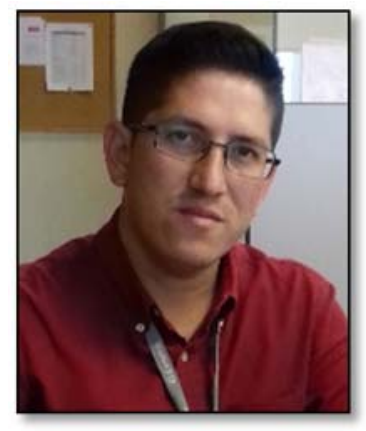
recuperación de capital. 


\section{Orosco Calero Karina Edith}

Profesional con estudios de Asistente de Gerencia y Diplomado en Gestión de Negocios. Con experiencia en el área administrativa de planificación de proyectos y presupuestos de investigación, ejecuciones, cumplimiento de metas y objetivos de planes estratégicos institucionales, y organización de eventos académicos. Ha trabajado en empresas del rubro educativo e idiomas. Su aporte estará enfocado a la planificación estratégica, observación y análisis de la ejecución del

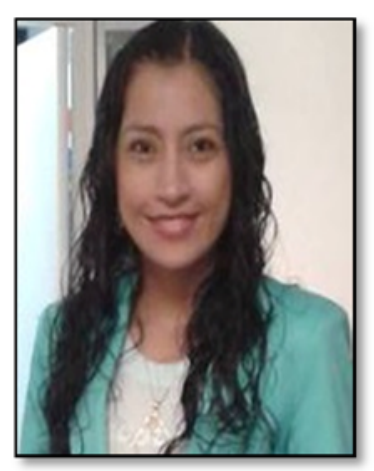
proyecto empresarial y todo lo referido a la gestión y dirección. 


\section{CAPÍTULO 2. PLANEAMIENTO ESTRATÉGICO}

\subsection{Análisis externo}

\subsubsection{Análisis PESTEL: político-legal, social-cultural, demográfico, global, económico, medioambiental y tecnológico.}

\section{Factor Político}

\section{Coyuntura política}

El año 2017 se ha caracterizado por ser complicado en varios sectores del país, provocado por el fenómeno del niño y por los escándalos de corrupción del llamado "club de la construcción". Durante el mes de diciembre el expresidente Pedro Pablo Kuczynski, tuvo que asumir una interpelación de vacancia por incapacidad moral lo que generó una inestabilidad política. Sin embargo, a inicios del 2018 esta intención de vacancia continuó, ya que salieron a la luz nuevas pruebas de corrupción, sumado a la presentación de unos videos de compra de voluntades que terminaron con el gobierno de turno. Esto ocasionó que el señor Martin Vizcarra asuma la presidencia de la republica a fin de asegurar una etapa de transición. La situación política actual aún es muy frágil, debido a que el nuevo presidente no cuenta con partido político y menos representación en el congreso, que lo obliga a pactar con las fuerzas políticas a fin de no seguir generando ingobernabilidad e inestabilidad política. La inestabilidad generada por el gobierno generó un tiempo corto de incertidumbre en todos los sectores, entre ellos el tecnológico, que nos afecta de manera directa. Sin embargo, la estabilidad política volvió a restablecerse. Por ello, el ambiente político permite de manera cautelosa salir al mercado con un nuevo producto, y a la vez acceder con sus restricciones a créditos e inversiones que permitan la expansión a futuro del proyecto. 


\section{Factor económico}

\section{Tipo de Cambio}

El tipo de cambio tiene un papel importante en este sector de innovación y desarrollo tecnológico y su volatilidad juega en contra, ya que hay un riesgo considerable que afecta al mercado de las inversiones. La economía global muestra un despegue considerable en distintos sectores, pero en la realidad local, observamos una desaceleración de la económica peruana en los últimos cinco años. Este factor se agudiza, ya que en la actualidad no se habla de una desaceleración, sino de un estancamiento económico.

Con el cambio de gobierno se rumoreo que este podría traer consecuencias fatales a nuestra economía e incluso se hablaba de un alza en el tipo de cambio, sin embargo, esto no fue así.

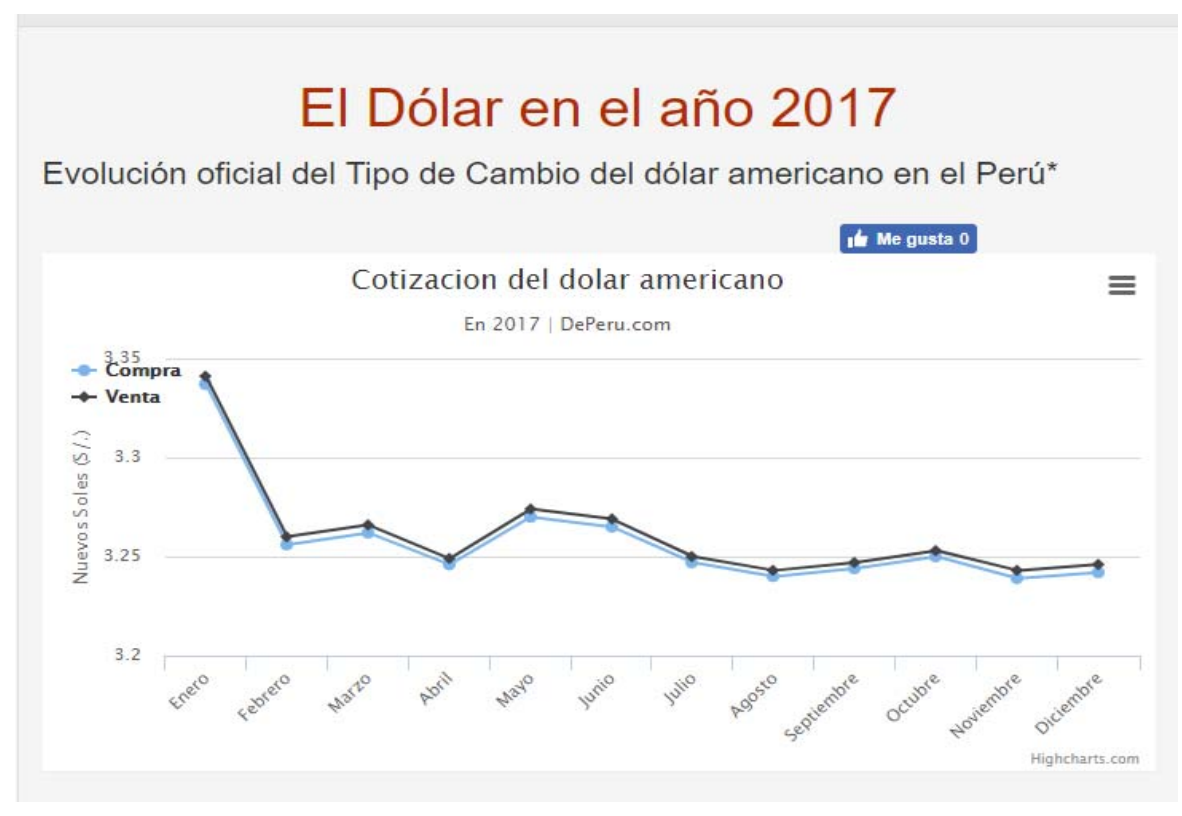

Figura 1. Evolución oficial del tipo de cambio de dólar americano en el Perú - 2017 por DePeru.com

El dólar en los últimos meses del año pasado ha subido muy ligeramente, lo cual afecto de manera negativa al sector, ya que el tipo inversión que se necesita para la plataforma de la aplicación Mi bodeguita y servidores están dolarizados. Es decir que los costos podrían incrementar con el alza del dólar, por los costos que 
generan el mantenimiento de la aplicación. Por otra parte, la demanda podría decrecer, ya que el sector tecnológico depende mucho de la innovación y modernización, la cual está supeditada a un factor tan sensible como el tipo de cambio. En el caso puntual de nuestro proyecto, este sería financiado en un inicio con capital propio, pero con una proyección de expansión con inversiones de terceros o créditos bancarios. Por ello, una variación en el tipo de cambio afectaría nuestros flujos de efectivo por tasas de interés que se tendrían que realizar para el buen desarrollo de la aplicación.

\section{PBI}

El crecimiento de la economía peruana se ha logrado sostener en los últimos meses gracias al buen desempeño que ha tenido los sectores primarios, puntualmente el de minería. El PBI del año 2017, se calcula que fue de un 2.5\%.

Por otro lado, para el proyecto de negocio, en la parte del factor económico, se podría ver afectado por el crecimiento o decrecimiento de la actividad de comercio, debido a que nuestros clientes se concentran en las bodegas (comercios pequeños).

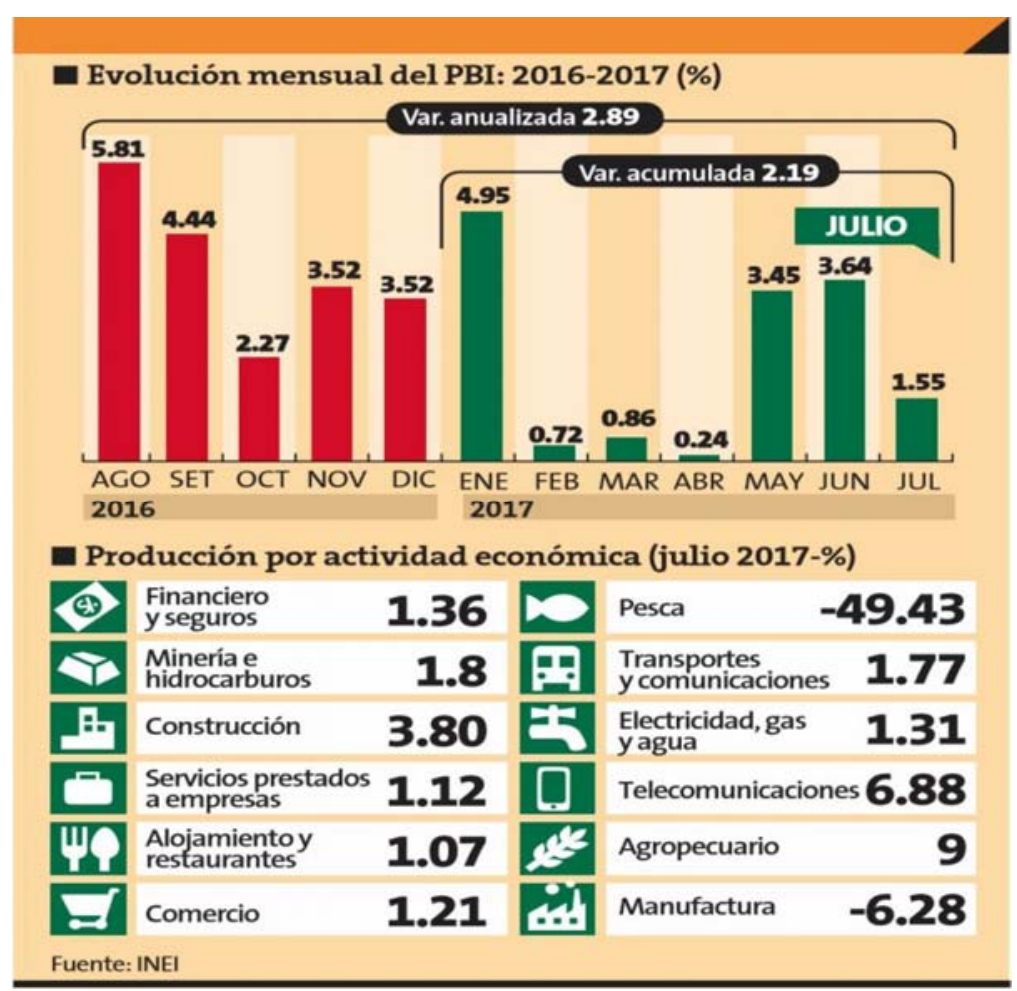

Figura 2. Cuadro de la evolución del PBI hasta mediados del 2017 por INEI 
Por otro lado, según el Instituto Nacional de Estadística e Informática (INEI) la inflación de Perú ascendió a 1,36 \% en 2017, la más baja desde 2009, con una tasa promedio mensual de 0,11. Sin embargo, se detalla que el Banco Central de Reserva del Perú emitió un informe de la inflación peruana hasta el año 2017, en donde se evidencia que en el 2017 se presenta una inflación del 3.80\%, que presenta una inflación medianamente estable.

Por otro lado, la cámara de comercio de Lima indica que la desaceleración de la economía y el aumento de restricciones en el acceso a créditos bancarios, han presionado al sector tecnológico, ocasionando una disminución en sus ventas.

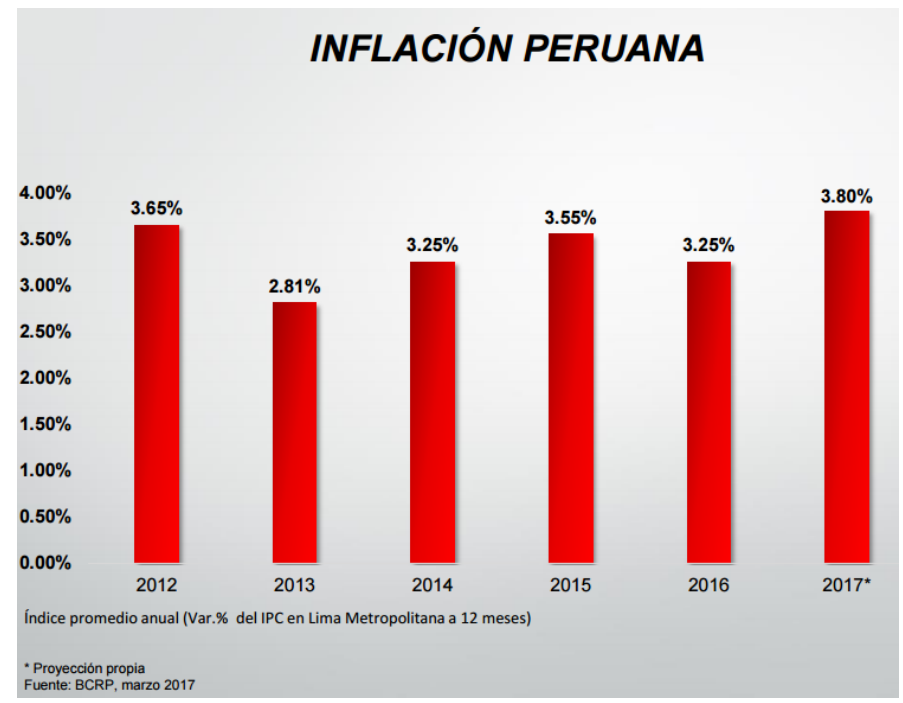

Figura 3. Inflación peruana del 2012-2017 por Banco Central de Reserva del Perú

\section{Factor Social}

La consultora Arellano indica que el nivel de consumo de los servicios y/o productos se ha elevado, a través de las plataformas virtuales. Este aumento del tráfico en las transacciones ayuda a analizar, no solo el mercado local sino el global, ya que el acceso a la comunicación y tecnología ha dejado de ser una exclusividad. La tendencia consumista del cliente ha variado considerablemente. Esto, debido a los gustos y tendencias de moda global, elevando el ingreso de las empresas con plataformas online y perfilando el nivel de la población segmentándola.

\section{Factor Tecnológico}


El boom tecnológico favorece significativamente a todos los mercados y mucho más al tecnológico e innovador, ya que la cifra de la población peruana con acceso a internet en Perú es del 49\% y se estima que éste se incrementará rápidamente en un futuro cercano. Este fenómeno ha sido favorable para las plataformas virtuales, puesto que, gracias a los aplicativos móviles actuales, se puede comunicar en tiempo real las ofertas de productos y/o servicios, también se puede acceder a un recorrido virtual y dinámico de las diversas tiendas físicas sin tener que salir de tu casa u oficina.

Se espera que en un futuro la demanda de las plataformas que optan por el comercio de productos crezca considerablemente, reduciendo los avisos en diarios y revistas de gran manera. El dinamismo del factor tiene un avance considerado en el sector que propicia la penetración de segmentos con el nuestro.

\section{Factor Legal:}

El marco legal fomenta el desarrollo constante de diversas plataformas virtuales e incluso va un poco más allá, puesto que no solo fomenta la innovación sino también la formalización, a través de leyes que incentivan a la creación de asociaciones productivas y/o Mypes. Dentro de una de las acciones legales considerables tenemos la reducción en los tiempos de la constitución de una empresa, así como también la flexibilidad en la tributación (IGV) de acuerdo con el esquema de facturación según escalas. Otra variable muy importante, es que nuestro proyecto fomenta la formalización de muchos pequeños negocios, lográndolos introducir al sistema financiero, bancarizando sus operaciones y así puedan lograr tener accesos a créditos. 


\subsection{Análisis interno}

\subsubsection{Análisis de las 5 fuerzas de Porter: Competidores, clientes, proveedores, productos sustitutos, competidores potenciales.}

\section{- Poder de negociación del cliente}

Los clientes (bodegueros) se encuentran en un rango de edad de 25 a 45 años y desean abarcar más mercado o captar mayor clientela, así como tienen la meta de abrir nuevas bodegas. Sin embargo, presentan algunos inconvenientes de financiamiento. Cabe señalar que los bodegueros del rango de edad descrito están familiarizados con el uso de aplicaciones en los celulares y podrían tener interés en una alternativa adicional para nuevos ingresos (Mi bodeguita) contra el canal tradicional se esperar que sus consumidores se acerquen a sus negocios. Por ello, el poder de negociación de los clientes es bajo. Esto, debido a los beneficios que le ofrece la aplicación para incrementar sus ingresos y atendiendo a un nicho de mercado que no han tenido en cuenta y que la aplicación les ofrece.

\section{- Poder de negociación del proveedor}

Los proveedores de este tipo de negocio están conformados por empresas que desarrollan apps y software para distintos servicios. Cabe señalar que, debido a la innovación en el uso de tecnología para diferentes tipos de usuarios, a través de los celulares, se ha incrementado la demanda de empresas que brinden este tipo de servicio. Por otro lado, los costos y precios de los recursos necesarios para esta industria (software y apps) son competitivos. Asimismo, el precio de venta de las aplicaciones en general está decreciendo, porque estas empresas se enfocan en atender a un gran volumen de usuarios para reducir sus precios. Por otra parte, los negocios de bodegas forman parte de la línea de proveedores, ya que son los encargados de contar con un stock adecuado y de la calidad esperada por el usuario del servicio. Así, como se puedan amoldar a los tipos de cobro, delivery y/o precios 
estándares para que sean más competitivos. Por ello, el poder de negociación de los proveedores es bajo. Esto se da por una gran oferta de proveedores que son competitivos en costos.

\section{- Amenaza de nuevos competidores}

Las barreras de ingreso para nuevos competidores son moderadas, debido a que no es necesario contar con gran conocimiento del uso o desarrollo de este tipo de aplicación por otros inversionistas. Esto se refleja en el acceso a programas que desarrollan las aplicaciones a cambio de una inversión mediana. Sin embargo, la amenaza del ingreso de nuevos competidores es moderada, ya que existe en el mercado una aplicación para bodegas: “Aló Bodega. Cabe señalar que, esta aplicación, maneja un distribuidor que le proporciona el pedido y delivery, pero tardan mucho tiempo en entregar los pedidos a sus usuarios. En contra parte, Mi bodeguita sería un intermediario entre las bodegas y los usuarios, pero se enfocaría en su cliente directo (bodegueros) para la uniformización de tiempos de entrega de los pedidos y beneficios de asesoría en manejo de stocks, gama de productos y el plus de bancarizar y llevar a estos negocios de barrio al siglo XXI.

\section{- Amenaza de productos o servicios sustitutos}

El mercado de uso de aplicativos para distintos servicios es bastante amplio. Asimismo, los usuarios poseen la potestad de sustituir una aplicación por otra, según su necesidad, así como descartarla de su celular para el ahorro de memoria. Sin embargo, para el caso del proyecto Mi bodeguita, este servicio se convierte en una alternativa fácil y rápida para usuarios que desean adquirir productos sin tener que invertir tiempo para hacerlo y la oportunidad de convertir a las bodegas en tiendas virtuales con procesos automatizados de control de stocks, proveedores y captación de un nicho del mercado no explotado o saturado. No obstante, los servicios sustitutos existen y se reflejan en los establecimientos de empresas (tiendas de conveniencia) que ofrecen un servicio de compra en línea o delivery con costo de recargo para el usuario, pero no a través de aplicaciones en el celular, sino por medio de plataformas virtuales. Cabe señalar que nuestro enfoque va dirigido a 
las zonas de Miraflores, San Isidro y Surco que poseen usuarios que valoran su tiempo y que requieren ser atendidos. Se identifica que la amenaza de productos o servicios sustitutos es baja.

\section{- Rivalidad entre los competidores existentes}

La competencia que se presenta en el mercado y que está establecida en el servicio de venta de alimentos directo, a través de bodegas es la aplicación "Aló Bodega". Esto, debido a que esta aplicación ofrece un servicio de conexión entre bodegas y usuarios a nivel de Lima Metropolitana. Sin embargo, su modelo de negocio se enfoca en el usuario, más no en el bodeguero. Por otro lado, se cuenta con competidores sustitutos como las tiendas de conveniencia (tiendas Tambo, Listo ¡Minimarket, Repshop, etc.). Así como otros rubros de empresas que podrían interferir como Wong, Tottus, Metro y Plaza Vea que cuentan con un público ganado y ofrecen el servicio adicional de tienda virtual a sus clientes para cubrir mayor demanda y formar parte de la red de empresas minoristas.

Cabe señalar que, para aminorar la consecuencia de la competencia, nuestro negocio se enfocará en los distritos de Miraflores, San isidro y Surco mediante el servicio de la aplicación Mi bodeguita, intermediario entre las bodegas y los usuarios.

Se verifica que la rivalidad entre los competidores es baja, debido a que las grandes empresas tienen otro modelo de negocio y el competidor directo se enfoca en otro tipo de cliente. 
Tabla 1 Puntaje de análisis de las 5 fuerzas de Porter sobre Mi Bodeguita

\begin{tabular}{|c|c|c|}
\hline $\begin{array}{l}\text { Descripción } \\
\text { de fuerza }\end{array}$ & $\begin{array}{l}\text { Puntaje obtenido } \\
\quad \text { (Ratio: } 1 \text { al 3) } \\
\text { 1: Poder de } \\
\text { negociación baja } \\
\text { 2: Poder de } \\
\text { negociación } \\
\text { mediana } \\
\text { 3: Poder de } \\
\text { negociación alta }\end{array}$ & Observaciones \\
\hline $\begin{array}{l}\text { Poder de } \\
\text { negociación } \\
\text { del cliente }\end{array}$ & 1 & $\begin{array}{l}\text { El análisis evidenció que el poder de negociación } \\
\text { del cliente es bajo, lo que permite a Mi Bodeguita } \\
\text { ofrecer beneficios a los bodegueros para que } \\
\text { incrementen sus ingresos y atender a un nicho de } \\
\text { mercado que no han tenido en cuenta y que la } \\
\text { aplicación les ofrece. }\end{array}$ \\
\hline $\begin{array}{l}\text { Poder de } \\
\text { negociación } \\
\text { del proveedor }\end{array}$ & 1 & $\begin{array}{l}\text { El análisis evidenció que el poder de negociación } \\
\text { del proveedor es bajo, debido a que Mi Bodeguita } \\
\text { tiene una amplia gama de proveedores que pueden } \\
\text { ser utilizados, sin depender de uno, } \\
\text { específicamente. }\end{array}$ \\
\hline $\begin{array}{l}\text { Amenaza de } \\
\text { nuevos } \\
\text { competidores }\end{array}$ & 2 & $\begin{array}{l}\text { El análisis evidenció que la amenaza de nuevos } \\
\text { competidores presenta un poder de negociación } \\
\text { mediana, debido a que existe una aplicación que } \\
\text { ofrece una alternativa de servicio, pero que no ha } \\
\text { desarrollado por completo su idea de negocio y } \\
\text { solo es medianamente competitiva contra Mi } \\
\text { Bodeguita. }\end{array}$ \\
\hline \begin{tabular}{lr|} 
Amenaza & de \\
productos & o \\
servicios & \\
sustitutos &
\end{tabular} & 1 & $\begin{array}{l}\text { El análisis evidenció que la amenaza de productos } \\
\text { o servicios sustitutos es baja, debido a que el } \\
\text { servicio que ofrece la aplicación para bodegueros } \\
\text { es exclusivo de Mi Bodeguita. }\end{array}$ \\
\hline $\begin{array}{l}\text { Rivalidad } \\
\text { entre los } \\
\text { competidores } \\
\text { existentes }\end{array}$ & 1 & $\begin{array}{l}\text { El análisis evidenció que la rivalidad entre los } \\
\text { competidores existentes es baja, debido a que el } \\
\text { competidor indirecto se enfoca en el usuario, más } \\
\text { no en el bodeguero. }\end{array}$ \\
\hline
\end{tabular}

Análisis: Como se observa la aplicación Mi Bodeguita obtiene en promedio el puntaje del 1.2 que lo posiciona en el nivel de bajo poder de negociación por parte de sus clientes, proveedores y competidores. Es decir, que la idea de negocio tiene un buen manejo de las cinco fuerzas de Porter que le permite ser atractivo para futuros inversionistas. 


\subsubsection{MATRIZ FODA CRUZADO}

\begin{tabular}{|c|c|c|}
\hline MATRIZ FODA CRUZADA & \multicolumn{2}{|c|}{ Factores externos } \\
\hline & Oportunidades & Amenazas \\
\hline & \multirow[t]{2}{*}{$\begin{array}{l}\text { 1. Competencia débil, poco conocida. } \\
\text { 2. Mercado mal atendido. } \\
\text { 3. Necesidad del producto. } \\
\text { 4. Crecimiento en el uso de tecnología en los clientes. }\end{array}$} & $\begin{array}{l}\text { 1. Ingreso de nuevos competidores al mercado. } \\
\text { 2. Cambios en la normativas y políticas de gobierno en } \\
\text { nuestro país } \\
\text { 3. Dependemos del cliente o bodega para obtener un buen } \\
\text { servicio. } \\
\text { 4. Incremento de tiendas de conveniencia en más distritos } \\
\text { (Tambo - Listo). }\end{array}$ \\
\hline Factores internos & & $\begin{array}{l}\text { 5. Barreras de entrada al sector por desconocimiento del } \\
\text { usuario final. }\end{array}$ \\
\hline Fortalezas & Estrategias FO (Fortalezas / Oportunidades) & Estrategias FA (Fortalezas / Amenazas) \\
\hline $\begin{array}{l}\text { 1. Continua innovación tecnológica, según los cambios } \\
\text { en el mercado. } \\
\text { 2. Alianza estratégica con proveedores. } \\
\text { 3. Excelente propuesta de valor para clientes. } \\
\text { 4. Producto novedoso y diferenciado. } \\
\text { 5. Capacidad de crecimiento y escalabilidad. }\end{array}$ & $\begin{array}{l}\text { - Diferenciación en productos y servicio al cliente } \\
\text { - Desarrollo e innovación de productos } \\
\text { - Penetración en nuevos mercados: Atender nuevos } \\
\text { requerimientos }\end{array}$ & $\begin{array}{l}\text { - Diferenciación de producto: incrementar el valor del } \\
\text { producto/servicio } \\
\text { - Implementación de nuevos procesos para optimizar los } \\
\text { tiempos y calidad del producto. } \\
\text { - Benchmarking de competidores: comparar algunos aspectos } \\
\text { de los productos/servicios de posibles competidores con los } \\
\text { propios. }\end{array}$ \\
\hline Debilidades & Estrategias DO (Debilidades / Oportunidades) & Estrategias DA (Debilidades / Amenazas) \\
\hline $\begin{array}{l}\text { 1. Débil situación financiera. } \\
\text { 2. Problema con los tiempos de entrega del } \\
\text { producto/servicio } \\
\text { 3. Baja capacidad de acceso a créditos. } \\
\text { 4. Mercado poco conocido. } \\
\text { 5. Personal minimo inicial. }\end{array}$ & $\begin{array}{l}\text { - Fortalecer la cultura organizacional, para asegurar el trabajo } \\
\text { en equipo y acercarnos a la visión de la empresa. } \\
\text { - Outsourcing de procesos. } \\
\text { - Mejora continua de los procesos y cadena de valor. } \\
\text { - Benchmarking: aprovechar las mejores prácticas de apps } \\
\text { similares para aplicarlas al negocio. }\end{array}$ & $\begin{array}{l}\text { - Motivar a los trabajadores buscando mejorar su } \\
\text { productividad } \\
\text { - Calidad: Dar mayor valor agregado al servicio, atencion } \\
\text { oportuna, flexibilidad con el cliente y usuario. } \\
\text { - Normas y procedimientos sencillo para que los procesos se } \\
\text { realicen con fluidez. }\end{array}$ \\
\hline
\end{tabular}

Figura 4. FODA cruzado de Mi Bodeguita - Elaboración propia 


\section{Definición de Estrategias de los cruces del FODA}

Después de desarrollar la matriz FODA cruzado, se han obtenido las siguientes estrategias:

- Conseguir una diferenciación en productos y servicio al cliente.

- Desarrollar e innovar productos.

- Penetración en nuevos mercados: Atender nuevos requerimientos.

- Diferenciación de producto: incrementar el valor del producto/servicio.

- Implementación de nuevos procesos para optimizar los tiempos y calidad del producto.

- Benchmarking de competidores: comparar algunos aspectos de los productos/servicios de posibles competidores con los propios.

- Fortalecer la cultura organizacional, para asegurar el trabajo en equipo y acercarnos a la visión de la empresa.

- Outsourcing de procesos.

- Mejora continua de los procesos y cadena de valor.

- Benchmarking: aprovechar las mejores prácticas de apps similares para aplicarlas al negocio.

- Motivar a los trabajadores buscando mejorar su productividad

- Calidad: Dar mayor valor agregado al servicio, atención oportuna, flexibilidad con el cliente y usuario.

- Normas y procedimientos sencillos para que los procesos se realicen con fluidez.

\subsection{Visión}

“Ser reconocidos como la aplicación número uno en el país para compras mediante bodegas virtuales al 2023, brindando soluciones a los clientes y satisfacción a los usuarios." 


\subsection{Misión}

“Ofrecer servicios tecnológicos de bajo costo a nuestros clientes (bodegas) para incremento de ventas y atención de nuevos mercados, así como brindar el acceso a bodegas virtuales para los usuarios ahorrando tiempo y dinero".

\subsection{Estrategia Genérica}

La estrategia utilizada por Mi Bodeguita es de Diferenciación, debido que nuestra empresa en marcha ha seleccionado segmento de mercado con preferencias y necesidades distintas.

De esta manera, Mi bodeguita tiene la capacidad de atender de manera especializada a los usuarios y desarrollando un nuevo sistema para nuestros futuros clientes.

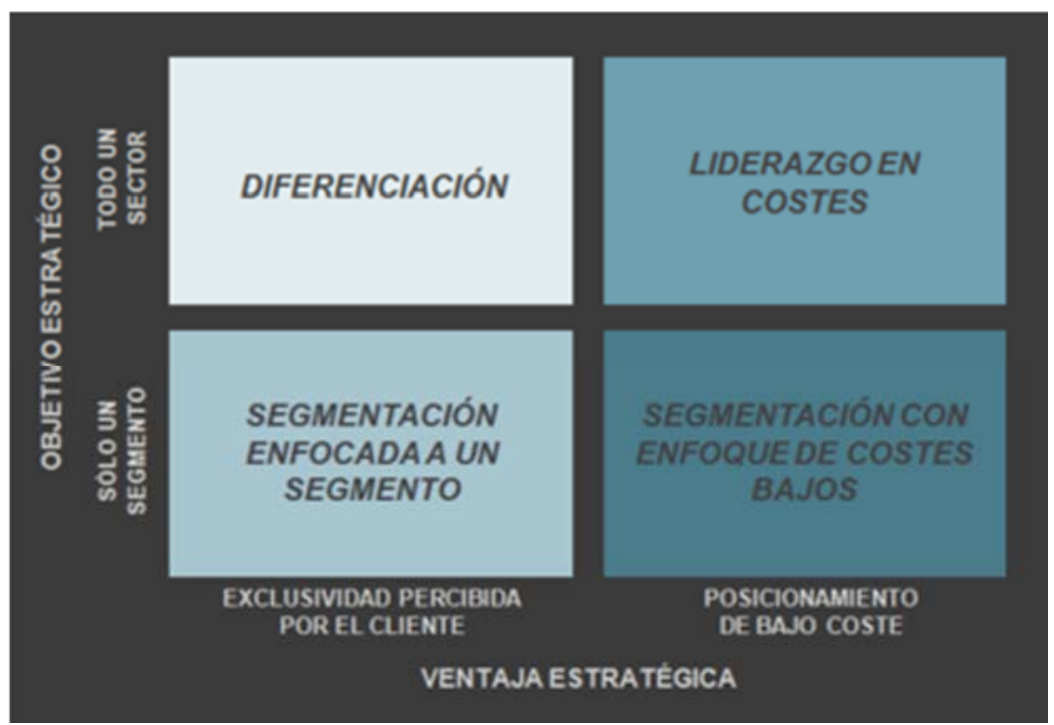

Figura 5. Estrategias genéricas de Porter por Wikipedia 


\subsection{Objetivos Estratégicos}

- Innovar de manera continua la aplicación Mi Bodeguita para conseguir una diferenciación en el servicio y atención de los clientes (bodegueros) y usuarios desde su inicio.

- Promocionar el nombre de la aplicación Mi Bodeguita para el incremento de nuevos y potenciales clientes por penetración de mercados durante los seis primeros meses.

- Mantenimiento y supervisión de los sistemas enlazados a la aplicación Mi Bodeguita para la optimización de tiempos de solicitudes de usuarios y calidad de entrega de los clientes (bodegueros) a usuarios a partir del tercer mes.

- Mantener en promedio 17 transacciones por bodega por día durante el primer año.

- Convertir a Mi Bodeguita en un referente confiable y posicionarlo entre los usuarios durante el primer año de funcionamiento.

- Brindar el $100 \%$ de seguridad en las operaciones del cliente y usuario.

- Mantener en promedio un total de 145 bodegas afiliadas y fidelizadas al servicio de Mi Bodeguita durante el primer año.

- Plantear campañas dirigidas, para sensibilizar a nuestros clientes, a fin comprometerlos con el servicio al cliente.

- Desarrollar, paralelamente, nuevas unidades de negocio con el fin de poder rentabilizar mucho más la idea inicial.

- Tener planeado el crecimiento sostenible en los distritos colindantes al inicio de las operaciones (Barranco, Molina, Magdalena) a fin de ampliar nuestra cobertura.

Cabe señalar que todos estos objetivos, están basados en los resultados obtenidos del cruce de nuestra matriz FODA y la aplicación a muestro modelo de negocio. 


\section{CAPITULO 3. INVESTIGACIÓN / VALIDACIÓN DE MERCADO}

\subsection{Diseño metodológico de la investigación / metodología de validación de hipótesis}

Se ha realizado un tipo de estudio cuantitativo y cualitativo sobre una muestra en poblaciones finitas.

De 225 bodegas (target) que nos servirían como el universo para determinar el tamaño de la muestra. De este universo de bodegas obtendremos el número de encuestas a realizar. Para ello, se realizó un estudio transversal descriptivo, que nos ayudó a identificar los elementos y cualidades de los bodegueros que utilizaran la aplicación en un tiempo determinado.

El muestreo fue realizado de manera probabilística aleatoria simple, tomando un tamaño de muestra con un margen de confianza del 95\% y con un error del 5\%.

Utilizaremos la siguiente formula estadística:

En donde:

$\mathrm{Z}=1.96^{\wedge} 2$

$\mathrm{p}=0.5$

$\mathrm{q}=0.5$

$\mathrm{N}=225$ (Total de bodegas de Miraflores, San Isidro y Surco) $\mathrm{e}=0.05$

Aplicando la fórmula nos da: 142 encuestas $=n$.

$$
\mathbf{n}=\frac{Z^{2} \cdot \text { p. q. } N}{\mathrm{NE}^{2}+\mathrm{Z}^{2} \text { p. q. }}
$$

$Z=$ Nivel de confianza $\mathrm{N}=$ Población-Censo $p=$ Probabilidad a favor $q=$ Probabilidad en contra e $=$ error de estimación $\mathrm{n}=$ Tamaño de la muestra

(Ver Anexo 1 - Muestra de encuestas realizadas a bodegueros)

\subsection{Resultados de la investigación}

Para la recolección de la información se utilizó como herramienta las encuestas, siendo 80 encuentras aplicadas. 


\section{Pregunta 1. ¿Cuál es su edad?}

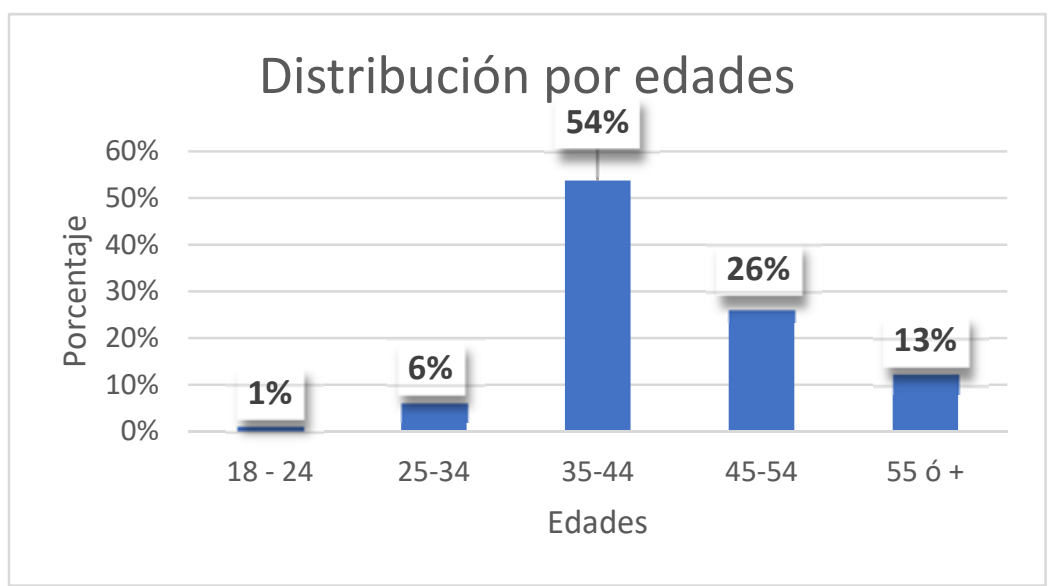

\begin{tabular}{|c|c|c|}
\hline Edades & Encuestados & Porcentaje \\
\hline $18-24$ & 1 & $1 \%$ \\
\hline $25-34$ & 5 & $6 \%$ \\
\hline $35-44$ & 43 & $54 \%$ \\
\hline $45-54$ & 21 & $26 \%$ \\
\hline 55 ó + & 10 & $13 \%$ \\
\hline Total & $\mathbf{8 0}$ & $\mathbf{1 0 0 \%}$ \\
\hline
\end{tabular}

Gráfica 1. Distribución por edades de los dueños de bodegas encuestados - Elaboración propia

Explicación 1: Los resultados describen dos rangos de edades entre los $35-44$ años, siendo el 54\% de los encuestados, y entre los 45 a 54 años siendo el 54\%. Esto muestra el adecuado alcance, ya que el público objetivo son aquellos bodegueros jóvenes que sepan manejar la tecnología y que deseen utilizar está tecnología para vender más y obtener mayores ingresos.

Pregunta 2. ¿Sexo?

\begin{tabular}{|c|c|c|}
\hline Sexo & Encuestados & Porcentaje \\
\hline Masculino & 47 & $59 \%$ \\
\hline Femenino & 33 & $41 \%$ \\
\hline Total & $\mathbf{8 0}$ & $\mathbf{1 0 0 \%}$ \\
\hline
\end{tabular}

Tipo de Sexo

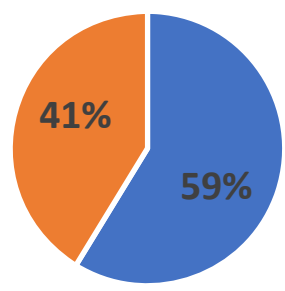

- Masculino - Femenino

Gráfica 2. Distribución por sexo de los dueños de bodegas encuestados - Elaboración propia 
Explicación 2: estos resultados evidencian que el 59\% del público objetivo son varones, mientras que, el $41 \%$ son mujeres que también toman decisiones del negocio e influyen en éstas.

Pregunta 3. ¿Tiene un smartphone?

\begin{tabular}{|c|c|c|}
\hline Smartphone & Encuestados & Porcentaje \\
\hline $\mathrm{Si}$ & 73 & $91 \%$ \\
\hline $\mathrm{No}$ & 7 & $9 \%$ \\
\hline Total & $\mathbf{8 0}$ & $\mathbf{1 0 0} \%$ \\
\hline
\end{tabular}

\section{¿Tiene smartphone?}

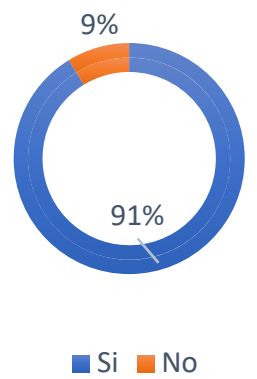

Gráfica 3. Distribución por uso de smartphones de los dueños de bodegas encuestados Elaboración propia

Explicación 3: Los resultados muestran que, el 91\% del público objetivo están conectados a la tecnología y al internet. Contando con equipos modernos y con conocimientos del manejo de estos.

\section{Pregunta 4. ¿Usa aplicaciones móviles?}

\begin{tabular}{|c|c|c|}
\hline App & Encuestados & Porcentaje \\
\hline $\mathrm{Si}$ & 69 & $86 \%$ \\
\hline No & 11 & $14 \%$ \\
\hline Total & $\mathbf{8 0}$ & $\mathbf{1 0 0} \%$ \\
\hline
\end{tabular}

\section{¿USA APLICACIONES MÓVILES?}

$\square \mathrm{Si}$ No

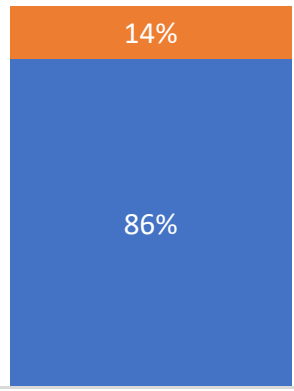

Gráfica 4. Distribución por uso de aplicaciones de los dueños de bodegas encuestados Elaboración propia 
Explicación 4: Como indica la pregunta anterior, el 86\% de los encuestados utiliza aplicaciones en su smartphone, ya sea para enviar mensajes de texto, para el uso de redes sociales y algunos para realizar compras por internet, y donde un número reducido usa el celular solo para recibir y realizar llamadas.

\section{Pregunta 5. ¿Ha realizado compras por internet?}

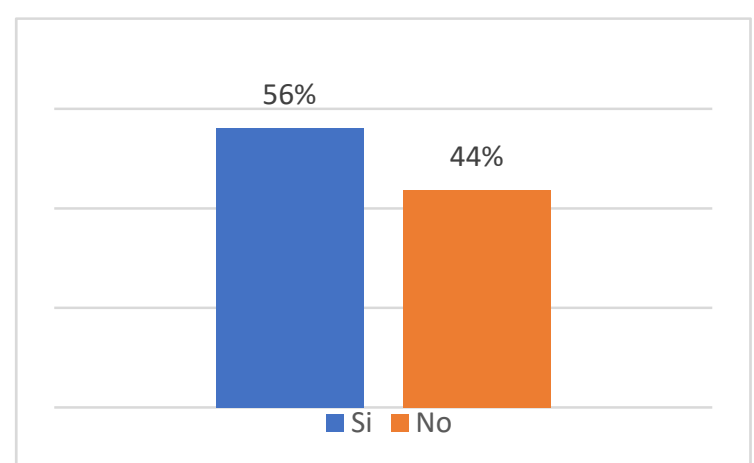

\begin{tabular}{|c|c|c|}
\hline Buy & Encuestados & Porcentaje \\
\hline $\mathrm{Si}$ & 45 & $56 \%$ \\
\hline No & 35 & $44 \%$ \\
\hline Total & $\mathbf{8 0}$ & $\mathbf{1 0 0} \%$ \\
\hline
\end{tabular}

Gráfica 5. Distribución de compras por internet de los dueños de bodegas encuestados Elaboración propia

Explicación 5: Casi la mitad de los bodegueros encuestados (56\%) conoce de compras por internet, esto nos da la idea que conocen del uso de la tecnología, siendo un factor positivo para los resultados del presente proyecto.

Pregunta 6. ¿Cuánto estaría dispuesto a pagar por un servicio que le ayudaría a vender más?

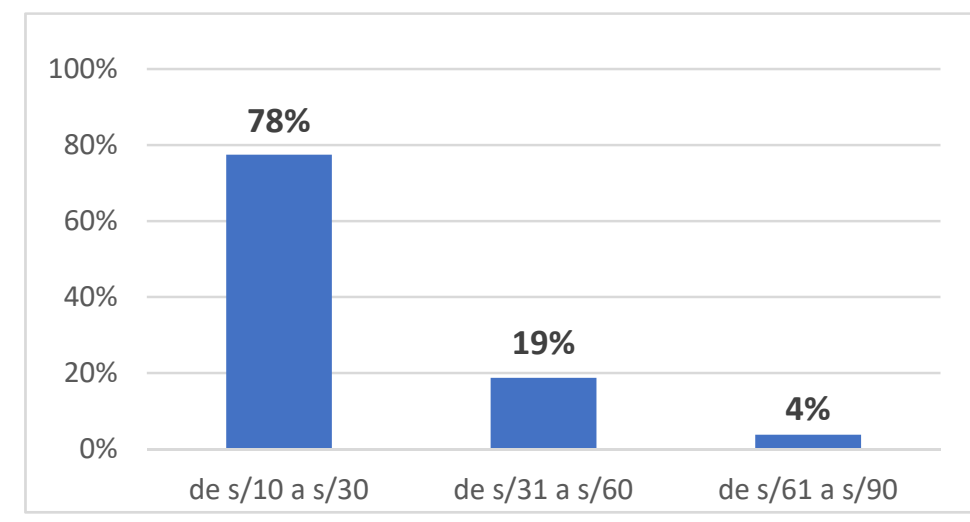

\begin{tabular}{|c|c|c|}
\hline Precio & Encuestados & Porcentaje \\
\hline de s/10 a s/30 & 62 & $78 \%$ \\
\hline de s/31 a s/60 & 15 & $19 \%$ \\
\hline de s/61 a s/90 & 3 & $4 \%$ \\
\hline Total & $\mathbf{8 0}$ & $\mathbf{1 0 0 \%}$ \\
\hline
\end{tabular}

Gráfica 6. Distribución de

disposición de pago por servicio de los dueños de bodegas encuestados - Elaboración propia 
Explicación 6: El 78\% de los encuestados ha manifestado que estarían dispuestos a pagar entre 10 a 30 soles, por un servicio tecnológico que le permita vendar más y obtener mayores ingresos. Cuando solo el rango de precios se eleva no le resulta interesante al bodeguero.

Pregunta 7. ¿Maneja sus stocks con un sistema?

\begin{tabular}{|c|c|c|}
\hline Sistema & Encuestados & Porcentaje \\
\hline $\mathrm{Si}$ & 11 & $14 \%$ \\
\hline $\mathrm{No}$ & 69 & $86 \%$ \\
\hline Total & $\mathbf{8 0}$ & $\mathbf{1 0 0 \%}$ \\
\hline
\end{tabular}

\section{Sistema para Stocks}

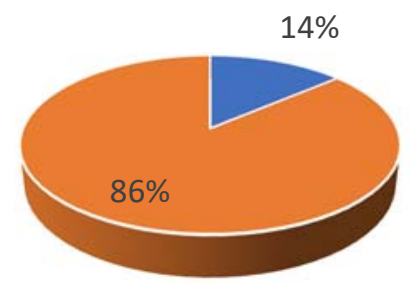

- Si $=$ No

Gráfica 7. Distribución de manejo de stocks con sistema virtual de los dueños de bodegas encuestados Elaboración propia

Explicación 7: La mayoría de las bodegas en los distritos encuestados no utiliza un sistema de control de inventarios, con un porcentaje del $86 \%$, a algunos les parece innecesario, otros lo hacen como sus padres y abuelos lo hacían. Mientras que el 14\% sí utiliza un control de stocks mediante un sistema o mediante el apoyo de terceros.

\section{Pregunta 8. ¿El orden y presentación de sus productos Ud. mismo lo realiza?}

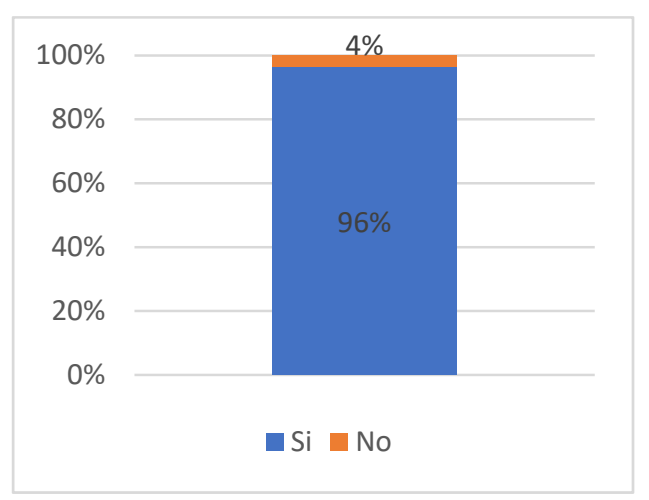

Gráfica 8. Distribución de manejo directo de exhibición de productos de los dueños de bodegas encuestados - Elaboración propia 
Explicación 8: El 96\% de los bodegueros no cuentan con un apoyo sistematizado de la presentación y orden de sus productos, lo hacen según su propio criterio y según sus comentarios: "se muestra lo que más sale". El 4\% sí tiene apoyo de terceros que lo orientan a clasificar los productos a mostrar según técnicas de marketing.

\section{Pregunta 9. ¿Brinda servicio delivery?}

\begin{tabular}{|l|l|l|}
\hline Delivery & Encuestados & Porcentaje \\
\hline Si & 9 & $11 \%$ \\
\hline No & 71 & $89 \%$ \\
\hline Total & 80 & $100 \%$ \\
\hline
\end{tabular}

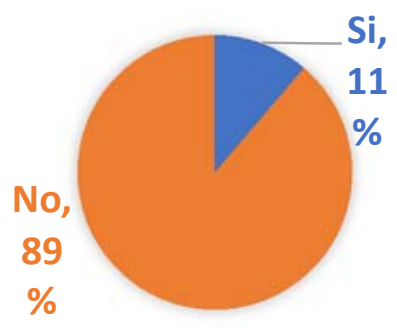

Gráfica 9. Distribución de manejo de servicio delivery de los dueños de bodegas encuestados - Elaboración propia

Explicación 9: E1 89\% de las bodegas encuestadas no cuenta con servicio delivery, esto quiere decir que, si llegáramos a empadronarlos en nuestro sistema, el dueño de la bodega tendría que contratar a una persona que se encargue del reparto; quien realizaría esta acción por medio de una bicicleta o moto. El 11\% sí hace entregas con delivery, pero en algunas zonas y con horario establecidos, adicionando un costo por el servicio.

\section{Pregunta 10. ¿Usa POS en su bodega?}

\begin{tabular}{|c|c|c|}
\hline POS & Encuestados & Porcentaje \\
\hline $\mathrm{Si}$ & 53 & $66 \%$ \\
\hline No & 27 & $34 \%$ \\
\hline Total & $\mathbf{8 0}$ & $\mathbf{1 0 0 \%}$ \\
\hline
\end{tabular}

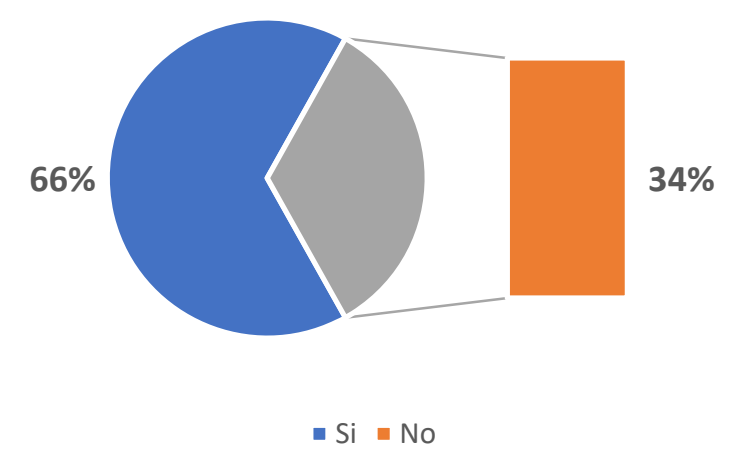

Gráfica 10. Distribución de uso de POS de los dueños de bodegas encuestados Elaboración propia

Explicación 10: Con un 66\% de encuestados que sí tienen un sistema de cobro mediante tarjetas de débito y crédito, se prueba que están sistematizados y que forman parte 
de nuestros clientes objetivo. Por otro lado, aún tenemos el 34\% de bodegas que solo usan efectivo como lo es tradicionalmente.

\subsection{Informe final: Elaboración de tendencias, patrones y conclusiones}

Según los resultados de las encuestas aplicadas, los hombres entre los 35 a 44 años son los que manejan el negocio, adicionalmente por la coyuntura actual, casi todos ellos contaban con un equipo smartphone de uso particular, en donde se pudo reconocer que tienen conocimiento del manejo de aplicaciones (apps) mediante el celular, también la mayoría habían realizado compras haciendo uso de su smartphone. Esto indica que están familiarizados con la tecnología que tienen en sus manos.

Cuando se les planteó el uso de tecnología para aumentar sus ventas, les pareció adecuada la idea, pero, siempre y cuando sea gratuita. y si requería un costo debería de ser mínimo, ya que actualmente el uso de aplicaciones es de descarga gratuita y no debería costarle. Al saber que esta aplicación también les ayudaría con el control de sus inventarios casi el total estuvo de acuerdo en pagar un mínimo por el servicio, siempre y cuando no tenga problemas con sus competidores más cercanos.

Se concluye que la idea de trabajar la aplicación inicialmente en las bodegas de estos distritos resultaría rentable por todas las características descritas de los bodegueros y también por los usuarios finales sofisticados y que no son sensibles al precio.

\section{Resultado de la investigación exploratoria inicial:}

Basado en los resultados de las entrevistas de profundidad que se realizaron a bodegas de Miraflores (como inicio - Ver Anexo 1), parte de la investigación exploratoria inicial, se presentan los resultados obtenidos en las áreas de mayor relevancia: 


\section{- Área de tecnología}

El $80 \%$ de los entrevistados muestran conocimiento y familiaridad con el término de aplicación para celulares (de manera directa o indirecta). La mayoría de los encuestados han realizado al menos una operación virtual y muestran interés en obtener herramientas que favorezcan el incremento de sus ventas. Esto, siempre cuando el costo del servicio (aplicación) no sea elevado.

\section{- Área de clientes}

El $100 \%$ de los entrevistados tienen amplio conocimiento de las preferencias, demandas y actitudes de sus clientes e incluso pueden identificarlos físicamente. Asimismo, conocen sus patrones, costumbres e incluso horarios de compra. Por la familiaridad con sus clientes, habituales atienden pedidos por delivery en algunos casos o preparan pedidos para el recojo de sus clientes en las bodegas.

\section{- Área de logística e inventario}

El $12.5 \%$ de los entrevistados maneja un control sistematizado (Excel) básico de su mercadería. Se ha identificado que el mayor porcentaje recae en bodegueros que presentan deficientes controles de stock, inadecuados seguimiento de inventarios para el vencimiento de productos, sistematización manual básica (anotaciones en cuadernos) de sus productos que no les permite tener un control para la reposición de mercadería que les hace perder ventas.

\section{- Área de proveedores y banca}

La gran mayoría de los entrevistados manejan directamente la operación de compra de productos para sus bodegas, existe un porcentaje equilibrado entre acceso y rechazo a créditos. 


\section{- Área de competencia, expansión y recursos humanos}

El $100 \%$ de entrevistados conoce a su competencia. Por ello, tratan de ofrecer novedades en productos o adaptarse a las necesidades de sus clientes. Presentan deseos de elevar sus ingresos y obtener financiamiento necesario para abrir más tiendas. Asimismo, la mayoría de los entrevistados son familias, por ende, cuentan con mínimo dos personas en la bodega. Esto, es un punto a favor para posibles servicios delivery.

Como se observa en los resultados de la exploración inicial, se presentan necesidades en los bodegueros, sobre todo en el área de expansión o incremento de ingresos como principal preocupación y podemos detectar un $75 \%$ de satisfacción en caso salga al mercado un producto como el nuestro. Cabe señalar que el perfil y expectativas de los bodegueros de San Isidro y Surco presentan las mismas características a los de Miraflores. Por ello, la aplicación Mi bodeguita podría cubrir sus necesidades de un mejor control de inventario de sus productos, asesoramiento básico en banca, presentación de rangos atractivos de usuarios por atender y a los cuales ellos no tienen acceso por no estar actualizados con el uso de tecnología. De igual manera, podrían abarcar nuevos mercados de usuarios virtuales que los bodegueros no están considerando y que les ayudaría a generar más ingresos y ser atractivos para créditos que les permitan cumplir sus metas comerciales de abrir nuevas tiendas. Bajo el uso del aplicativo Mi bodeguita, los bodegueros obtendrían mayores beneficios por una pequeña inversión del uso.

\section{Referencia sobre usuarios}

Cabe señalar que, de acuerdo con lo trabajado en Desarrollo de Negocios 1, en donde se utilizó el landing page Unbounce para obtener información relevante sobre la aceptación e interés por parte de usuarios finales sobre la idea de negocio, se obtuvo aproximadamente una tasa de conversión del 20\% de interés por parte de usuarios. Se enfatiza que las visitas al landing del proyecto fueron un total de 739 
y que dejaron sus datos de contacto para inscripción en el servicio un total de 148 usuarios.

\begin{tabular}{|l|l|}
\hline Visitas & 739 \\
\hline Leads & 148 \\
\hline Sin respuesta & 591 \\
\hline
\end{tabular}

Tasa de conversión

\begin{tabular}{|cc|}
\hline 739 & $100 \%$ \\
\hline 148 & $\mathrm{X} \%$ \\
\hline
\end{tabular}

$\mathrm{N}^{\circ}$ de Leads

$\mathrm{N}^{\circ}$ de visitas

\begin{tabular}{l}
148 \\
\hline 739
\end{tabular}$=$\begin{tabular}{|l|l|}
\hline 0.20 & $20 \%$ \\
\hline
\end{tabular}

Promoción de página

Finaliza en 5 horas

Amigo bodeguero, quieres incrementar tus ve..

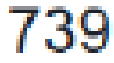

Personas alcanzadas

Figura 6. Número de visitas de la página de Facebook de M4rk3t (Negocios 1) - Base de la investigación de mercado

Por lo tanto, contar con un $20 \%$ mínimo de aceptación por parte de potenciales usuarios, nos permite tener una base atractiva de usuarios que nuestros clientes (bodegueros) podrían atender e incrementar sus ingresos mediante el uso de la aplicación Mi Bodeguita. 


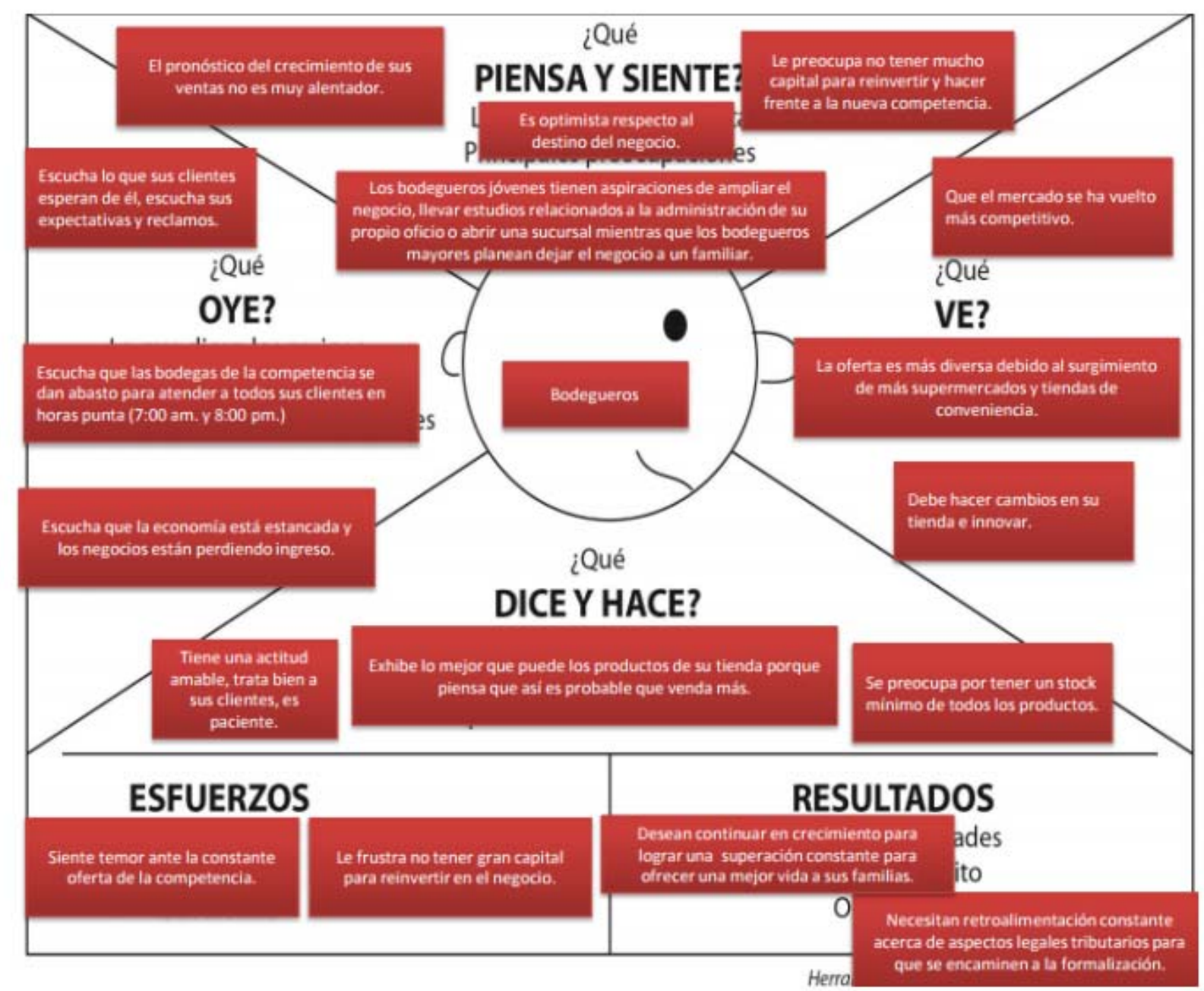

Figura 7. Mapa de empatía elaborado por ex M4rk3t (Mi Bodeguita)

\section{Análisis}

Se identifica que los bodegueros tienen la preocupación que sus negocios no tienen un prospecto de crecimiento alentador por no contar con un capital suficiente para reinvertir. El canal tradicional que atienden, solo les permite mantenerse. Sin embargo, los bodegueros tienen metas aspiracionales de crecimiento que pueden ser satisfechos por el uso de la aplicación Mi Bodeguita. En donde, los mismos atiendan a un nuevo mercado que generen mayores ingresos a los bodegueros para reinvertir en sus negocios. 


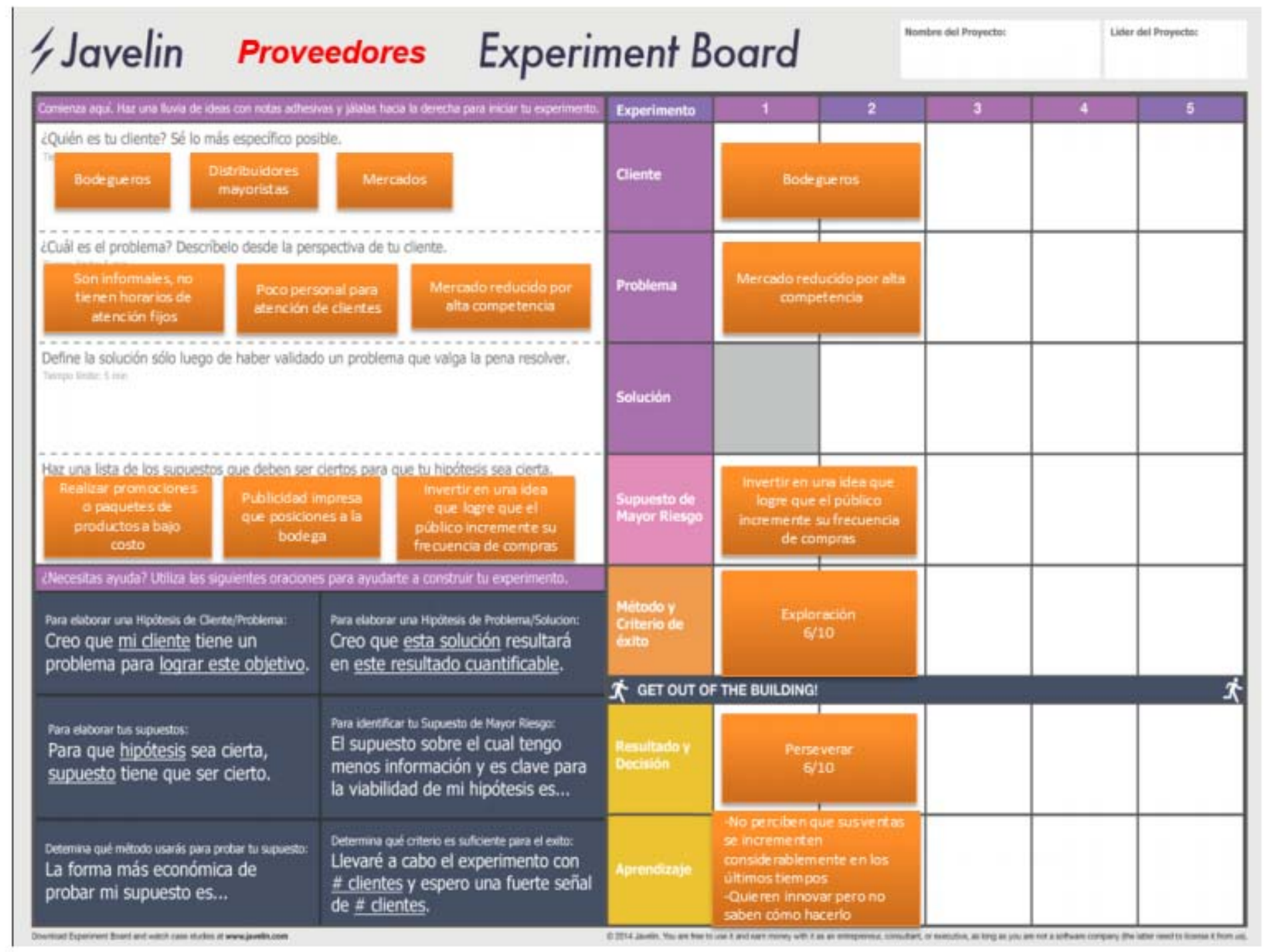

Figura 8. Experiment Board elaborado por ex M4rk3t (Mi Bodeguita) 


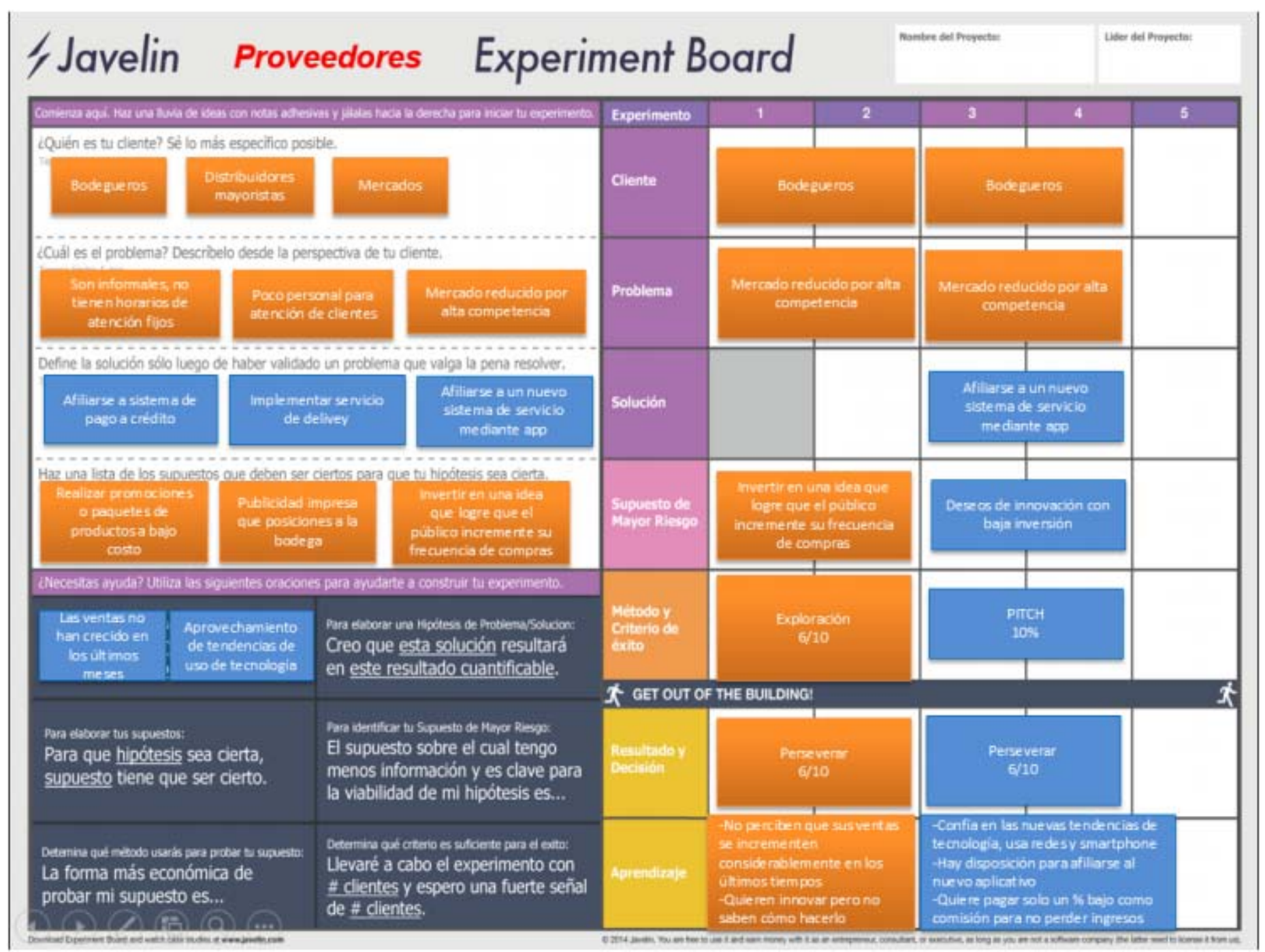

Figura 9. Experiment Board por ex M4rk3t (Mi Bodeguita) 
Tabla 2 Canvas de Mi Bodeguita - Elaboración propia

\begin{tabular}{|c|c|c|c|c|}
\hline $\begin{array}{l}\text { SOCIOS CLAVE } \\
\text { - Bodegas } \\
\text { - Minimarkets }\end{array}$ & $\begin{array}{l}\text { ACTIVIDADES CLAVE } \\
\text { - Software para app móvil } \\
\text { - Distribuir/ comercializar el } \\
\text { producto. } \\
\text { - Operaciones de manejo de base } \\
\text { datos de usuarios y proveedores }\end{array}$ & $\begin{array}{l}\text { PROPUESTAS DE VALOR } \\
\text { USUARIO } \\
\text { "Rapidez y derivación de actividad } \\
\text { que consume tiempo / Facilidad / } \\
\text { Seguridad } \\
\text { CLIENTE INTERNO } \\
\text { (BODEGUERO) } \\
\text { Accesibilidad a un nuevo canal de } \\
\text { ventas (no tradicional) } \\
\text { Incremento de ventas por nueva } \\
\text { captación de clientes (modalidad } \\
\text { virtual) para el control de } \\
\text { Facilidad para } \\
\text { inventarios (como ventaja adicional } \\
\text { de la utilización de la app) } \\
\text { Evita la acumulación de efectivo, a } \\
\text { través de la bancarización } \\
\text { (depósitos en cuenta, cheques, etc.) } \\
\text { Facilidad de pago a sus proveedores }\end{array}$ & $\begin{array}{l}\text { RELACIONES CON LOS } \\
\text { CLIENTES } \\
\text { - } \begin{array}{l}\text { Servicio automatizado: } \\
\text { recuperación de contraseña }\end{array} \\
\text { - } \begin{array}{l}\text { Comunidades: evaluación } \\
\text { constante de bodegueros }\end{array}\end{array}$ & 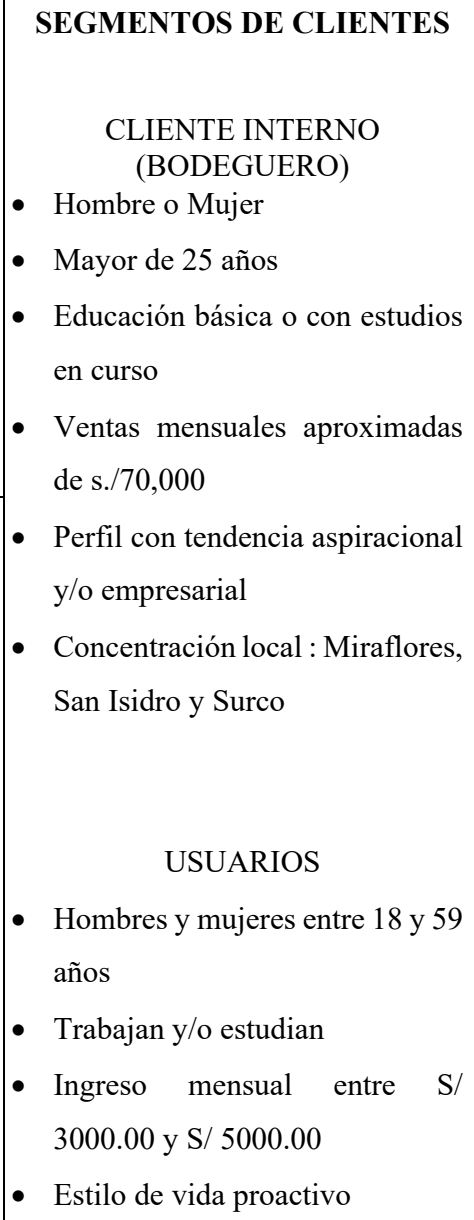 \\
\hline
\end{tabular}




\begin{tabular}{|l|l|l|l|}
\hline & & & Viven o trabajan en Lima \\
& ESTRUCTURA DE COSTOS & \multicolumn{1}{c|}{ FUENTE DE INGRESOS } \\
- Mantenimiento & Porcentaje de comisión a las bodegas por los tickets de ventas \\
- Personal & Costos (luz, agua, etc.) & \\
- Capacitación a socios & \\
\hline
\end{tabular}




\section{CAPITULO 4. PLAN DE MARKETING}

Para el adecuado desarrollo de un plan de marketing del proyecto $\mathrm{Mi}$ bodeguita, se ha realizado un análisis situacional, en donde se ha tomado en cuenta el análisis interno del proyecto. Asimismo, se ha observado y realizado un análisis externo para determinar a los clientes (bodegas de los distritos de Miraflores, San Isidro y Surco), los competidores que existen en el mercado, los proveedores (programadores, servidores, etc.) y usuarios finales. Así, como a las fuerzas que impactan de manera macro al proyecto de empresa que se propone como negocio.

\subsection{Planteamiento de objetivos de marketing}

\section{Objetivo general}

- Posicionar a Mi bodeguita como la aplicación líder de compras en bodegas de Miraflores, San Isidro y Surco para el 2023.

\section{Objetivos específicos}

- Lanzar una campaña de publicidad atractiva y beneficiosa para las bodegas que permita generar mayores afiliaciones en el primer año.

- Lanzar una campaña de publicidad clara del servicio que permita conseguir el 100\% de bodegas afiliadas (145), de modo que se conviertan en clientes regulares durante el primer año.

- Lograr una frecuencia de transacciones de un promedio de 15 tickets de S/ 20.00 por 20 días útiles al mes.

- Realizar una encuesta de satisfacción de la aplicación para cuantificar la aceptación de los clientes (bodegueros) y usuarios.

- Generar información relevante sobre el impacto de la aplicación que permita mejorar e innovar el valor agregado del mismo. 


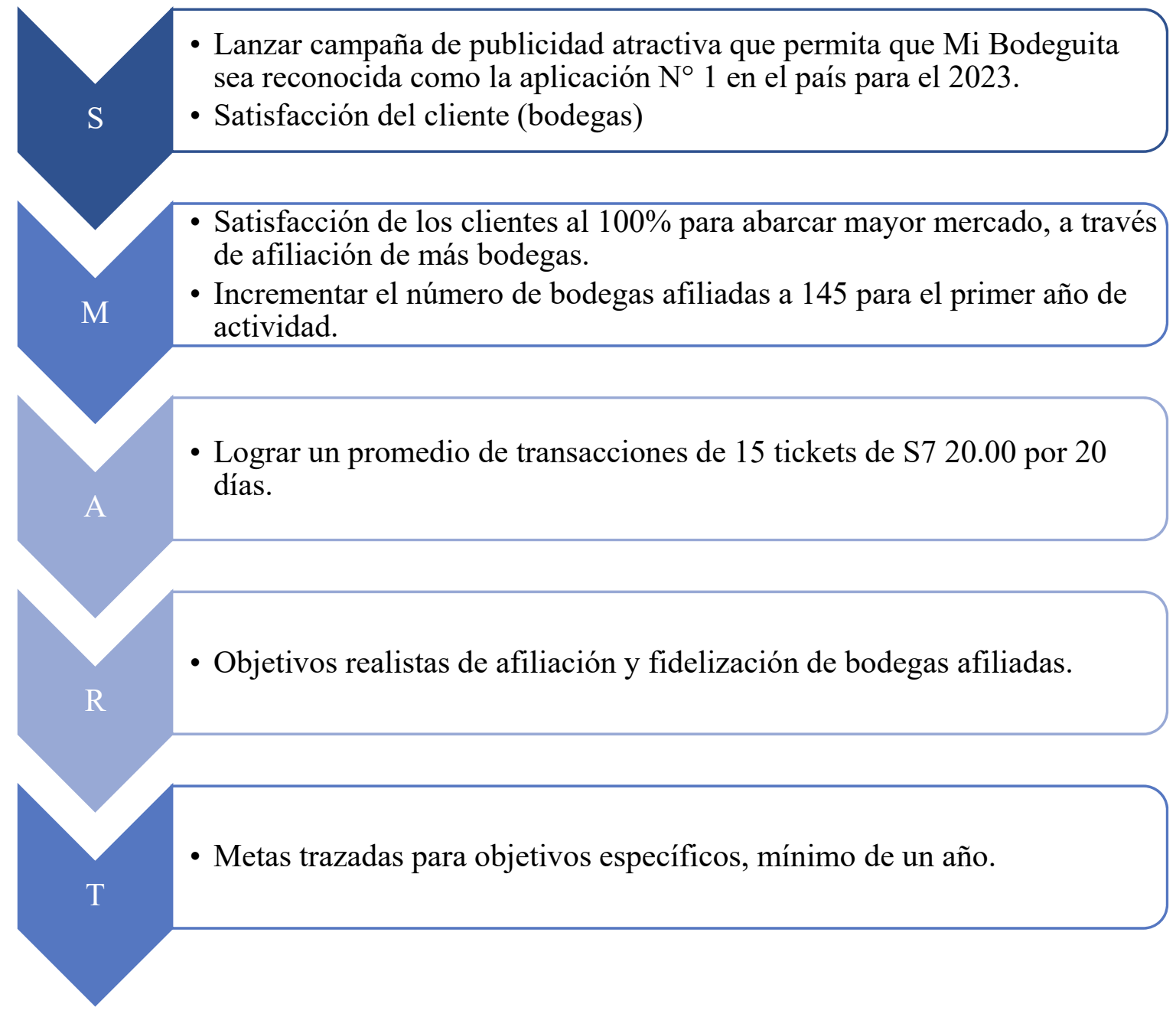

Gráfica 11. Objetivos de marketing - Elaboración propia

\subsection{Estrategias de marketing:}

\subsubsection{Segmentación}

El público objetivo de Mi bodeguita está conformado por adultos (hombres y mujeres) entre 25 y 45 años que trabajan de manera independiente, solteros y/o casados, que cuentan con negocios de bodegas en el distrito de Miraflores, San Isidro y Surco. Presentan metas empresariales de abrir más bodegas para incrementar sus ingresos y buscan la manera de elevar sus ventas. Asimismo, se 
encuentran familiarizados con el uso de aplicativos en sus Smartphones y tienen un estilo de vida proactivo y progresista.

Por otro lado, se encuentra el usuario que es todo adulto (hombre y mujer) entre 18 y 59 años que reside o trabaja en los distritos de Miraflores, San Isidro y Surco y presenta la necesidad de adquirir productos de una bodega, sin tener que invertir tiempo en ir a comprar físicamente.

Cabe señalar que tomando en cuenta el mapa de empatía de los bodegueros, se puede identificar la necesidad de generar mayores ingresos que les permitan expandir sus negocios y reinvertir. Es decir que es un mercado no atendido que Mi Bodeguita ha identificado para atender y satisfacer su necesidad. Asimismo, las bodegas de Miraflores, San Isidro y Surco mantienen similares formas de trabajo, cartera de clientes, procesos de atención básica que son atractivos para emprender la idea de negocio.

Por otro lado, se decide iniciar con tres distritos que pertenecen a Lima Moderna que está adecuado al uso de aplicaciones en su gran mayoría (bodegueros y usuarios).

\subsubsection{Posicionamiento}

El proyecto empresarial busca posicionarse en el insigth de los clientes (bodegueros) y usuarios como la aplicación más fiable y rápida para el incremento de ventas (bodegas) y obtener lo que se necesita en el hogar sin invertir tiempo (usuarios).

Para lograr el posicionamiento se desarrollará un programa de beneficios para los bodegueros que se afilien a la aplicación, en donde se detallen temas de optimización y control de inventarios, técnicas de exhibición, guía de bancarización, entre otros. Esto con la finalidad de posicionar a la aplicación como una alternativa segura y rápida de elevar los ingresos de los afiliados. De la mano, se incluye al usuario en el posicionamiento. Esto, debido a que formarán parte de 
los beneficios que se ofrezcan para los bodegueros. Los usuarios y sus compras serán la base para posicionar a la aplicación con nuestros clientes directos (bodegas).

\subsection{Mercado objetivo}

\subsubsection{Tamaño de mercado}

Según informe de la Asociación de Bodegueros del Perú - ABP (27/01/16) en Lima existen 113 mil bodegas y a nivel nacional 414 mil.

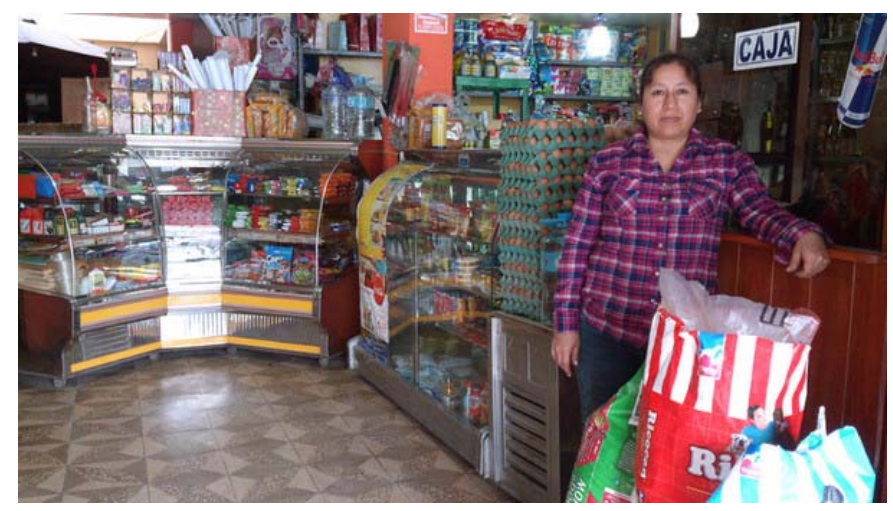

Figura 10. Ejemplo de bodega en Lima, elaborado por RPP Noticias

El estudio reveló que la mayor cantidad de bodegas se concentra en Lima Norte (43.1\%) y Lima Sur (21.7\%). Lima Este concentra el 20.8\%, Lima Centro 8.3\% y Lima Centro Medio 6.1\%. Si bien en el cono norte se encuentran la mayoría de bodegas se tomará en cuenta para el lanzamiento los distritos de Miraflores, San Isidro y Surco porque son el mercado objetivo que cumple con las características requeridas: bodegas A1. 
Tabla 3: Basada en datos recopilados por la empresa; encuestas y datos de la Municipalidad de Miraflores, San Isidro y Surco.

\begin{tabular}{|c|c|c|c|}
\hline \multicolumn{4}{|c|}{ TAMAÑO DE MERCADO } \\
\hline & Perú & & Porcentaje \\
\hline Bodegas & 414,000 & & $100 \%$ \\
\hline Bodegas en Lima & 113,000 & & $27 \%$ \\
\hline & Miraflores & San Isidro & Surco \\
\hline Bodegas (Target) & 55 & 9 & 161 \\
\hline
\end{tabular}

Según los datos arrojados de nuestras fuentes tenemos 225 bodegas que utilizarían nuestra aplicación para atender a sus clientes.

Por otro lado, según el informe "Estadísticas de las Tecnologías de Información y Comunicación en los Hogares" del INEI al 2017, tienen acceso a internet el $47.5 \%$ de la población, es decir, 15 millones y medio aprox. Y de esa cifra la mayoría de las internautas navega en la web para buscar información, también para comunicarse, otros para jugar, ver películas y escuchar música.

El documento señala que seis de cada diez (61.6\%) peruanos accede a Internet a diario. En tanto, el $34.4 \%$ se conecta una vez a la semana y solo el $4.0 \%$ lo usa una vez al mes o cada dos meses. El 61.9\% de varones y el 61.3\% de mujeres, accede a Internet una vez al día. Y de estos el 69\% ha realizado una compra por internet al menos ${ }^{1}$.

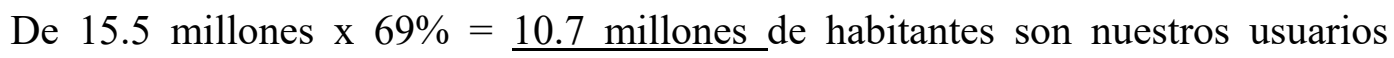
potenciales.

\subsubsection{Tamaño de mercado disponible}

Un informe de RPP revela que la mayoría de los bodegueros tiene educación básica (primaria y secundaria) y casi la tercera parte educación superior (32\%). Los

\footnotetext{
${ }^{1}$ Fuente: Portal web de RPP Noticias
} 
bodegueros con mayor nivel de educación son de Lima Centro Medio (44\%) y Lima Centro (40\%). La mayoría de ellos $(75.3 \%)$ son adultos con edades superiores a 35 años. Sin embargo, como primera etapa solo consideraremos tres distritos (Miraflores, San Isidro y Surco) que cumplen con las características necesarias para el uso de la aplicación con un mínimo de pedidos necesarios para que sea sostenible, en total 225 bodegas tipo A.

\subsubsection{Tamaño de mercado operativo (target)}

Como primera etapa este proyecto se centrará en las bodegas del distrito de Miraflores con 55 bodegas, San Isidro con 9 y Santiago de Surco con 161 bodegas que cuentan con los requisitos mínimos solicitados para obtener nuestro servicio (se adjunta base de datos de las bodegas registradas). Según las encuestas del total de bodegas $\mathrm{A} 1$ de los tres distritos podríamos iniciar con un 64\%, aproximadamente, como primera etapa, es decir: 145 bodegas (\% derivado de un total de 225 bodegas en los distritos de Miraflores, San Isidro y Surco).

Según nuestro estimado de entre 15 a 17 transacciones de las bodegas target, obtendríamos ingresos en "promedio" de 195,000.00 mil soles mensuales. Se da el detalle en el Plan de Ventas.

Se consideran los siguientes criterios para los usuarios finales o compradores: edades entre 18 y 59 años, NSE A y B, uno por domicilio y que esté dispuesto a tomar un servicio de compras en bodegas desde la app. 


\begin{tabular}{|c|c|c|c|c|c|}
\hline $\begin{array}{l}\text { CARACTE RISTICA } \\
\text { POBLACION AL }\end{array}$ & $\begin{array}{l}\text { GRUPOS DE } \\
\text { EDADES }\end{array}$ & TOTAL & $\%$ & HOMBRES & MUJERES \\
\hline & TOTAL & 81,932 & 100 & 36,422 & 45,510 \\
\hline Niños & 0.10 & 7,903 & 10 & 4,017 & 3,886 \\
\hline Ad olesce ntes & $11-17$ & 5,772 & 7 & 2,747 & 3,025 \\
\hline Jóvenes & 18. 29 & 15,643 & 19 & 6,849 & 8.794 \\
\hline Adultos & $30 \cdot 59$ & 35,201 & 43 & 15,945 & 19,258 \\
\hline Ancianos & $80 \mathrm{~g} \mathrm{mas}$ años & 17,413 & 21 & 6,864 & 10,549 \\
\hline
\end{tabular}

Figura 11. Proyecciones de población por sexo, edad, elaborado por INEI- Perú

Resultado de edades entre 18 y 59 años y los NSE A y B -> 50,844 personas

Para los clientes o bodegueros se considera el target requerido total de 145 de un universo de 225 bodegas, en una etapa inicial (primer año).

\subsubsection{Potencial de crecimiento del mercado}

Según una publicación del diario Gestión, se estima un crecimiento de las bodegas en 5\% a nivel nacional anualmente, es decir, que nuestro modelo de negocio se puede ampliar también a otros distritos que cuenten con bodegas A1 y usuarios non cierto uso de tecnología y en donde el precio no sea un factor determinante de compra.

Se ha considerado que el modelo de negocio es escalable a otros distritos y a otras provincias o departamentos del Perú. Como cultura el peruano tiene que tener cerca siempre una bodega, muy aparte de un supermercado o una tienda de conveniencia, la bodega es la que nos ayuda a encontrar aquello que requerimos a última hora.

Cuando esté bien posicionado y consolidada el uso de la aplicación en los vecinos buscaremos implementarlo en los distritos aledaños que cuenten con los mismos criterios de uso y necesidad, adicionalmente de los usuarios promedio requeridos. 


\subsection{Desarrollo y estrategia del marketing mix}

\subsubsection{Diseño de producto / servicio}

Nuestro Servicio Real es una aplicación que tiene una presentación simple y amigable que le permite al usuario identificar diariamente una variedad de bodegas cercanas a su domicilio, estas bodegas cumplen un perfil definido. El lanzamiento del producto contempla en esta etapa inicial los distritos de Miraflores, San Isidro y Surco. A inicios del 2019, estaremos ampliando nuestra cobertura a los distritos colindantes. De esta manera podremos satisfacer a más usuarios, ampliando nuestro portafolio de bodegas y/o tiendas de conveniencia, para poder entrar con fuerza para cubrir Lima Metropolitana.

Nuestras aplicaciones cuentan con algunas características como, por ejemplo:

1. Geolocalización actualizada.

2. Facilidad de registro.

3. Codificación de productos.

4. Facilidad de pago (tarjeta o efectivo).

5. Control de Stock.

6. Capacitaciones.

7. Confiabilidad de información.

8. Servicio de ayuda al cliente y usuario.

9. Incentivos para mejorar la competitividad y el servicio.

Nivel Aumentado. El trato que le damos al cliente (bodegas) será directo y lo más personalizado posible. Esto con el fin de poder asesóralos y lograr una sociedad estratégica. Atenderemos todas las consultas correo o celular. Cualquier consulta que se le hace a la página será contestada en el plazo de 12 horas, dando siempre respuestas en positivo.

- La marca es conocida como: Mi Bodeguita y como atributo principal se busca: Facilitar el acceso de los clientes (bodegas) a un nuevo nicho de mercado; ya que el producto está preparado para facilitar el contacto con potenciales consumidores. La idea es posicionarnos con nuestros clientes (bodegas) para que seamos la primera opción en la expansión y crecimiento de su negocio. 
- La Marca que trabajamos es Mi bodeguita. Un concepto de fácil recordación y que mezcla los términos usados en el día a día por las familias y que, además es fácilmente asociada a la hora de compra de los productos diarios de primera necesidad.

- El Logo será una de nuestras fortalezas porque la presentación del producto es llamativa y novedosa. Siendo una de las primeras aplicaciones para bodegueros que les permite una administración y modernización de sus negocios.

\subsubsection{Estrategia de precios (Análisis de costos, precios de mercado)}

Nuestra segmentación está ubicada en compradores de valor.

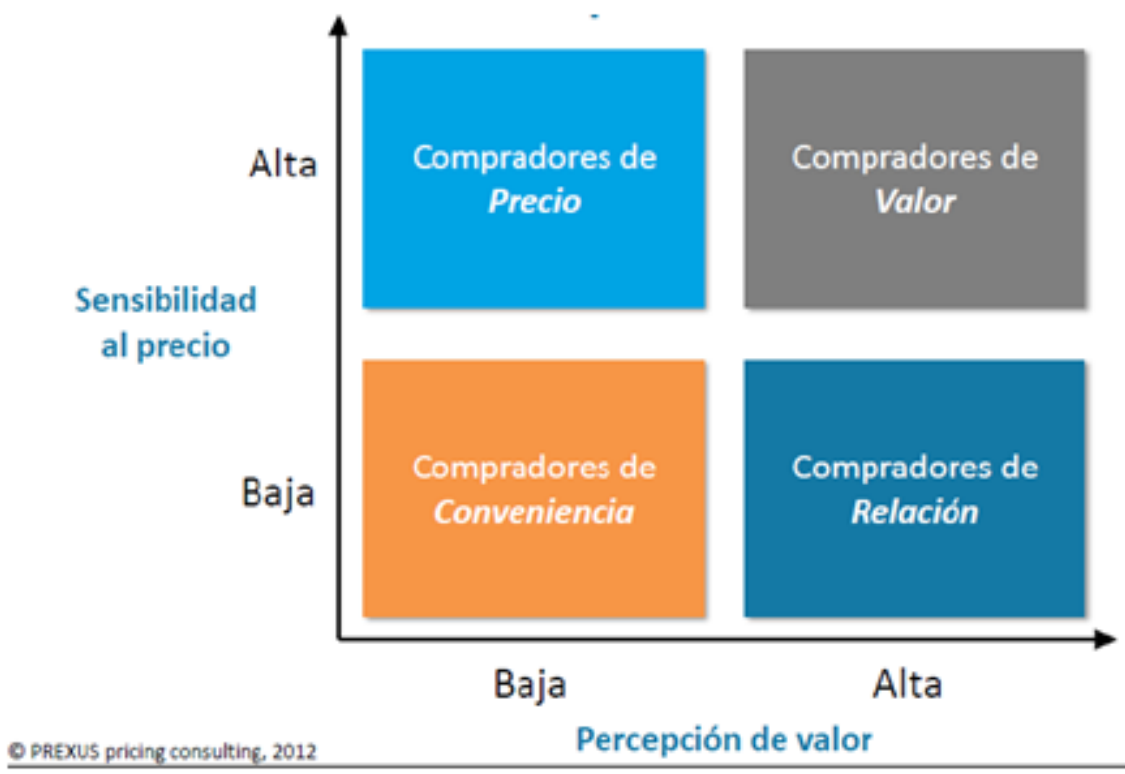

Figura 12. Ejemplo de percepción de valor y sensibilidad al precio ${ }^{2}$, elaborado por Prexus pricing consulting 2012

\footnotetext{
${ }^{2}$ Figura obtenida de https://sites.google.com/site/escaincomercial4/home/1-modulo-pricing
} 
Las características que posee este cuadrante, nos permite ubicarnos en él, pues buscará satisfacer las necesidades de compra de productos de primera necesidad pagando un precio que esté acorde al mercado. Actualmente, hay empresas que brindan un servicio similar al de nosotros y su porcentaje de comisión oscila entre 25 a $30 \%$.

Ingresaremos al mercado con una comisión de lanzamiento de $15 \%$, que incluye el delivery o recojo en tienda, el mismo se mantendrá por todo el primer año.

\section{BENCHMARKING}

- Tenemos como competencia directa a las tiendas de conveniencia, librerías y grifos presentes en los distritos de Miraflores, San Isidro y Surco los cuales poseen un ticket promedio entre S/. 20.00 a S/. 30.00 nuevos soles.

- Competencia indirecta a supermercados y autoservicios como: Wong, Metro, Vivanda, Plaza vea y Tottus cuyo ticket promedio es de entre S/. 70.00 a S/. 100.00 nuevos soles.

- Ninguno de nuestras competencias directas o indirectas brinda el servicio de Delivery.

\subsubsection{Estrategia comunicacional}

\section{Marketing Digital}

- Página web: $\underline{w w w . m i b o d e g u i t a . c o m . p e}$

En ella, publicamos de manera diaria las promociones del día, para las cuales buscaremos el apoyo de las grandes marcas. Esto incentivará el consumo de los usuarios y en el caso de nuestros clientes (bodegueros) los ayudará a saber qué productos ofertar. 


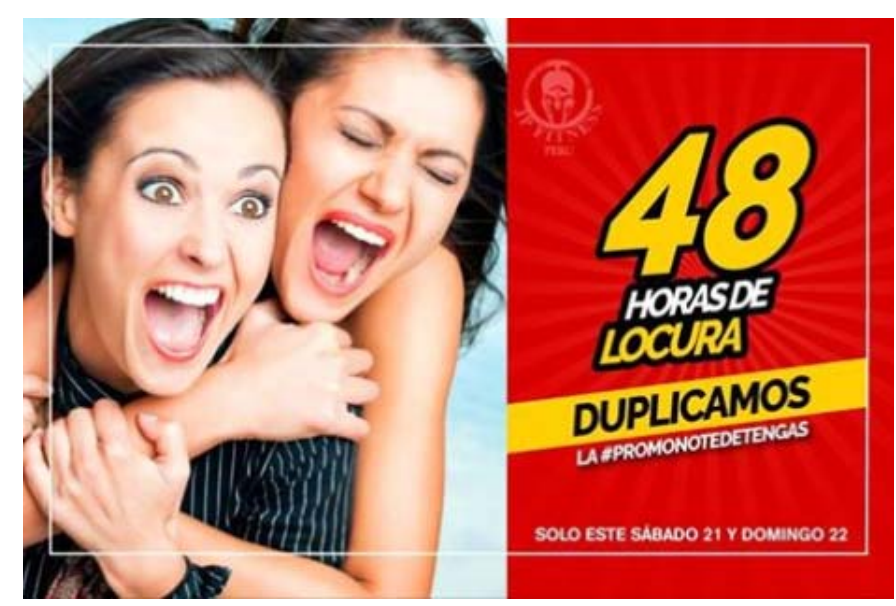

Figura 13. Ejemplo de promoción, elaborado por JPFitness

La página web, también contará con un formulario para que las bodegas nuevas puedan inscribirse:

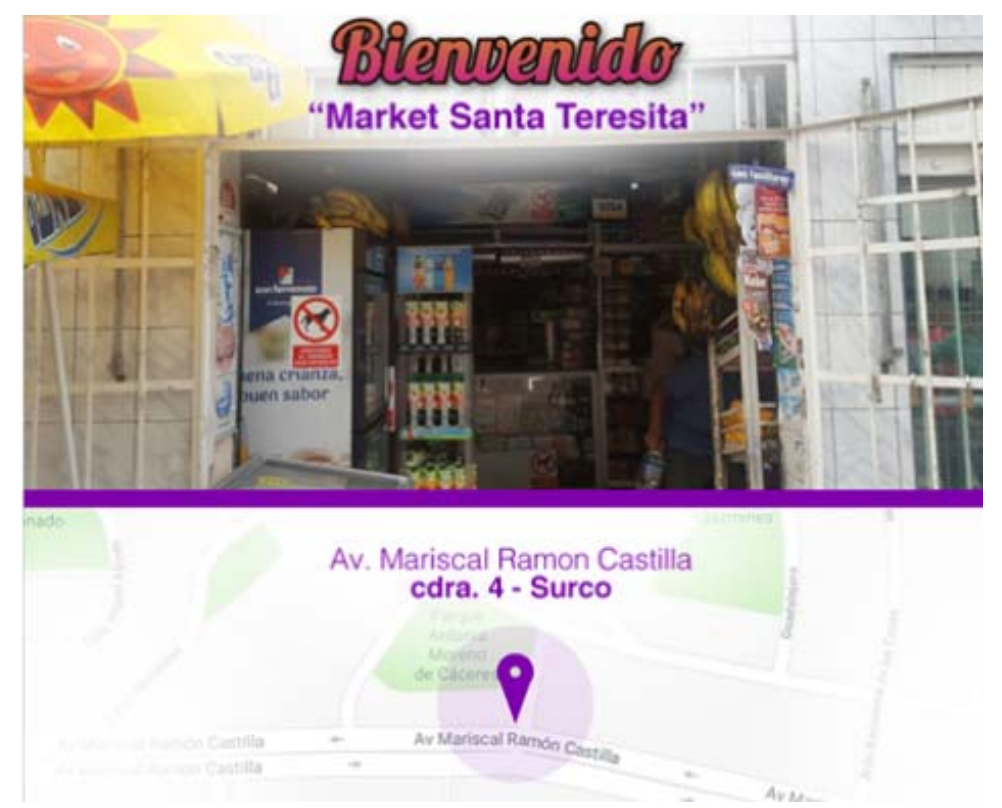

Figura 14. Ejemplo de formulario para ubicación de la bodega, elaborado por AlóBodega

\section{- Facebook: /Mibodeguita}

Usamos esta estrategia digital, principalmente, porque en ella podemos segmentar y llegar de esa forma al público objetivo (usuarios). Con relación al tipo de pautas que usamos en la red: Estamos colocando anuncios para incrementar el 
alcance de mercado al que llegamos. En ese sentido, nuestras acciones están generadas a la obtención de "likes".

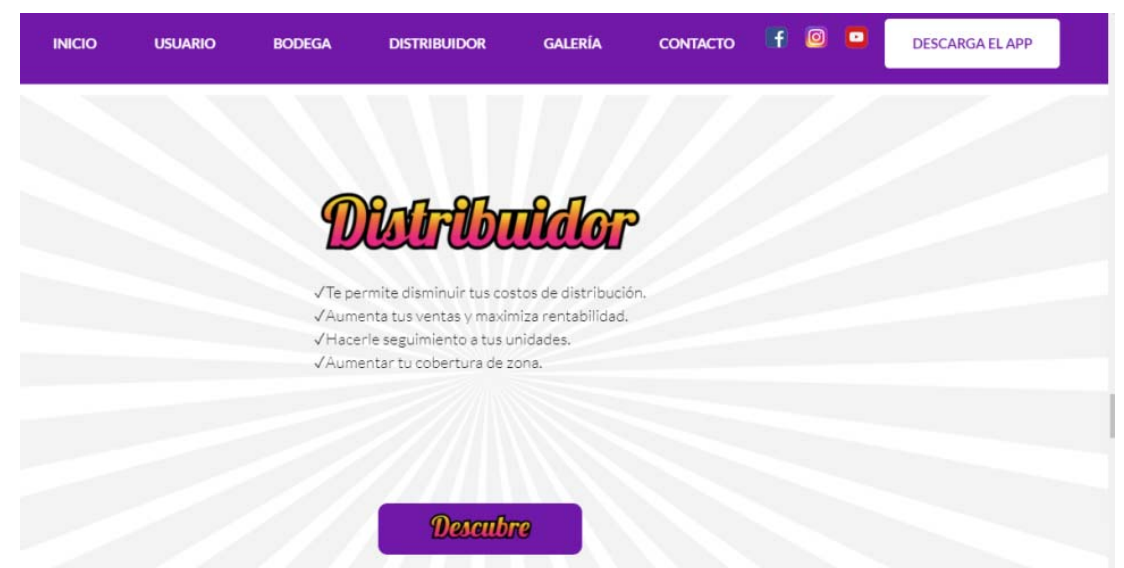

Figura 15. Ejemplo de formulario para inscripción de distribuidores, elaborado por AlóBodega

Paralelamente se trabajará otras redes como: Instagram, Twitter, pero nos concentraremos más en el Facebook. En esta plataforma también incentivaremos el registro de nuevos asociados y comunicaremos a los usuarios la aplicación de la cobertura.

\section{Marketing Directo}

- Volantes: Estos son entregados directamente a las bodegas (clientes) y en él se fomentará su afiliación y empadronamiento. También, se fomentará que las bodegas incluyan el servicio de delivery.

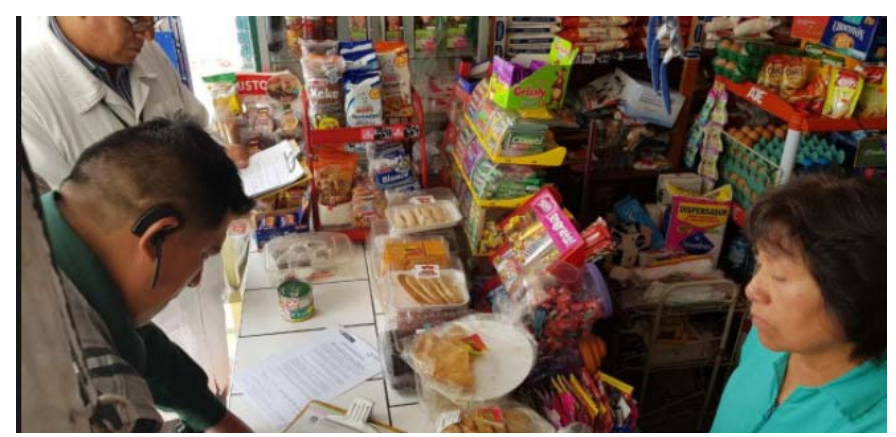

Figura 16. Contacto con bodegueros, elaborado por El Comercio 
El marketing directo también será una forma de cubrir y ampliar nuestro mercado, lo haremos de manera que nuestro personal que se encargue del volanteo y se concentre en realizar pequeñas activaciones en las cuales explotaremos los casos de éxito de nuestros asociados.

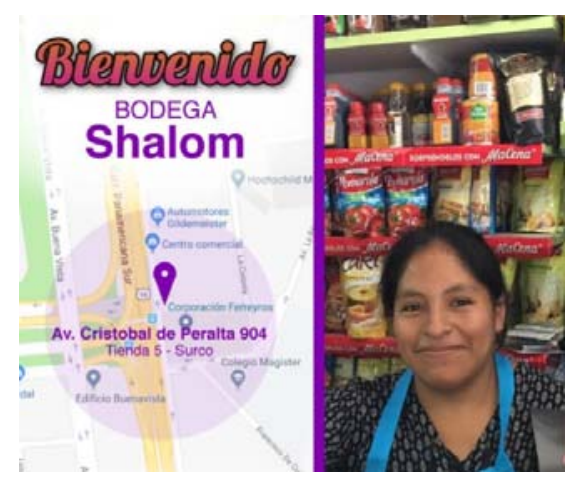

Figura 17. Ejemplo de inscripción de bodega, elaborado por AlóBodega

\subsubsection{Estrategia de distribución}

En la distribución pondremos al acceso de nuestros asociados (bodegas), proveedores que facilitaran el servicio de delivery de sus productos. La empresa se llama GeoBici y es una empresa que hace distribución en bicicleta para varios negocios.

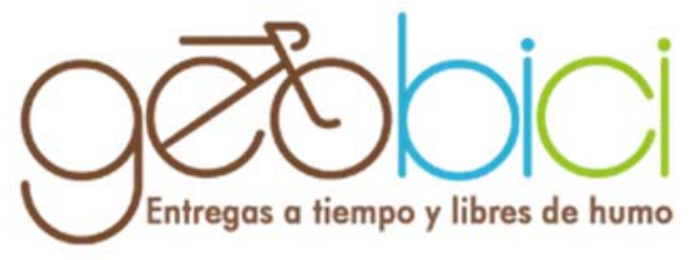

Figura 18. Logo, elaborado por GeoBici

Cumpliendo con la estrategia de reducción de costos de distribución de nuestros asociados, GeoBici realiza un descuento por cantidad de delivery realizados, que en conjunto al ampliar nuestra distribución a más distritos tendremos más puntos de entrega, y obtendremos más descuento para nuestras bodegas afiliadas (clientes). 
Además, implementaremos una estrategia de incentivos, sorteando periódicamente bicicletas, totalmente equipadas, para que los productos lleguen en perfectas condiciones a nuestros usuarios; de esta manera generaremos una reducción en el costo de distribución, pues pasando un tiempo aproximado de 18 meses, cada bodega asociada podría contar con su propio servicio de delivery de esta manera no se generara una dependencia de los servicios de GeoBici, y armar nuestra fuerza de distribución indirecta de Mí bodeguita, cumpliendo así nuestro objetivo propuesto.

\subsection{Plan de Ventas y proyección de la Demanda}

Para realizar nuestro plan de ventas utilizaremos el método de la investigación de mercado debido a que en el sector no contamos con competidores.

Luego de realizar un trabajo de campo realizando visitas a las bodegas que cuentan con el perfil para nuestro negocio y que se encuentren en sector demográfico, logramos conocer el promedio de clientes bodegueros de nuestra zona. 
Proyección de la Demanda

\begin{tabular}{|c|c|c|c|c|c|c|c|c|c|c|c|c|}
\hline MES & Tickets & Comisión & & Ingresos & $\begin{array}{c}\mathbf{N}^{\circ} \text { de } \\
\text { transacciones } \\
\text { por día }\end{array}$ & $\begin{array}{l}\text { Ingreso por } \\
\text { Transacción }\end{array}$ & $\begin{array}{c}\text { No de }^{\circ} \\
\text { bodegas }\end{array}$ & $\begin{array}{l}\text { Ingreso por } \\
\text { Día No de } \\
\text { Bodegas }\end{array}$ & $\begin{array}{l}\text { No de días } \\
\text { laborables }\end{array}$ & $\begin{array}{c}\text { Ingreso por } \\
\text { Mes }\end{array}$ & $\begin{array}{c}\text { Crec\% de } \\
\text { vtas } / \text { mes } \\
\text { vs mes } \\
\text { anterior }\end{array}$ & $\begin{array}{c}\text { Crec } \% \text { de } \\
\# \text { bod } / \text { mes } \\
\text { vs. Mes } \\
\text { anterior }\end{array}$ \\
\hline ENERO & $\mathrm{S} / 20.00$ & $15.00 \%$ & $\mathrm{~S} /$. & 3.00 & 15 & $\mathrm{~S} / .45 .00$ & 50 & $\mathrm{~S} / .2,250.00$ & 20 & $\mathrm{~S} / 45,000.00$ & & \\
\hline FEBRERO & $\mathrm{S} / 20.00$ & $15.00 \%$ & $\mathrm{~S} /$. & 3.00 & 12 & $\mathrm{~S} / .36 .00$ & 60 & $\mathrm{~S} / .2,160.00$ & 20 & $\mathrm{~S} / 43,200.00$ & $-4.0 \%$ & $20.0 \%$ \\
\hline MARZO & $\mathrm{S} / 20.00$ & $15.00 \%$ & $\mathrm{~S} /$. & 3.00 & 11 & $\mathrm{~S} / .33 .00$ & 70 & $\mathrm{~S} / .2,310.00$ & 20 & $\mathrm{~S} / 46,200.00$ & $6.9 \%$ & $16.7 \%$ \\
\hline ABRIL & $\mathrm{S} / 20.00$ & $15.00 \%$ & $\mathrm{~S} /$. & 3.00 & 15 & $\mathrm{~S} / .45 .00$ & 80 & $\mathrm{~S} / .3,600.00$ & 20 & $\mathrm{~S} / 72,000.00$ & $55.8 \%$ & $14.3 \%$ \\
\hline MAYO & $\mathrm{S} / 20.00$ & $15.00 \%$ & $\mathrm{~S} /$. & 3.00 & 17 & $\mathrm{~S} / .51 .00$ & 90 & $\mathrm{~S} / .4,590.00$ & 20 & $\mathrm{~S} / 91,800.00$ & $27.5 \%$ & $12.5 \%$ \\
\hline JUNIO & $\mathrm{S} / 20.00$ & $15.00 \%$ & $\mathrm{~S} /$. & 3.00 & 13 & $\mathrm{~S} / .39 .00$ & 100 & $\mathrm{~S} / .3,900.00$ & 20 & $\mathrm{~S} / 78,000.00$ & $-15.0 \%$ & $11.1 \%$ \\
\hline JULIO & $\mathrm{S} / 20.00$ & $15.00 \%$ & $\mathrm{~S} /$. & 3.00 & 17 & $\mathrm{~S} / .51 .00$ & 120 & S/. 6,120.00 & 20 & $\mathrm{~S} / 122,400.00$ & $56.9 \%$ & $20.0 \%$ \\
\hline AGOSTO & $\mathrm{S} / 20.00$ & $15.00 \%$ & $\mathrm{~S} /$. & 3.00 & 14 & $\mathrm{~S} / .42 .00$ & 130 & $\mathrm{~S} / .5,460.00$ & 20 & $\mathrm{~S} / 109,200.00$ & $-10.8 \%$ & $8.3 \%$ \\
\hline SEPTIEMBRE & $\mathrm{S} / 20.00$ & $15.00 \%$ & $\mathrm{~S} /$. & 3.00 & 14 & $\mathrm{~S} / .42 .00$ & 140 & $\mathrm{~S} / .5,880.00$ & 20 & $\mathrm{~S} / 117,600.00$ & $7.7 \%$ & $7.7 \%$ \\
\hline OCTUBRE & $\mathrm{S} / 20.00$ & $15.00 \%$ & $\mathrm{~S} /$. & 3.00 & 13 & $\mathrm{~S} / .39 .00$ & 145 & $\mathrm{~S} / .5,655.00$ & 20 & $\mathrm{~S} / 113,100.00$ & $-3.8 \%$ & $3.6 \%$ \\
\hline NOVIEMBRE & $\mathrm{S} / 20.00$ & $15.00 \%$ & $\mathrm{~S} /$. & 3.00 & 15 & $\mathrm{~S} / .45 .00$ & 145 & $\mathrm{~S} / .6,525.00$ & 20 & $\mathrm{~S} / 130,500.00$ & $15.4 \%$ & $0.0 \%$ \\
\hline DICIEMBRE & $\mathrm{S} / 20.00$ & $15.00 \%$ & $\mathrm{~S} /$. & 3.00 & 17 & $\mathrm{~S} / .51 .00$ & 145 & $\mathrm{~S} / .7,395.00$ & 20 & $\mathrm{~S} / 147,900.00$ & $13.3 \%$ & $0.0 \%$ \\
\hline & & & & & & & & & $\begin{array}{l}\text { TOTAL DE } \\
\text { INGRESOS }\end{array}$ & $\mathrm{S} / 1,116,900.00$ & & \\
\hline
\end{tabular}

Nota: Como se detalló en el punto de tamaño del mercado operativo, se cuenta con un total de 225 bodegas, repartidas entre los distritos de Miraflores, San Isidro y Surco, de los cuales 145 (etapa inicial durante el primer año) serán el $\mathrm{N}^{\circ}$ de bodegas requeridas para la viabilidad de este proyecto de negocio Mi Bodeguita. Como se observa se calcula un total de S/ 1'116,900.00 para el primer año de inserción en el mercado de Mi Bodeguita. Asimismo, se detalla el porcentaje de crecimiento de afiliación de bodegas incremental. 
Con una proyección a 5 años tal como muestra el cuadro:

\section{PROYECCION DE 5 AÑOS}

\begin{tabular}{|l|c|c|c|c|c|}
\hline & AÑO 2019 & AÑO 2020 & AÑO 2021 & AÑO 2022 & AÑO 2023 \\
\hline $\begin{array}{l}\text { \% DE } \\
\text { CONVERSION }\end{array}$ & & $8 \%$ & $10 \%$ & $11.50 \%$ & $14 \%$ \\
\hline INGRESOS & $\mathrm{S} / .1,116,900.00$ & $\mathrm{~S} / 1,206,252.00$ & $\mathrm{~S} / 1,326,877.20$ & $\mathrm{~S} / 1,479,468.08$ & $\mathrm{~S} / 1,686,593.61$ \\
\hline$\%$ & $100 \%$ & & & & \\
\hline & & & & & \\
\hline $\begin{array}{l}\text { Ingresos por Visa } \\
(50 \%)\end{array}$ & $\mathrm{S} / .558,450.00$ & $\mathrm{~S} / .603,126.00$ & $\mathrm{~S} / .663,438.60$ & $\mathrm{~S} / .739,734.04$ & $\mathrm{~S} / .843,296.80$ \\
\hline $\begin{array}{l}\text { Comisiones por } \\
\text { servicio (S/1.00) }\end{array}$ & $\mathrm{S} / .186,150.00$ & $\mathrm{~S} / .201,042.00$ & $\mathrm{~S} / .221,146.20$ & $\mathrm{~S} / .246,578.01$ & $\mathrm{~S} / .281,098.93$ \\
\hline $\begin{array}{l}\text { Ingresos contra } \\
\text { entrega (50\%) }\end{array}$ & $\mathrm{S} / .558,450.00$ & $\mathrm{~S} / .603,126.00$ & $\mathrm{~S} / .663,438.60$ & $\mathrm{~S} / .739,734.04$ & $\mathrm{~S} / .843,296.80$ \\
\hline $\begin{array}{l}\text { Comisiones por el } \\
\text { servicio (S/.00) }\end{array}$ & & & & & \\
\hline
\end{tabular}

\subsection{Presupuesto de Marketing}

\section{Marketing Digital \\ Facebook /Mi bodeguita.}

Usaremos esta herramienta porque en ella podemos segmentar y llegar a nuestros posibles usuarios. Con esta publicidad en Facebook podemos incrementar el alcance de mercado al cual nos dirigimos. Lo cual hace que nuestras acciones están generadas a la obtención de likes que solo es muestra de posibilidad de futuros usuarios compren en nuestra aplicación.

\section{LANDING PAGE}

Anuncio de publicidad: Por un mes de anuncio 310 soles.

\begin{tabular}{|c|ccc|} 
Anuncio de Publicidad & & Monto & \\
\hline 4 & días & 40 & soles \\
\hline 8 & días & 80 & soles \\
\hline 12 & días & 120 & soles \\
\hline 16 & días & 160 & soles \\
\hline 20 & días & 200 & soles \\
\hline 24 & días & 240 & soles \\
\hline 28 & días & 280 & Soles \\
\hline 31 & días & 310 & soles \\
\hline & & & \\
\hline
\end{tabular}




\section{Marketing Directo}

\section{Volantes}

Usaremos esta herramienta de publicidad en las bodegas afiliadas a nuestra App, que serán entregados a nuestros usuarios, que también serán distribuidos en las zonas de nuestro segmento.

\begin{tabular}{|c|c|c|c|c|c|}
\hline Volantes & & Costo & & $\mathbf{N}^{\circ}$ de Bodegas & Total de Efectivo \\
\hline 1000 & unidades & 45 & soles & 113 & $5,085.00$ \\
\hline
\end{tabular}

\section{Agente de BTL}

La fuerza de venta con la que trabajaremos será indirecta, y estará a cargo de Doctor BTL que es una empresa especializada en el trabajo con el canal tradicional. Por otro lado, en la etapa inicial contaremos con cuatro promotores para poder trabajar los distritos seleccionados. La supervisión y manejo de las operaciones seguirán en manos de nosotros. Es decir que toda decisión que se tome, el proveedor la debe consultar antes.

El presupuesto que se trabajara con Doctor BTL es el siguiente:

Agente de Presupuesto que se trabajará con BTL Doctor BTL

\begin{tabular}{|c|c|c|c|c|}
\hline & & & \multirow{2}{*}{ Meses } & \\
\hline & & & & 12 \\
\hline $\begin{array}{l}\text { Numero de } \\
\text { Promotores }\end{array}$ & $\begin{array}{c}\text { Costos } \\
\text { mensual } \\
\text { (Incluido } \\
\text { Igv) }\end{array}$ & $\begin{array}{c}\text { Costos anual } \\
\text { (Incluido Igv) y } \\
\text { bonificación (J/D) }\end{array}$ & $\begin{array}{c}\text { Gratificaciones } \\
\text { totales } \\
\text { anual }\end{array}$ & 18400 \\
\hline 4 & 4200 & $\mathrm{~S} / .68,800.00$ & & \\
\hline $\begin{array}{l}\text { Numero de } \\
\text { Promotores }\end{array}$ & $\begin{array}{c}\text { Costos } \\
\text { mensual } \\
\text { (Sin Igv) } \\
\end{array}$ & $\begin{array}{c}\text { Costos anual (Sin } \\
\text { Igv) y bonificación } \\
(\mathrm{J} / \mathrm{D})\end{array}$ & & \\
\hline 4 & $\mathrm{~S} / .3,559.32$ & $\mathrm{~S} / .58,305.08$ & & \\
\hline
\end{tabular}




\section{CAPÍTULO 5. PLAN DE OPERACIONES}

En el plan de operaciones se detallarán diferentes aspectos sobre el servicio que se ofrece a nuestros clientes (bodegueros). Esto, con base en la calidad, procesos, planificación y política de inventarios.

Cabe señalar que el plan de operaciones se logrará, mediante la aplicación de los siguientes procesos:

- Seleccionar y contratar servicios de terceros para la fuerza de ventas que brindarán y, recopilarán información, así como afiliarán a los clientes (bodegueros) para que formen parte de la base de datos de bodegas en los distritos de Miraflores, San Isidro y Surco. Parte fundamental del proyecto de negocio.

- Seleccionar y reclutar a proveedores adecuados (servidores) que permitan ofrecer un servicio de conexión ininterrumpida entre los clientes (bodegueros) y los usuarios para una gestión rápida, práctica y proceso completo del servicio.

- Gestionar la validación y el seguimiento semanal al plan de negocios del proyecto. Esto, para revisar que el mismo se encuentre alineado a las estrategias establecidas. Así como corregir los inconvenientes presentados para la búsqueda de rentabilidad con excelente servicio.

- Actualizar de manera continua la base de bodegas. Esto, con el fin de realizar promociones e identificar a que clientes se les puede ofrecer otros servicios adicionales para fidelización.

- Efectuar un servicio de calidad en el pago a los proveedores, así como en el cobro por transacción de nuestros clientes. Con la finalidad de tener mayor liquidez y emplear herramientas adecuadas para incrementar la rentabilidad del proyecto. 


\subsection{Políticas Operacionales}

Las políticas operacionales de Mi Bodeguita buscan que las transacciones estén alineadas a la calidad del servicio, mejora continua, innovación, uso de tecnología adecuada, etc. Este proyecto de negocio incluye una propuesta de valor:

Para los clientes:

- Accesibilidad a un nuevo canal de ventas (no tradicional)

- Incremento de ventas por nueva captación de clientes (modalidad virtual)

- Facilidad para el control de inventarios y pagos a proveedores de clientes (bodegueros).

- Innovación tecnológica del servicio para clientes.

Para los usuarios:

- Geolocalización, que permite ubicar en tiempo real, el servicio.

- Red de bodegas afiliadas que brinden confiabilidad al usuario sobre los productos adquiridos.

- Servicio de aplicación para celulares con tarifas accesibles y adecuadas de productos.

- Innovación tecnológica del servicio para usuarios.

\subsubsection{Calidad}

La calidad del servicio está enfocada en satisfacer las necesidades de los clientes (bodegueros) para el incremento de ingresos por mercados no atendidos (usuarios virtuales). Asimismo, la calidad se mide, según el nivel de satisfacción y valoración que el cliente otorgue al servicio: 


\section{Servicio virtual (App)}

\section{Proceso antes del servicio}

- Reconocimiento de necesidad por satisfacer de clientes (bodegueros) para incrementar sus ingresos y valores agregados (Empresa).

- Evaluación de alternativas de solución ante necesidad por satisfacer de clientes (bodegueros). (Empresa)

- Establecimiento de solución idónea para satisfacer la necesidad de los clientes con la finalidad de incrementar sus ingresos. (Empresa)

- Diseño, plan estratégico y de acción, estructura, organización, etc., de la solución: aplicación "Mi Bodeguita". (Empresa).

- Sistematización de total de usuarios por atender en los distritos de Miraflores, San isidro y Surco como herramienta del servicio.

- Sistematización de total de clientes (bodegas) por atender en los distritos de Miraflores, San isidro y Surco (plan de acción de visitas).

- Capacitación de la fuerza de ventas para realizar el primer contacto con clientes. Bajo el objetivo de interiorizar en los potenciales clientes los beneficios del servicio, valores agregados (mercado no atendido) derivados del mismo y mínimos requeridos para la afiliación.

- Definir contrato de afiliación e inicio de toma de datos (ubicación, productos, precios, etc.).

- Empadronamiento de los clientes (bodegueros) con información detallada para sus accesos.

- Descarga de la aplicación, por parte de los clientes, para creación de usuarios y contraseñas para el manejo de inventario y acceso a red de usuarios.

Control de calidad en la cantidad mínima requerida inicial de bodegas afiliadas para inicio del servicio. (145 bodegas durante el primer año). 


\section{Proceso durante el servicio}

- Acceso de clientes para ingresar datos adicionales sobre su bodega que lo haga más atractivo (variedad de productos, precios, promociones, datos de contacto, etc.)

- Control de tiempos de entrega de productos a usuarios.

- Sistematización de montos de compras de usuarios.

- Identificación de número de transacciones por hora, día, semana (Identificación de horarios bajos de ventas).

\section{Proceso después del servicio}

- Sistema de valoración del servicio de Mi Bodeguita para los clientes como para los usuarios, a través de la aplicación (Valoración de 1 a 5 estrellas). En donde el usuario brinde calificación para tiempos de entrega, precios y calidad de productos entregados por las bodegas. Esto, con la finalidad que más usuarios encuentren atractivo utilizar la aplicación. Asimismo, el bodeguero pueda calificar el servicio brindado por Mi Bodeguita, respecto a utilidad de la aplicación, cumplimiento e incremento de ventas, manejo de inventarios para la afiliación de más bodegas, que se puedan beneficiar del servicio ofrecido por Mi Bodeguita. Cabe señalar que el servicio brindado por Mi Bodeguita debe mantener una calificación mínima de 4 estrellas, tanto para clientes como para usuarios. Esto, con el propósito de mantener estándares de calidad del servicio ofrecido. Así como brindar asesoría continua a los clientes (bodegueros) para que brinden mejor atención, productos adecuados que repercutan en mayores pedidos que generen incremento de ventas.

- Control y seguimiento de procesos de recepción y entrega de pedidos. Con la finalidad de llevar un registro de solicitudes atendidas y no atendidas. (Empresa y bodega) 


\section{Bodegas}

\section{Políticas}

- Uso adecuado de las herramientas proporcionadas en la aplicación para acceso de datos de usuarios registrados.

- Mantener un servicio de calidad en la selección de productos, atención de usuarios y tiempos de entrega.

- Mantener actualizado el stock de productos para acceso de compras de los usuarios.

\section{Revisiones generales}

- Contar con personal mínimo con capacitación estándar de atención al usuario.

- Contar con plan de adquisición a mediano plazo de medios de transporte (bicicletas, motos) para optimización de tiempos de entrega.

\section{Validaciones}

- Promedio de valorizaciones recibidas por parte de usuarios al finalizar el proceso de atención. (Mínimo 4 estrellas).

\section{Protocolo de servicios}

\section{- Atención virtual}

Cuando el bodeguero (cliente) reciba la solicitud de compra por parte de usuarios afiliados a la aplicación Mi Bodeguita, debe:

- Verificar que la información del pedido del usuario contenga los mínimos requeridos para dar respuesta o alerta de atención del mismo (datos de contacto, teléfono, dirección, medio de pago, etc.).

- Antes de enviar las alertas de atención al usuario, se debe revisar el stock de productos para garantizar el envío completo de los mismos. 
- Las respuestas de alertas de atención deben ser atendidos a la brevedad posible (tiempo mínimo: 5 minutos).

- Manejar un lenguaje puntual, sencillo y respetando las normas de ortografía y redacción en caso el usuario ingrese comentarios al pedido.

- Al final del servicio invitar al usuario a emitir calificación de atención.

\section{- Atención telefónica}

Cuando el usuario requiera llamar al bodeguero (cliente) para consultas o seguimiento de tiempos de entrega de manera telefónica, el bodeguero debe:

- Saludar al usuario de forma amable: "Buenos días, tardes o noches, lo saluda Bodega (...), en que puedo servirle.

- Tomar nota de cualquier detalle adicional sobre el pedido para la satisfacción del cliente.

- Brindar al usuario la atención completa y personalizada durante el tiempo de contacto.

- Brindar detalle claro y preciso de alternativas o soluciones frente a dudas.

- Despedirse de forma cortes.

\section{- Atención personal}

Cuando el personal de la bodega (cliente) realice la entrega de los productos solicitados por los usuarios, debe:

- Saludar al usuario de forma amable: "Buenos días, tardes o noches, lo saluda Bodega (.....), y venimos a entregar el pedido realizado a través de la aplicación Mi Bodeguita.

- Proceder a la entrega de los productos de manera cordial, ser empáticos con el usuario. 
- Proceder a la entrega de los comprobantes de pago (pagos por aplicación), respectivos vueltos en caso de pago en efectivo.

- Despedirse de forma cortes y agradecer al usuario por haber utilizado la aplicación y escoger a la Bodega (......), y que con gusto se le atenderá en caso requiera algo más.

Cabe señalar que lo descrito anteriormente, permitirá el desarrollo y mejora continua de la aplicación Mi bodeguita.

- Canal de asistencia - mensajería instantánea: Mi Bodeguita

Para la adecuada calidad del servicio de Mi Bodeguita se incluirá un canal para la atención de reclamos de clientes y usuarios, así como un canal de mensajería instantánea.

\section{- Comunicación entre la aplicación y clientes (bodegueros)}

La comunicación en línea y continua entre la aplicación y las bodegas será a través de un chat con los usuarios para detalle del pedido y otros. Asimismo, la interacción de la aplicación con los bodegueros será rápida y útil para el manejo de inventarios y establecimiento de procesos de pago.

\section{- Comunicación entre bodegueros y Mi Bodeguita (Empresa)}

La comunicación entre las bodegas y la empresa será mediante correo electrónico, vía chat de la página web o contacto directo a través de teléfonos de atención (reportes de inconvenientes con la aplicación, etc.). 


\subsubsection{Políticas Procesos}

Mi Bodeguita ha definido sus procesos, como parte de su objetivo, que es satisfacer la necesidad de incrementar los ingresos de las bodegas en los distritos de Miraflores, San Isidro y Surco. Por ello, para comprender de forma más integral los procesos de Mi Bodeguita, se ha diseñado un gráfico que detalla los diferentes niveles de la operación.

Cabe señalar que los procesos de Mi Bodeguita están enfocados en la generación de valor, así como de reducir factores de costos y tiempos para lograr una eficiencia en el servicio ofrecido. Con esta premisa, el servicio dirige sus esfuerzos para satisfacer a los clientes y usuarios. Cada parte involucrada en el proceso de $\mathrm{Mi}$ Bodeguita se alinean a los objetivos estratégicos. El punto determinante se encuentra en la dirección de este proyecto, que debe tener en cuenta la importancia del liderazgo, así como realizar un seguimiento y mejora continua de los procesos.

Esquema guía de procesos de negocios de Mi Bodeguita

Mi Bodeguita

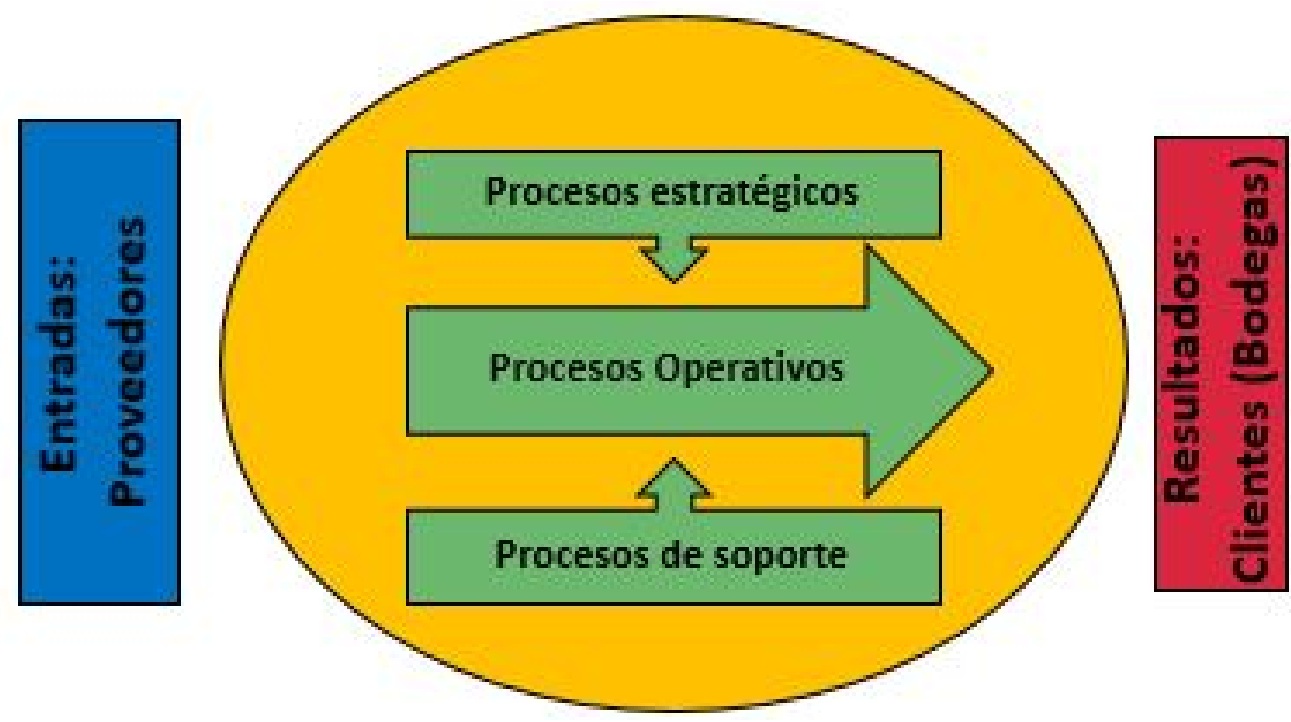

Figura 19. Ejemplo de proceso de negocios, elaborado por UPC Curso Desarrollo de Negocios 2 BlackBoard (Ciclo 2018-1) 
Con el enfoque de obtener una excelencia en el servicio ofrecido por $\mathrm{Mi}$ Bodeguita, y que permita cumplir con los objetivos, el proyecto dirige sus acciones y políticas de procesos a lo siguiente:

- Interiorizar, capacitar y entrenar a cada miembro directo o tercerizado que participa en el proceso (desde inicio hasta la entrega del servicio al cliente). Con ello, se obtiene el compromiso de cada miembro para el correcto trato y empatía entre los involucrados y los clientes.

- Reconocer procesos críticos que puedan aminorar la calidad del servicio. Esto con la finalidad de mantener el valor agregado del servicio ofrecido.

- Clasificar los procesos claves de Mi Bodeguita para comprender los niveles de importancia para cumplir con los objetivos.

- Comprender la relación de los procesos y la interacción de los agentes involucrados (clientes, proveedores, empresa, etc.) para anticipar consecuencias negativas.

- Fijar la actividad del servicio de Mi Bodeguita a la estrategia, debido a que cada acción debe tener como base la estrategia de diferenciación.

- Realizar procesos de calidad y establecer indicadores de resultados para medir la satisfacción de los clientes e ir innovando y mejorando los servicios ofrecidos. El feedback es primordial para mantener el nivel de satisfacción de los clientes de manera óptima.

A continuación, se presenta los procesos generales de Mi Bodeguita: 


\section{Mi Bodequita}

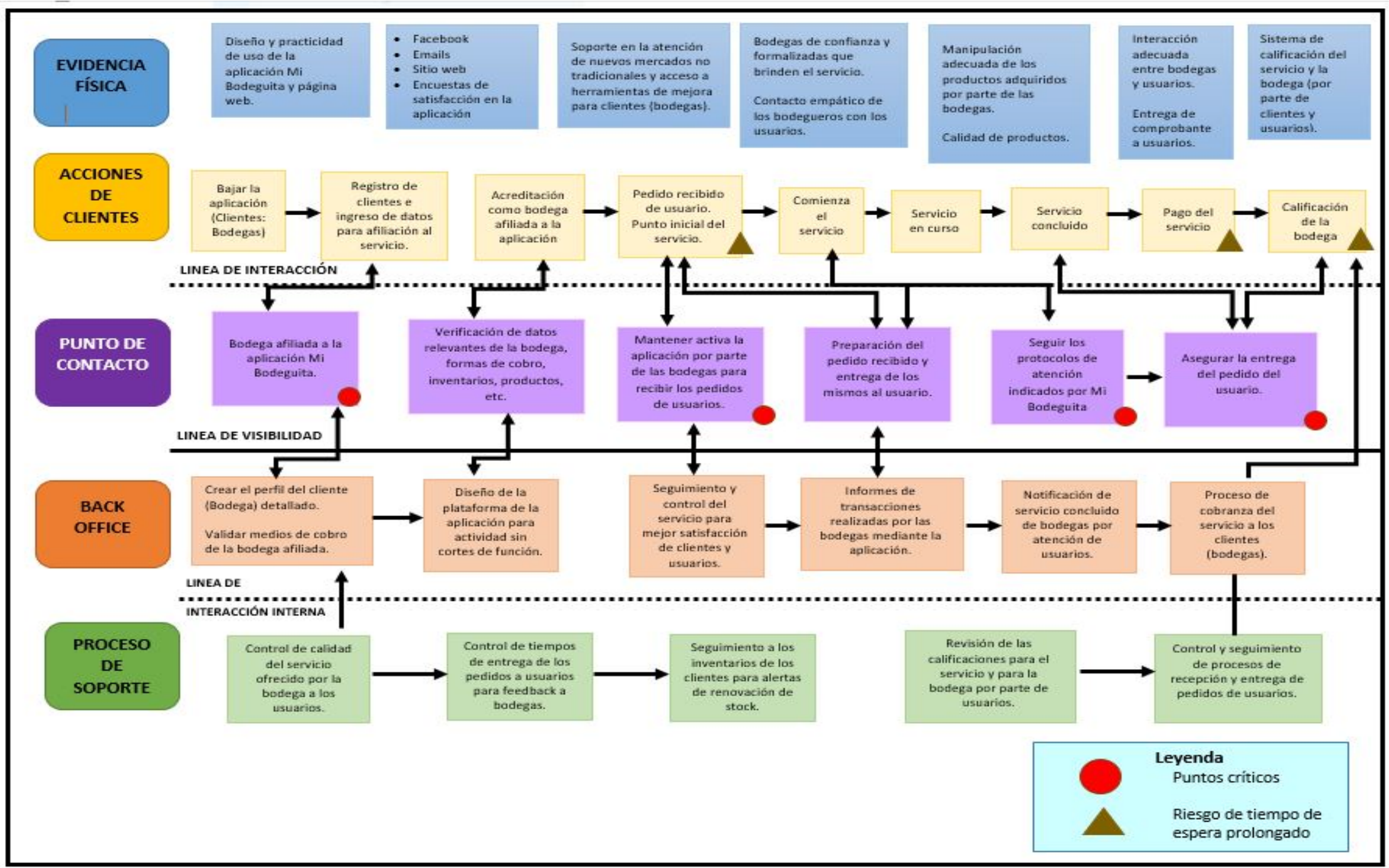

Figura 20. Elaboración propia de Mi Bodeguita 
Procesos diferenciados:

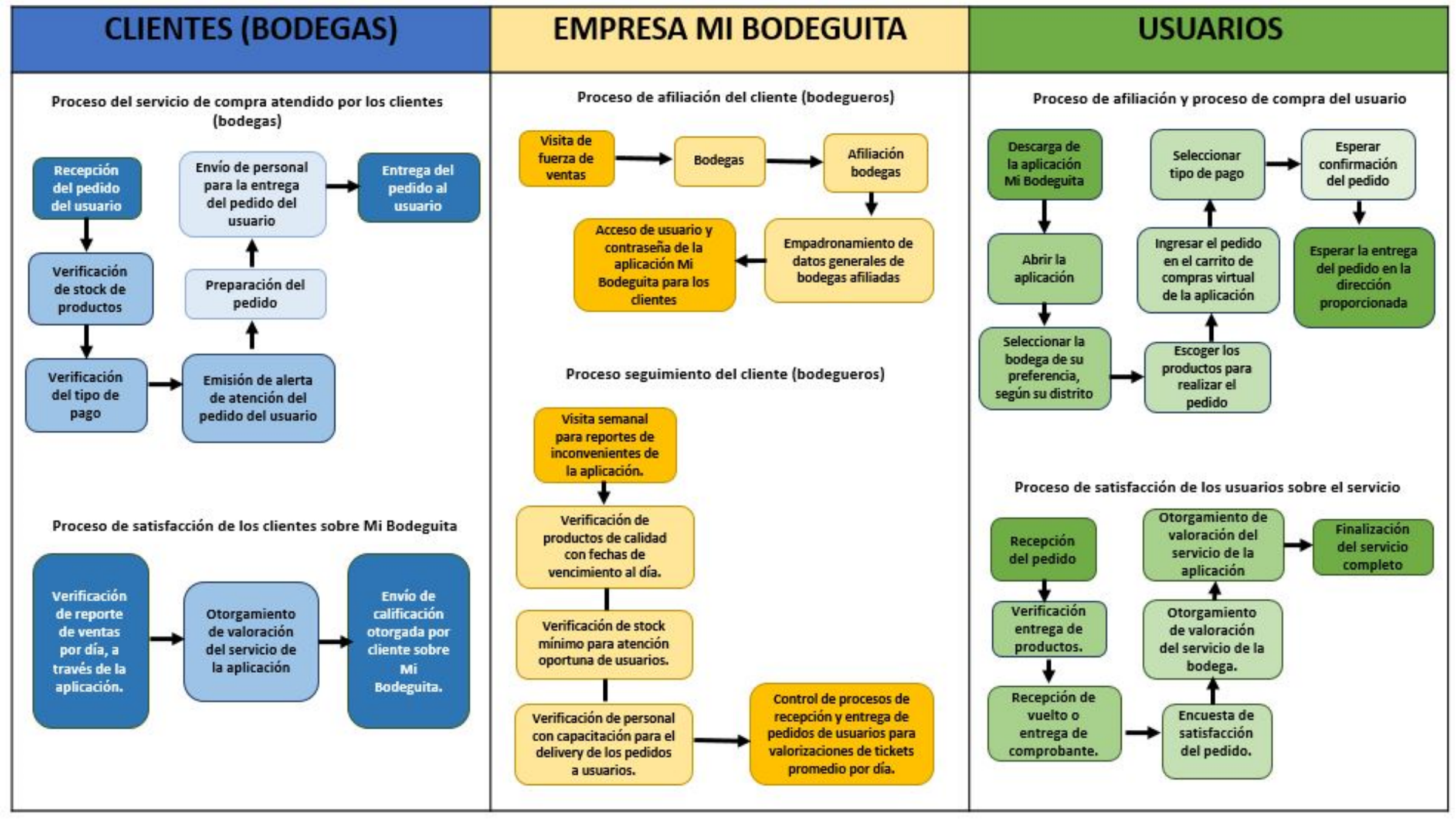

Figura 21. Elaboración propia de Mi Bodeguita 


\section{Mi Bodeguita}

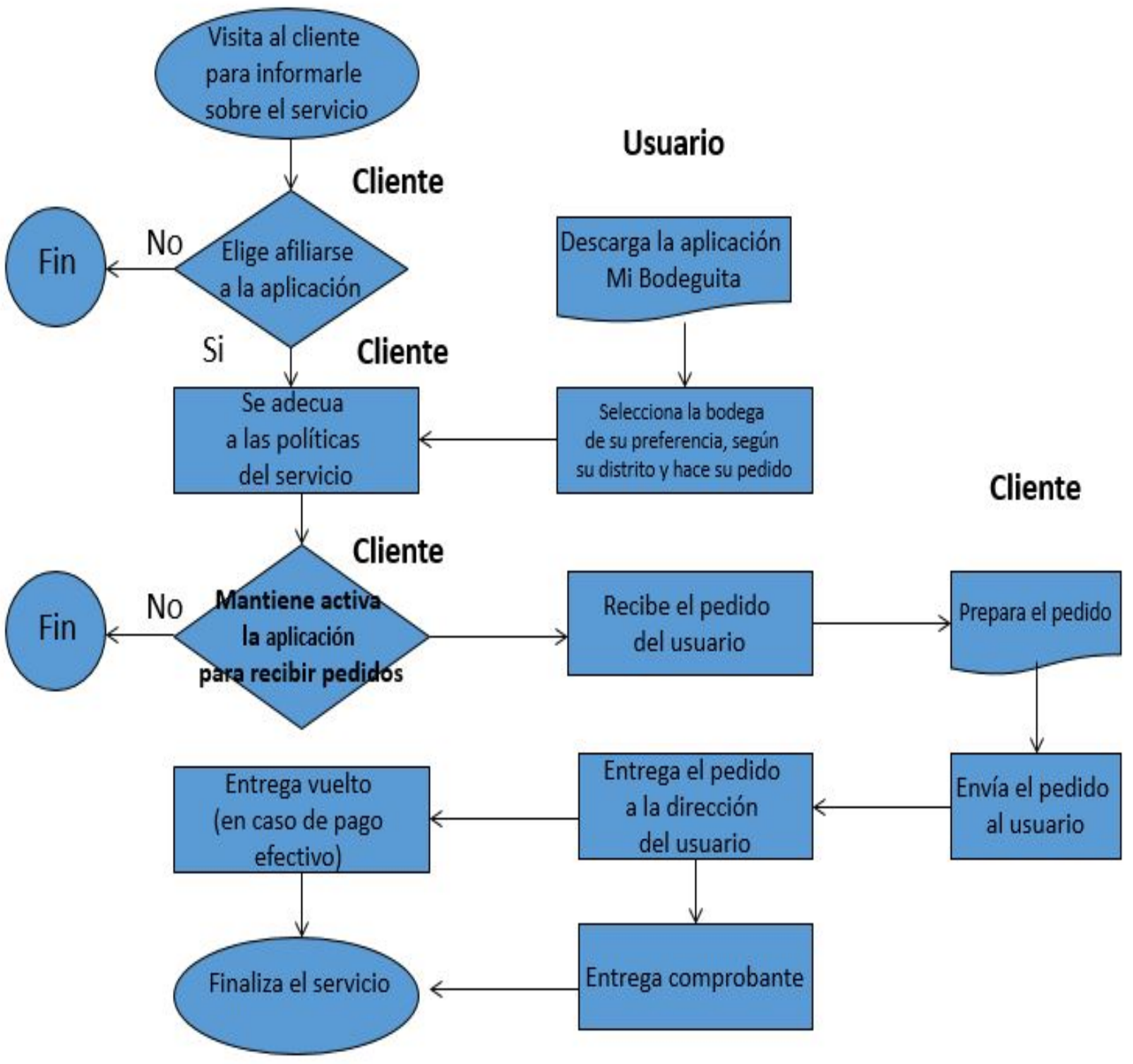

Figura 22. Elaboración propia de Mi Bodeguita 


\subsubsection{Políticas de Planificación}

La planeación es primordial para lograr el éxito del proyecto de negocio Mi Bodeguita, debido a que permitirá aminorar la incertidumbre y riesgos. Como tal se debe organizar, coordinar y controlar.

Las políticas de planificación se enfocan en:

- Análisis de la situación actual

- Establecimiento de herramientas para la actividad de las operaciones.

- Acciones para la viabilidad del servicio.

- Inicio del servicio, seguimiento y control.

Se empleará un diagrama Gantt para definir actividades a realizar y el tiempo (en meses) que demandará a la empresa para iniciar sus operaciones. 
DIAGRAMA GANTT DE MI BODEGUITA

\begin{tabular}{|c|c|c|c|c|c|c|c|c|c|c|c|c|c|c|}
\hline \multirow{2}{*}{$\mathbf{N}^{\circ}$} & \multirow{2}{*}{ ACTIVIDADES } & \multirow{2}{*}{$\begin{array}{l}\text { Tiempo en } \\
\text { meses }\end{array}$} & \multicolumn{12}{|c|}{ Meses por actividad } \\
\hline & & & 1 & 2 & 3 & 4 & 5 & 6 & 7 & 8 & 9 & 10 & 11 & 12 \\
\hline 1 & Constitución de la empresa en general & 2 & & & & & & & & & & & & \\
\hline 2 & Establecimiento de proveedores en general & 3 & & & & & & & & & & & & \\
\hline 3 & $\begin{array}{l}\text { Lanzar una campaña de publicidad atractiva y } \\
\text { beneficiosa para las bodegas que permita generar } \\
\text { mayores afiliaciones en el primer año. }\end{array}$ & Permanente & & & & & & & & & & & & \\
\hline 4 & $\begin{array}{l}\text { Afiliación de bodegas de Miraflores, San Isidro y } \\
\text { Surco, que se conviertan en clientes regulares. }\end{array}$ & 2 & & & & & & & & & & & & \\
\hline 5 & $\begin{array}{l}\text { Elaborar una base de datos de las bodegas afiliadas } \\
\text { para la creación de usuarios y accesos. }\end{array}$ & 3 & & & & & & & & & & & & \\
\hline 6 & $\begin{array}{l}\text { Lanzar una campaña de publicidad atractiva y } \\
\text { beneficiosa para los usuarios. }\end{array}$ & Permanente & & & & & & & & & & & & \\
\hline 7 & $\begin{array}{l}\text { Lograr una frecuencia de transacciones de un } \\
\text { promedio de } 15 \text { con tickets de } \mathbf{S} 30.00 \text { por } 20 \text { días } \\
\text { útiles al mes. }\end{array}$ & Permanente & & & & & & & & & & & & \\
\hline 8 & $\begin{array}{l}\text { Realizar una encuesta de satisfacción de la } \\
\text { aplicación para cuantificar la aceptación de los } \\
\text { clientes (bodegueros) y usuarios. }\end{array}$ & 8 & & & & & & & & & & & & \\
\hline 9 & $\begin{array}{l}\text { Generar información relevante sobre el impacto de la } \\
\text { aplicación que permita mejorar e innovar el valor } \\
\text { agregado del mismo. }\end{array}$ & 10 & & & & & & & & & & & & \\
\hline
\end{tabular}




\subsubsection{Políticas de Inventarios}

Mi Bodeguita es un servicio que no maneja un inventario de manera directa, debido a que es el nexo entre los clientes (bodegas) y usuarios. Es decir que el servicio trabajará en todo momento con el stock del cliente. Mi Bodeguita, se plantea como un intermediario que ofrece el servicio de una aplicación en el celular para vender productos (bodegas) y realizar compras (usuarios).

Sin embargo, debido a que el proyecto de negocio debe mantener un mínimo de recursos para su buen funcionamiento, se considera lo siguiente:

\begin{tabular}{|c|c|c|}
\hline $\mathbf{N}^{\circ}$ & Artículo & Descripción \\
\hline 1 & Folletería & $\begin{array}{l}\text { Material con información detallada del } \\
\text { servicio para los clientes (bodegueros). }\end{array}$ \\
\hline 2 & Útiles de oficina & Uso general para actividades administrativas. \\
\hline 3 & Espacio físico & $\begin{array}{l}\text { Ambientes adecuados para las coordinaciones } \\
\text { o reuniones de trabajo entre personal de la } \\
\text { empresa o fuerza de ventas y afiliación de } \\
\text { clientes. }\end{array}$ \\
\hline
\end{tabular}

\subsection{Diseño de Instalaciones}

Se ha determinado alquilar oficinas mediante el método Coworking (cotrabajo). Es decir, se empleará los servicios de la empresa Comunal Coworking (Ver Anexo 2), donde se brindará oficinas completamente equipadas. Ubicada en pleno corazón de Miraflores, a una cuadra de la Av. Pardo y muy bien conectado con las principales avenidas.

\subsubsection{Localización de las instalaciones}

La oficina central estará ubicada en el distrito de Miraflores, en una zona de acceso total. La oficina estará en Calle Recavarren 111, Piso 7 - Miraflores: 


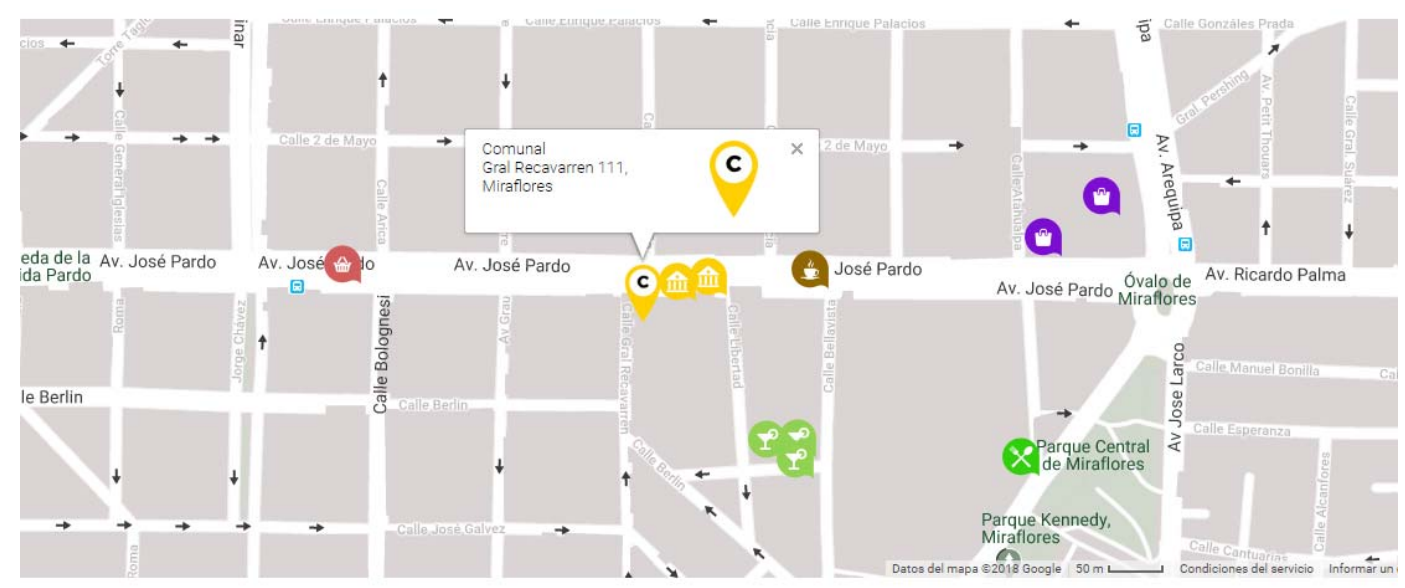

Figura 23. Mapa de ubicación de oficinas, elaborado por Comunal Coworking

Se puede utilizar las instalaciones $24 \times 7$. No se tiene que implementar nada, viene incluido en el alquiler. Es un lugar estratégico para tener a nuestros clientes cerca. Es una oficina privada totalmente equipado para 6 personas a un costo mensual de 1,800 dólares.

\subsubsection{Capacidad de las instalaciones}

La oficina tiene $25 \mathrm{~m} 2$, y se ha distribuido de la siguiente manera:

- Gerencia General con su asistente.

- Encargado de Comercial.

- Encargado de Ventas y Marketing (toma de pedidos y mercadeo)

- Encargado de Operaciones con un asistente.

- Sala de reuniones acondicionada para capacitar a la fuerza de ventas.

- Sala de impresiones.

- Internet con fibra óptica.

- Recepción, cafetería, áreas comunes, lockers, seguridad.

- Acceso a estacionamiento público y/o privado. 


\subsubsection{Distribución de las instalaciones}

De esta forma realizaremos la distribución de las instalaciones:
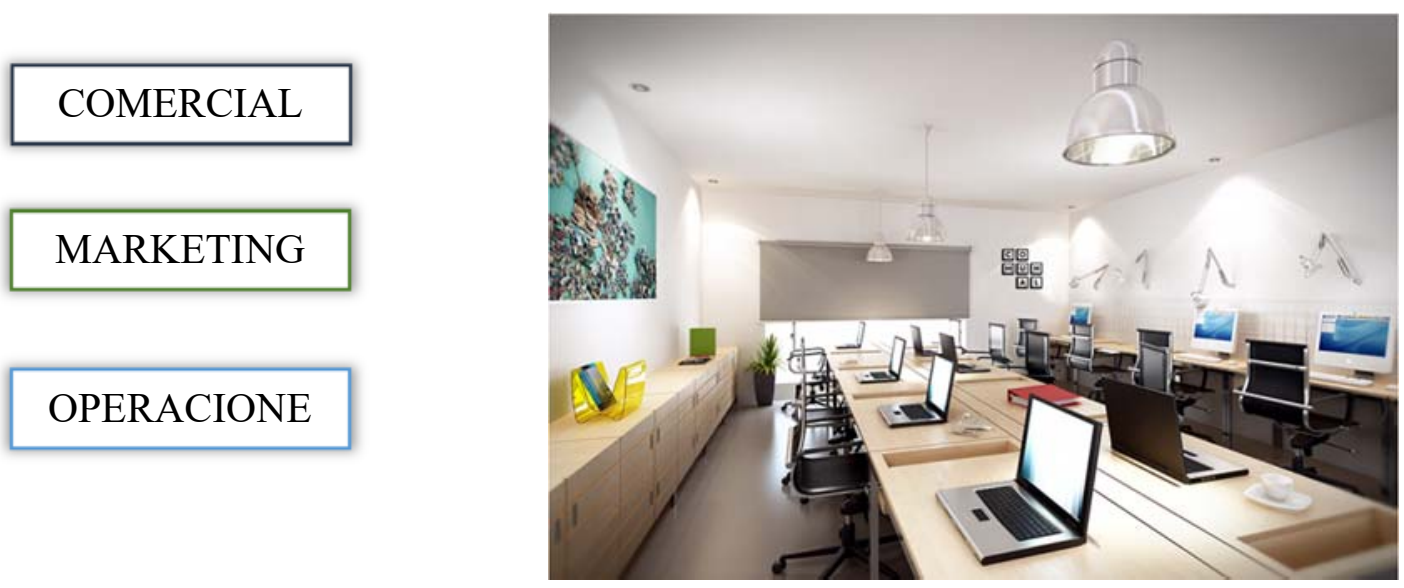

Figura 24. Modelo de oficina, elaborado por Comunal Coworking

Al contratar una empresa de coworking, se trabajará con escritorios compartidos en amplias oficinas. Esto ayudará a que contemos con espacios para que nuestra creatividad fluya, además de hacer networking como aliados, clientes y proveedores.

\subsection{Especificaciones Técnicas del Producto / servicio}

La mayoría de los smartphones en el mercado local utilizan el sistema Android (72.6\%), por ello la app debe ser compatible con este sistema operativo. 


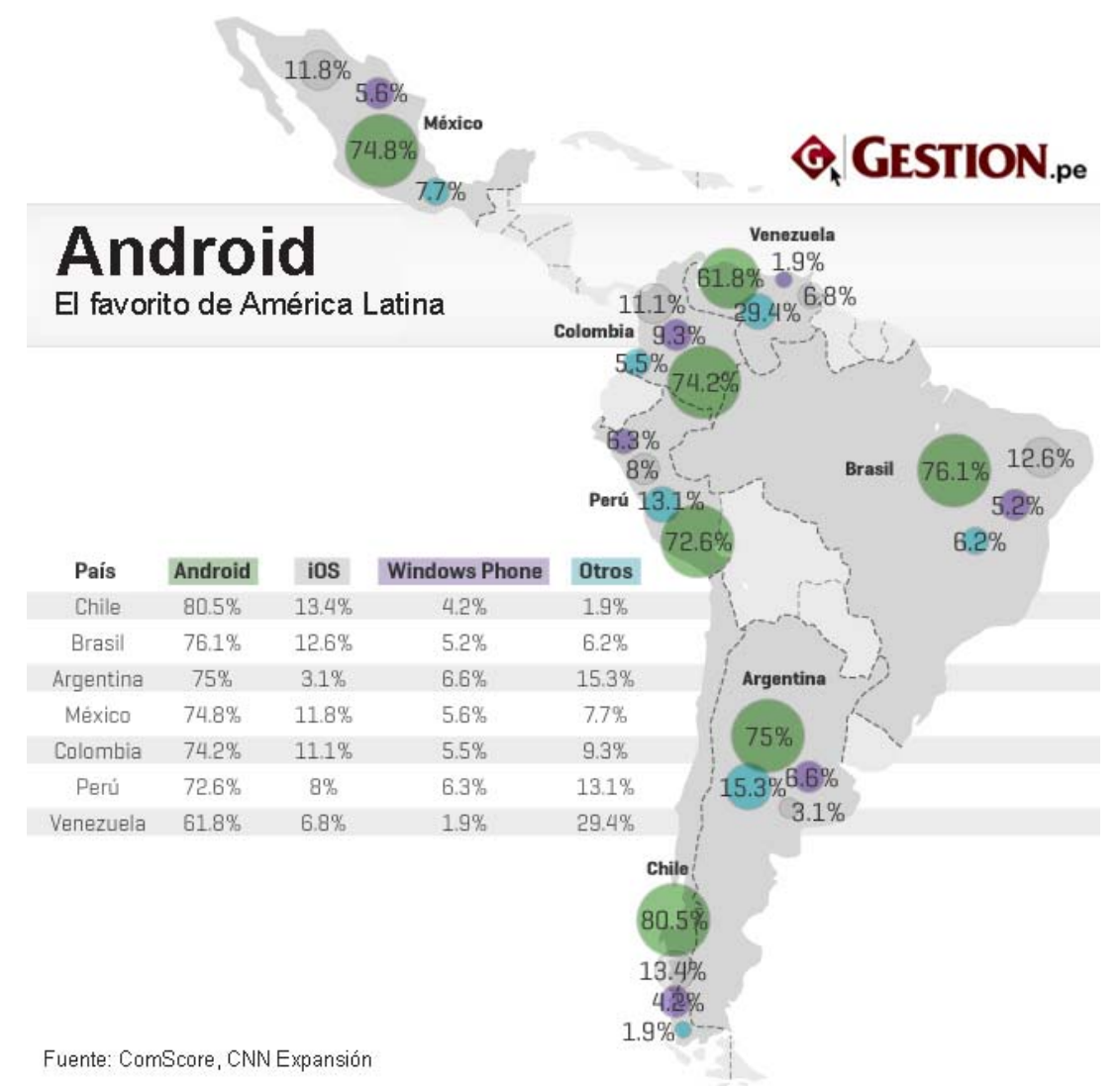

Figura 25. Modelo de oficina, elaborado por ComScore - CNN Expansión ${ }^{3}$

Especificaciones técnicas de la app:

- Android Studio, software para programar y crear los aplicativos. Es un sistema operativo de código abierto.

- Lenguaje de Programación JAVA, donde se utiliza para programar en el Android Studio.

- Base de Datos SQL, donde se albergará toda nuestra información.

- Adaptable a muchas pantallas y resoluciones.

- Núcleo basado en el Kernel de Windows.

- Navegador web basado en WebKit incluido.

Integrando todas estas herramientas tecnológicas, se logrará crear la aplicación con todas sus funcionalidades. Adicionalmente a esto, se necesita implementar la

\footnotetext{
${ }^{3}$ Figura extraída de Gestión: https://gestion.pe
} 
geolocalización del usuario mediante GPS y crear un módulo de pago con la ayuda de bancos locales.

El costo de la creación depende de lo complejo que sea su realización, también depende de cuánto tiempo tome, porque es necesario todo un equipo de trabajo. En este caso se consultó a la empresa MCL Proyect (http://mclproyect.com/) donde nos dieron un aproximado de 10,000 a 20,000 nuevos soles. Con un costo de mantenimiento bimestral de 200 dólares.

\subsection{Mapa de Procesos y PERT}

Los proveedores que se requieren para poder emprender el negocio serán de forma fija en la primera parte. Con la finalidad de dar inicio al aplicativo de la App a nuestros clientes y usuarios.

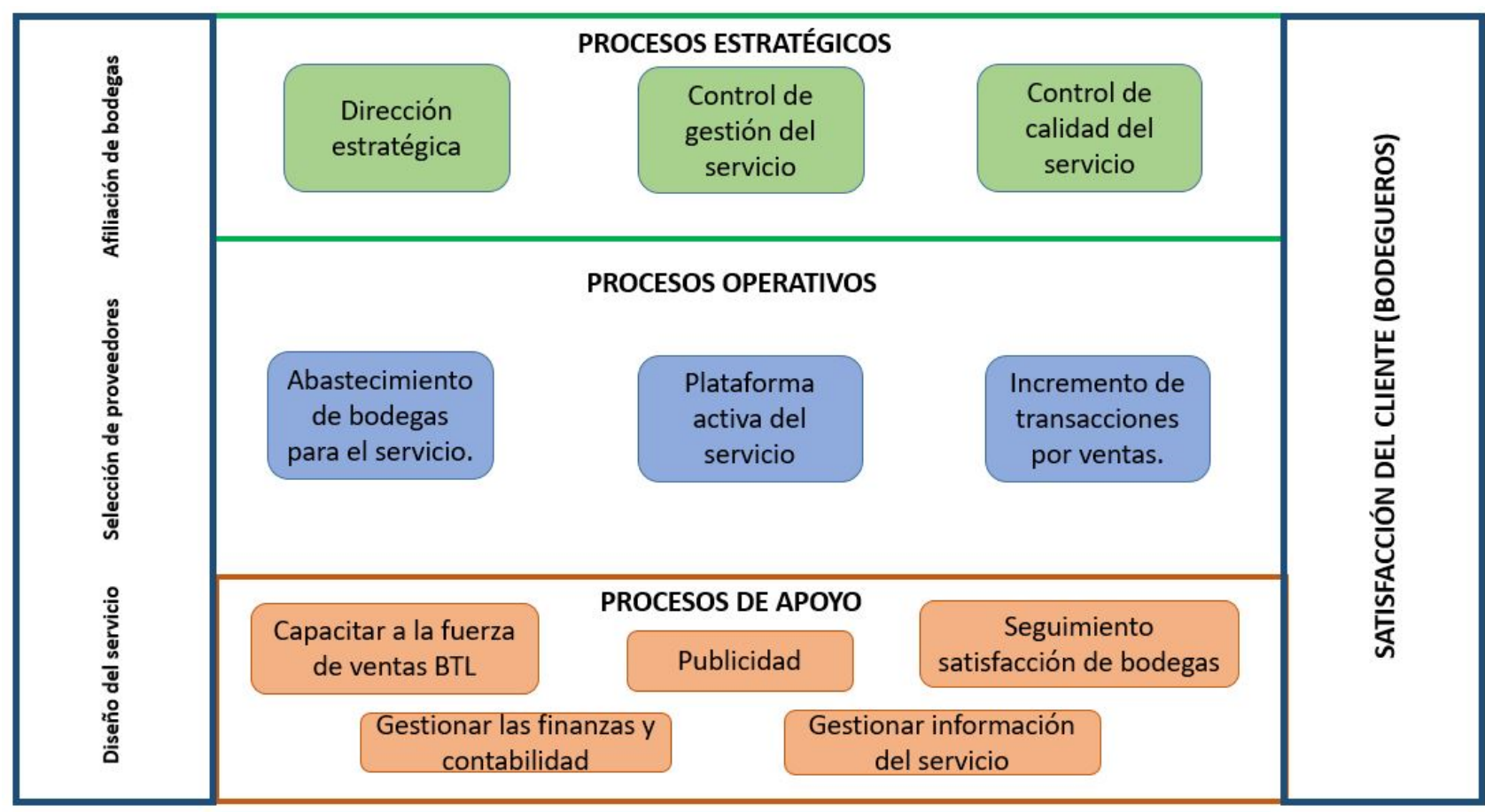

Figura 26. Elaboración propia de Mi Bodeguita 


\section{Procesos estratégicos:}

- Controlado por la gerencia general, quien se encarga de supervisar los procesos operativos y de apoyo para mantener la gestión y calidad del servicio en buen funcionamiento.

\section{Procesos operativos:}

- Afiliación de bodegas para abastecimiento de clientes, base del servicio.

- Plataforma activa y continua del servicio para el uso de la aplicación de manera eficiente.

- Tasación de ventas por día de los clientes para histórico de productividad del servicio.

\section{Procesos de apoyo:}

- Capacitación del personal tercerizado de afiliación y ventas BTL para mayor control de impacto del servicio.

- Publicidad continua del servicio para afiliación de bodegas y usuarios.

- Seguimiento de satisfacción de clientes (bodegas) por incremento de ventas.

- Gestión de la información acumulada para mejoramiento del servicio.

\section{Mapa PERT del proceso de servicio: Aplicación Mi Bodeguita}

A continuación, se muestra el mapa de procesos PERT CPM 


\begin{tabular}{|l|c|c|}
\multicolumn{1}{|c|}{ Actividad } & Precedentes & Duración \\
\hline A: Recepción del pedido & $-\ldots-$ & 5 \\
\hline B: Verificación de productos & A & 7 \\
\hline C: Preparación de pedidos & A & 12 \\
\hline D: Envío de pedido & B & 18 \\
\hline E: Entrega de pedido & $\mathrm{C}$ & 7 \\
\hline F: Finalización del servicio & D,E & 5 \\
\hline
\end{tabular}

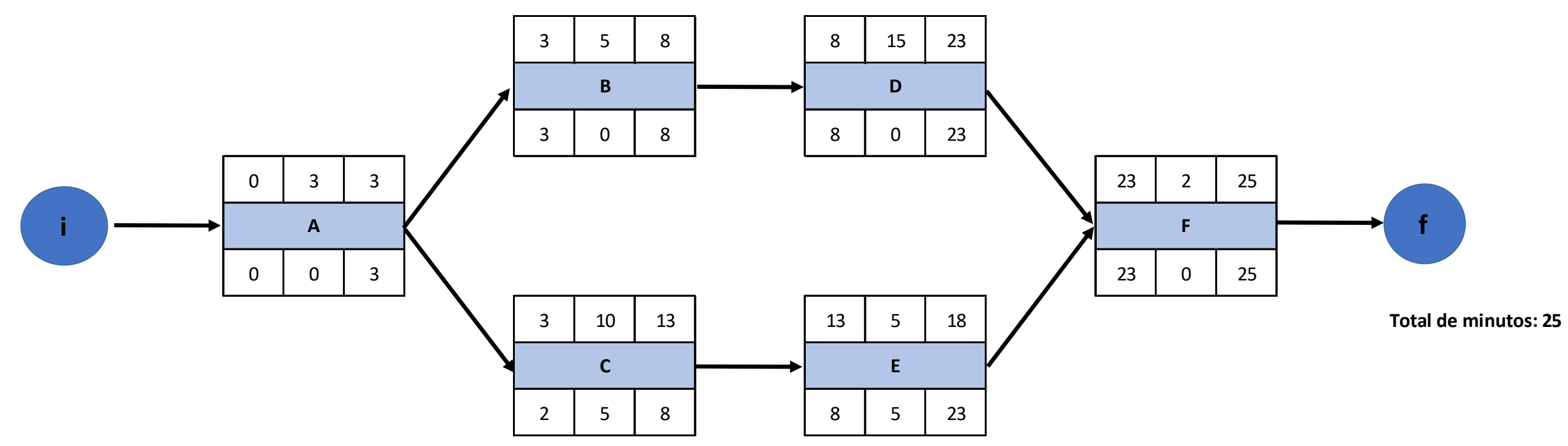

Análisis: Con el uso del PERT CPM, se puede identificar que el tiempo de atención del servicio en tiempos estimados de duración deseada, debería ser aproximadamente de 25 minutos. 


\subsection{Planeamiento de la Operaciones}

Las operaciones que se van a realizar en MI BODEGUITA son los pedidos de nuestros usuarios por medio del aplicativo hacia sus bodegas más cercanas las cuales estén afiliadas con nuestra APP

\section{PEDIDO}

- El usuario al momento de tener una necesidad de un producto podrá descargar nuestra App Mi Bodeguita y que se encuentre en las zonas de nuestro principal segmento.

- Al encontrar el producto de necesidad que desee podrá consultar en que bodegas se encuentra y podrá realizar el pedido y ver el periodo de entrega de este mismo producto no siendo un plazo mayor de 30 minutos y menor de 10 minutos.

\section{ENTREGA}

- El Bodeguero que recepciona el pedido

- El bodeguero verifica el lugar de entrega exacto.

- A lista los pedidos asignados por el usuario.

- El bodeguero hace la entrega de pedido no siendo un plazo mayor de 15 minutos, ya que los usuarios son de la misma zona y cuenta con bicicletas para que sea mucho más gil la entrega de los pedidos.

\section{APP}

- La herramienta que se va usar para poder realizar nuestro negocio es por medio de un aplicativo, lo cual va a permitir al usuario una facilidad de que encuentre sus productos necesarios por medio nuestra App, sin salir de casa y productos de calidad.

- El bodeguero al tener esta herramienta como un valor agregado para su negocio tendrá un mejor manejo de inventario en su negocio, lo que le permite tener un mejor manejo de pedido a los proveedores y saber que productos son de mayor 
salida y de mejor rotación, para que pueda evitar en un futuro mercadería obsoleta ya sea por fecha de vencimiento.

\subsubsection{Gestión de compras y stock}

En la gestión de compras y stock del proyecto a que vamos a emprender se trata de una APP por ello no contamos con stock.

Pero nuestro aplicativo va ayudar a nuestros principales clientes poder gestionar su inventario de comprar para su propia bodega ya que la App le permite ingresar todo las mercaderías que tiene el bodeguero en stock y descontar los productos que vende, así nuestros clientes podrá verificar que productos son de mayor rotación y de menor salida con ello puedo realizar las compras a sus principales proveedores ya que esta APP, es muy sencilla para su aplicación pero muy útil para que el bodeguero puedo tener un inventario con una mayor de rotación de sus productos, lo cual antes no lo podía tener esa facilidad.

Para los principales usuarios de nuestros clientes le va permitir tener una mayor comodidad al realizar sus pedidos por nuestro aplicativo ya que es una APP muy rápida donde le permite ver los productos que se encuentran disponibles en su bodega más cercana y lo mejor de todo es que le entregan sus productos en la puerta de su casa.

\subsubsection{Gestión de la calidad}

Nuestra gestión de calidad será determinada a base nuestras políticas de Calidad que tenemos en nuestro negocio.

\section{$>$ SERVICIO VIRTUAL}

- Gestionar de una manera rápida y efectiva los procesos de pedido.

- Gestionar mantenimiento necesario a nuestro aplicativo para poder evitar caídas de sistema o demoras en el proceso de envió de pedido. 
- Gestionar de manera rápida la recepción de pedidos de los usuarios a nuestros principales clientes.

- Tener una base de datos actualizada de los productos con el inventario actualizado que ofrece nuestro App a los bodegueros, para así evitar futuras incomodidades con los usuarios.

- Optimizar frecuentemente procesos en envió por medio del Maps.

\section{BODEGAS}

- Poder gestionar los pedidos realizados por usuarios de manera eficiente y con la lista de pedidos actualizado.

- Gestionar de manera óptima su control de stock e inventarios.

- Realizar mantenimientos de la APP bimestralmente para no generar futuras complicaciones con los pedidos.

\subsubsection{Gestión de los proveedores}

- Dirección Estratégica, contamos con la capacidad de escoger a nuestros socios estratégicos o aliados como son los bodegueros que acepten las condiciones del plan. 


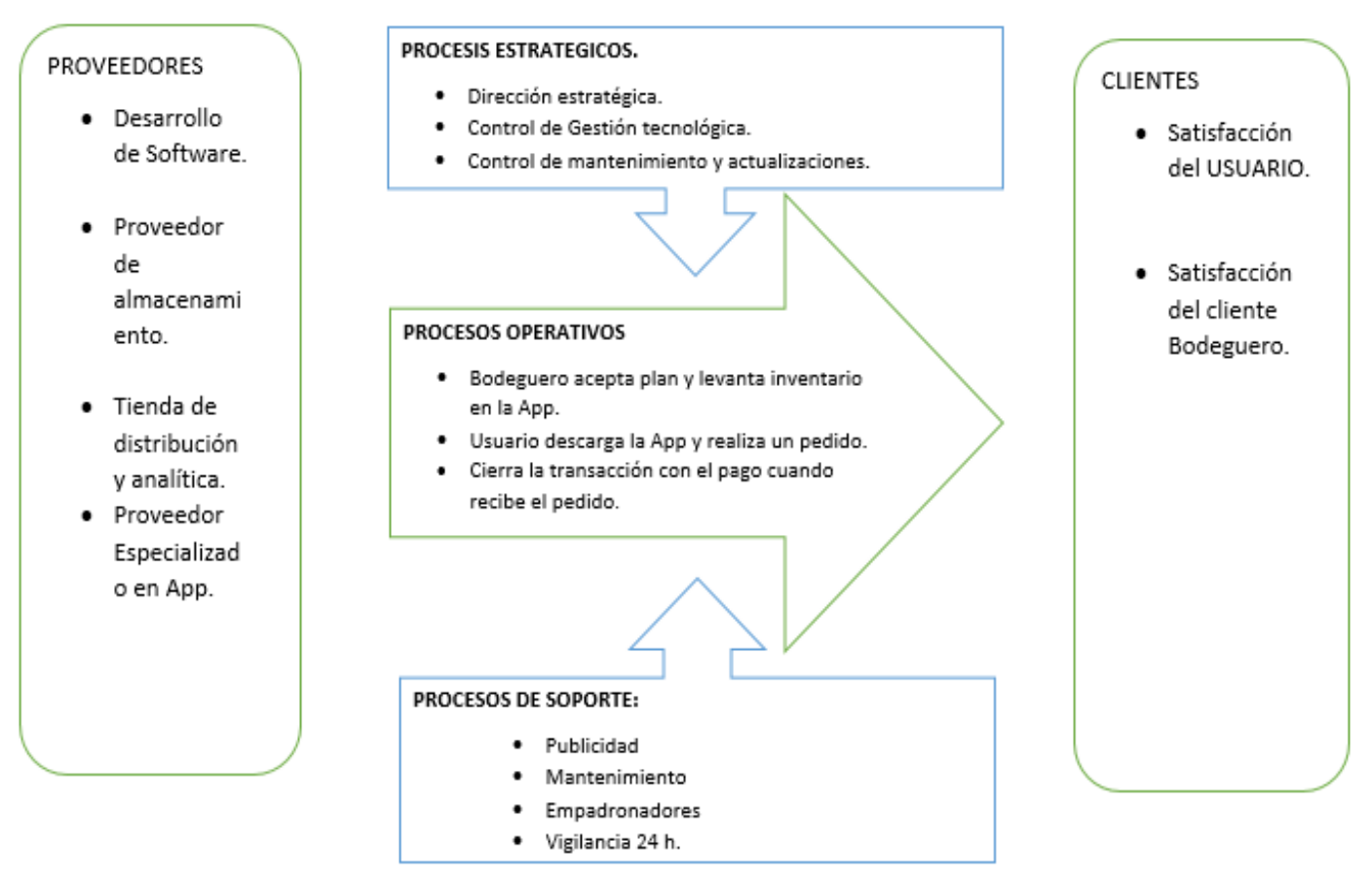

Figura 27. Elaboración propia de Mi Bodeguita

\subsection{Inversión en activos fijos vinculados al proceso productivo.}

La inversión que vamos a contar de activos fijos es mínima ya que nuestro negocio se realizará por medio de aplicativo.

\begin{tabular}{|c|c|c|c|}
\hline $\begin{array}{c}\text { ACTIVO FIJO } \\
\text { TANGIBLE }\end{array}$ & $\begin{array}{c}\text { PRECIO (SIN } \\
\text { IGV) } \\
\end{array}$ & $\begin{array}{c}\text { TASA DE } \\
\text { DEPRECIACION }^{4}\end{array}$ & $\begin{array}{c}\text { TASA DE } \\
\text { DEPRECIACION }\end{array}$ \\
\hline LAPTOP & $\mathrm{S} / 15,000.00$ & $20 \%$ & $\mathrm{~S} / 3,000.00$ \\
\hline TOTAL & $\mathrm{S} / \mathbf{1 5 , 0 0 0 . 0 0}$ & & $\mathrm{S} / 3,000.00$ \\
\hline $\begin{array}{l}\text { ACTIVO FIJO } \\
\text { INTANGIBLE }\end{array}$ & $\begin{array}{l}\text { PRECIO (SIN } \\
\text { IGV) }\end{array}$ & $\begin{array}{c}\text { TASA DE } \\
\text { AMORTIZACION }\end{array}$ & $\begin{array}{c}\text { TASA DE } \\
\text { AMORTIZACION }\end{array}$ \\
\hline APP & $\mathrm{S} / 15,000.00$ & $10 \%$ & $\mathrm{~S} / 1,500.00$ \\
\hline TOTAL & $\mathrm{S} / \mathbf{1 5 , 0 0 0 . 0 0}$ & & $\mathrm{S} / 1,500.00$ \\
\hline
\end{tabular}
4 Tasa de depreciación obtenida de Sunat: http://www.sunat.gob.pe/legislacion/oficios/2009/oficios/i118-
2009.htm 


\subsection{Estructura de costos de producción y gastos operativos.}

Para poder realizar nuestro proyecto hemos decido tener un espacio de alquiler de modalidad coworking, que es en alquilar un espacio para poder tener una oficina de con un foro de 6 personas, ya que esta modalidad de servicio es un beneficio de ahorro para nuestra empresa a emprender, lo cual nos alquila el espacio con todo acondicionado para poder trabajar cómodamente.

Sin embargo, se tienen los siguientes costos y gastos:

\begin{tabular}{|l|l|}
\hline Suministros & Precio \\
\hline Hojas bond & $\mathrm{S} / 60.00$ \\
\hline Toners & $\mathrm{S} / 750.00$ \\
\hline Lapiceros & $\mathrm{S} / 35.00$ \\
\hline Folder & $\mathrm{S} / 25.00$ \\
\hline TOTAL MENSUAL & S/870.00 \\
\hline
\end{tabular}

\begin{tabular}{|l|}
\hline ALQUILER DE OFICINA \\
MENSUAL \\
1800 DOLARES \\
EMPRESA COMUNAL \\
TRABAJO \\
INCLUYE: \\
RECEPCION \\
INTERNET FIBRA OPTICA \\
LOCKERS \\
ESCRITORIOS \\
CAFETERIA \\
ESPACIOS LIBRES \\
\end{tabular}




\section{CAPÍTULO 6. Estructura organizacional y recursos humanos}

\subsection{Objetivos Organizacionales}

\section{Objetivo de largo plazo}

Como primer objetivo, se desea incrementar el personal en un $10 \%$, yendo con el crecimiento rápido del negocio y cubriendo la demanda, además se desea tener un índice de rotación mínima de personal en los 3 primeros años de negocio.

\section{Objetivo de mediano plazo}

Capacitar trimestral a la Gerencia y Jefaturas (coordinadores) en habilidades blandas, como en temas técnicos relacionados con el giro de negocio esto con el fin de siempre estar actualizados y a la par del mercado.

Crear un clima y cultura organizacional adecuado para la pequeña organización inicial, esto con el fin de estar preparados para el crecimiento del negocio y por ende de la organización. Para esto último se trabajará planes de bienestar que fomenten el compromiso, responsabilidad y creatividad.

Se tiene planeado una adecuada selección de indicadores para el tamaño de nuestra organización que puedan asegurarnos alcanzar un $90 \%$ de satisfacción del personal.

\section{Objetivo de corto plazo}

Cubrir los puestos necesarios en el primer año para cumplir con la demanda y los estándares de calidad y satisfacción que el cliente requiere. 


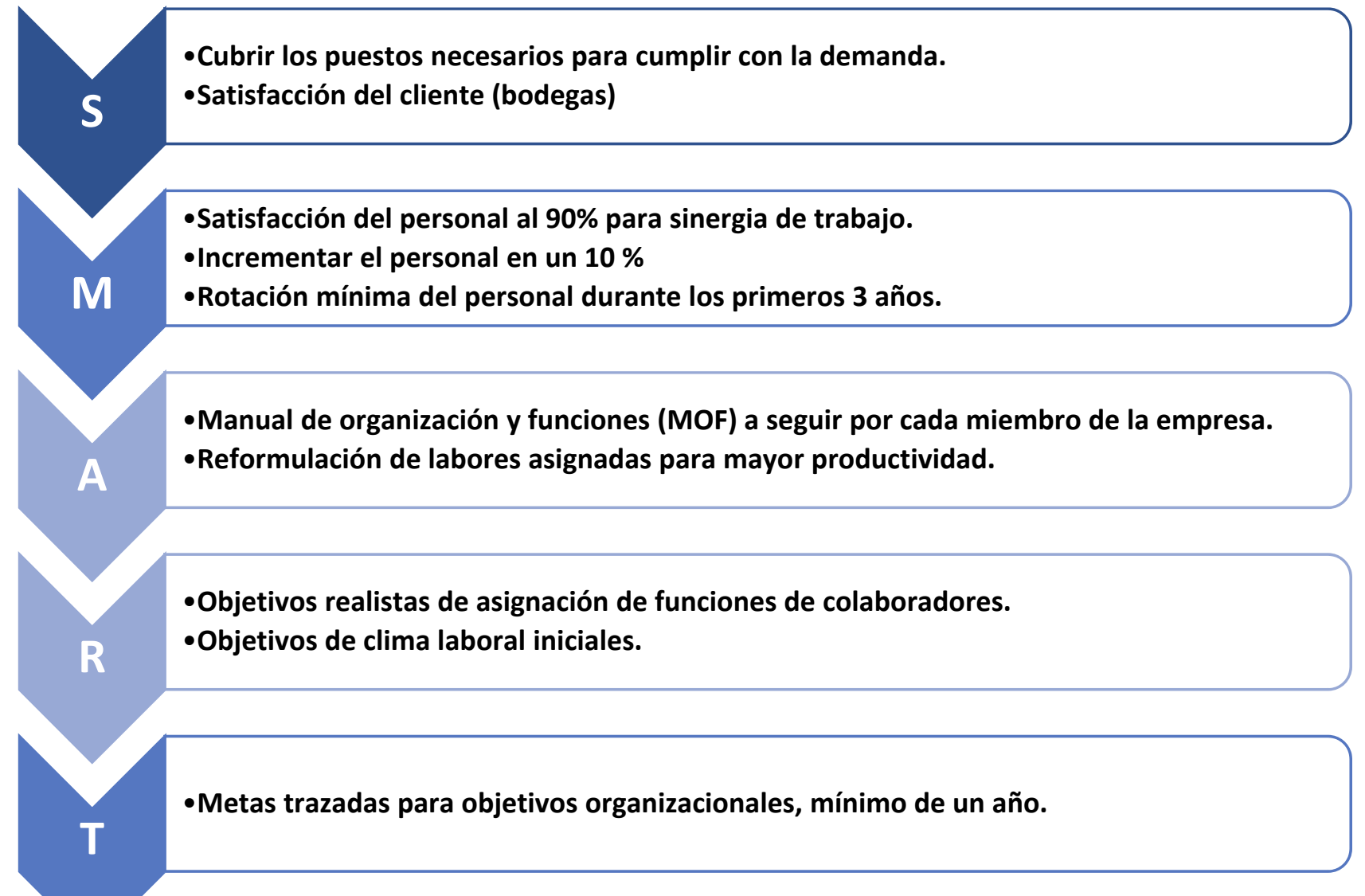

Gráfica 13. Elaboración propia de Mi Bodeguita

\subsection{Naturaleza de la Organización}

"Mi Bodeguita" es una organización dedicada a brindar un servicio (intermediación) de manera virtual, debida a que la naturaleza de sus operaciones se realiza a través de una app.

El negocio es una organización formada bajos los lineamientos del estado peruano y en base a esto se acogerá, inicialmente, bajo el Régimen Especial de la Micro y Pequeña Empresa. De esta manera, se reducirán significativamente los costos laborales para darle una mayor eficiencia a la administración del personal durante la etapa de introducción y se incrementara progresivamente conforme se vaya desarrollando la empresa. 


\subsubsection{Organigrama}

El presente organigrama se elabora, tomando en cuenta las diversas experiencias y carreras del equipo; además se espera tener el crecimiento necesario con el cual el organigrama también variara.

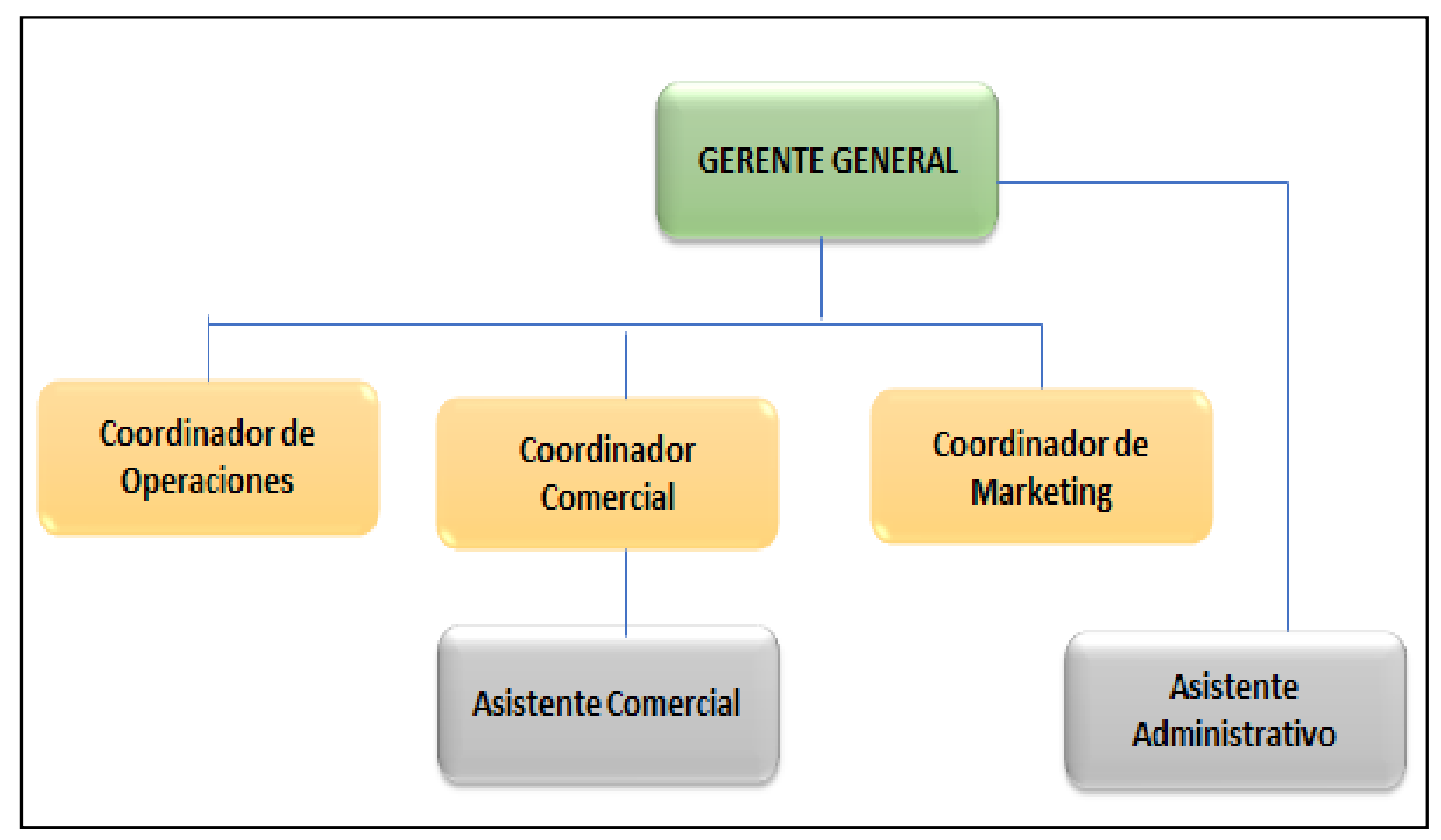

Figura 28. Elaboración propia de Mi Bodeguita

\subsubsection{Diseño de Puestos y Funciones}

A continuación, se procede a realizar las funciones que realizaran cada colaborador de la organización con el fin de contribuir al cumplimiento de los objetivos organizacionales. 


\begin{tabular}{|c|c|}
\hline \multicolumn{2}{|l|}{ I. INFORMACIÓN DE PUESTO } \\
\hline 1. NOMBRE DE PUESTO & Gerente General \\
\hline 2. JEFE INMEDIATO SUPERIOR & Accionistas \\
\hline \multicolumn{2}{|c|}{ II. FUCIONES ESPECÍFICAS Y RESPONSABILIDADES } \\
\hline \multicolumn{2}{|c|}{$\begin{array}{l}\text { - Administrar, planificar y controlar para el buen funcionamiento y logro de los objetivos } \\
\text { - } \text { - Representas de la empresa. } \\
\text { - Definir las funciones y metas de cada área. } \\
\text { - Planificar los objetivos de corto y largo plazo. } \\
\text { - Evaluar el cumplimiento de las proyecciones de venta. } \\
\text { - Velar por la integridad del cumplimiento del plan estratégico. } \\
\text { - Presenta anualmente el informe correspondiente a los estados financieros de la empresa. } \\
\text { - Fomenta la creación de la filosofía de trabajo que se convierta en una cultura } \\
\text { organizacional. } \\
\text { - Analiza los problemas de la empresa en el aspecto financiero, administrativo, personal, } \\
\text { contable, entre otros. }\end{array}$} \\
\hline \multicolumn{2}{|l|}{\begin{tabular}{|l} 
III. PERFIL DEL PUESTO \\
\end{tabular}} \\
\hline EDUCACIÓN & Posgrado en Administración y Finanzas. \\
\hline FORMACIÓN & Administración de empresas, economía, marketing. \\
\hline EXPERIENCIA & 4 años en Jefaturas o 2 Gerencia. \\
\hline
\end{tabular}




\begin{tabular}{|c|c|}
\hline \multicolumn{2}{|l|}{ I. INFORMACIÓN DE PUESTO } \\
\hline 1. NOMBRE DE PUESTO & Asistente Administrativo / Gerencia \\
\hline 2. JEFE INMEDIATO SUPERIOR & Gerente General \\
\hline \multicolumn{2}{|c|}{ II. FUCIONES ESPECÍFICAS Y RESPONSABILIDADES } \\
\hline \multicolumn{2}{|c|}{$\begin{array}{l}\text { - Gestionar y administrar la agenda de la Gerencia. } \\
\text { - Apoyar en la atención de las llamadas. } \\
\text { - Apoyo en funciones contables (Facturación). } \\
\text { - Apoyo con la gestión de cobranza. } \\
\text { - Asistencia directa a la Gerencia en sus diversas funciones. }\end{array}$} \\
\hline \multicolumn{2}{|l|}{ III. PERFIL DEL PUESTO } \\
\hline EDUCACIÓN & Técnico en Administración \\
\hline FORMACIÓN & Gestión en Administración \\
\hline EXPERIENCIA & 1 años en puestos administrativos/contables. \\
\hline
\end{tabular}




\begin{tabular}{|c|c|}
\hline \multicolumn{2}{|l|}{ I. INFORMACIÓN DE PUESTO } \\
\hline 1. NOMBRE DE PUESTO & Coordinador de Operaciones \\
\hline 2. JEFE INMEDIATO SUPERIOR & Gerente General \\
\hline \multicolumn{2}{|c|}{ II. FUCIONES ESPECÍFICAS Y RESPONSABILIDADES } \\
\hline \multicolumn{2}{|c|}{$\begin{array}{l}\text { - Se encargará de realizar la selección y crear relaciones con los socios } \\
\text { - Groveedores) de la empresa. } \\
\text { - Gestionar con los proveedores la prestación oportuna del producto y/o serv con los proveedores una adecuada política de pagos (días). } \\
\text { - Realizar las coordinaciones operativas para la prestación de los servicios. } \\
\text { - Gestionar una adecuada política de compras y/o adquisiciones. } \\
\text { - Supervisar el trabajo de los proveedores. } \\
\text { - Realizar informe a la Gerencia por la gestión del área. }\end{array}$} \\
\hline \multicolumn{2}{|l|}{ III. PERFIL DEL PUESTO } \\
\hline EDUCACIÓN & $\begin{array}{l}\text { Universitario administración, comercio } \\
\text { y/o afines. }\end{array}$ \\
\hline FORMACIÓN & Especialización en logística y/u operaciones \\
\hline EXPERIENCIA & 2 años en supervisión o jefaturas \\
\hline
\end{tabular}




\begin{tabular}{|c|c|}
\hline \multicolumn{2}{|l|}{ I. INFORMACIÓN DE PUESTO } \\
\hline 1. NOMBRE DE PUESTO & Coordinador Comercial \\
\hline 2. JEFE INMEDIATO SUPERIOR & Gerente General \\
\hline \multicolumn{2}{|c|}{ II. FUCIONES ESPECÍFICAS Y RESPONSABILIDADES } \\
\hline \multicolumn{2}{|c|}{$\begin{array}{l}\text { - Desarrollo comercial del negocio, es decir la ampliación del mismo, posicionando la } \\
\text { marca (generándole valor). } \\
\text { - } \text { Implementación de la política comercial. } \\
\text { - } \quad \text { Renerar informe trimestral sobre captación de nuevos clientes. } \\
\text { - Informa sobre las mejoras que se deben plantear para el cumplir con la satisfacción total } \\
\text { - } \quad \text { Proyección de ampliación de la cobertura a fin de lograr mayor participación del } \\
\text { - } \text { mercado. } \\
\text { - Administrar la cartera de clientes, gestionando una adecuada política de post venta. } \\
\text { - Preparar planes, presupuesto e informes de ventas. }\end{array}$} \\
\hline \multicolumn{2}{|l|}{ III. PERFIL DEL PUESTO } \\
\hline EDUCACIÓN & Universitario en administración o Marketing \\
\hline FORMACIÓN & Especialización en mercadotecnia y/o ventas. \\
\hline EXPERIENCIA & $\begin{array}{l}2 \text { años en supervisión o Jefatura de áreas } \\
\text { comerciales. }\end{array}$ \\
\hline
\end{tabular}




\begin{tabular}{|l|l|}
\hline \multicolumn{1}{|l|}{ I. INFORMACIÓN DE PUESTO } \\
\hline 1. NOMBRE DE PUESTO & Asistente Comercial \\
\hline 2. JEFE INMEDIATO SUPERIOR & Coordinador Comercial \\
\hline II. FUCIONES ESPECÍFICAS Y RESPONSABILIDADES \\
- $\quad$ Atender de las llamadas de los clientes. \\
- $\quad$ Actualizar las ventas diarias del área comercial. \\
- $\quad$ Coordinar los requerimientos del equipo de ventas. \\
- $\quad$ Realizar encuestas de satisfacción del cliente. \\
\hline \begin{tabular}{l} 
EOR la gestión de cobranza. \\
\hline EDUCACia directa al área comercial en funciones diversas.
\end{tabular} \\
\hline
\end{tabular}




\begin{tabular}{|c|c|}
\hline \multicolumn{2}{|l|}{ I. INFORMACIÓN DE PUESTO } \\
\hline 1. NOMBRE DE PUESTO & Coordinador de Marketing \\
\hline 2. JEFE INMEDIATO SUPERIOR & Gerente General \\
\hline \multicolumn{2}{|c|}{ II. FUCIONES ESPECÍFICAS Y RESPONSABILIDADES } \\
\hline \multicolumn{2}{|c|}{$\begin{array}{l}\text { - Elaboración del plan y presupuesto de marketing. } \\
\text { - Elección de proveedores del servicio BTL. } \\
\text { - Elaboración de campañas y activaciones de la empresa. } \\
\text { - Informe trimestral de la participación y crecimiento del mercado. } \\
\text { - Manejo y elección de las redes sociales. }\end{array}$} \\
\hline \multicolumn{2}{|l|}{ III. PERFIL DEL PUESTO } \\
\hline EDUCACIÓN & Universitario en Marketing \\
\hline FORMACIÓN & Marketing \\
\hline EXPERIENCIA & 2 años en supervisión o Jefatura de áreas marketing \\
\hline
\end{tabular}




\subsection{Políticas Organizacionales}

"Mi Bodeguita" establecerá políticas organizacionales en base al mejoramiento continuo, porque el compromiso es prestar un servicio de calidad para satisfacer y fidelizar a los clientes. Estas políticas serán de cumplimiento obligatorio, las mismas que se revisarán periódicamente y de los cuales se elaborarán informes a la Gerencia.

La idea es identificar y establecer políticas con la finalidad de permitir a los colaboradores de la empresa a actuar en favor de sus iniciativas, fomentar el trabajo en equipo, de tal forma que estén coordinado los esfuerzos de todas las áreas de la empresa en una misma dirección, de esta manera se lograra fidelizar al cliente interno.

\section{Política Salarial}

Debido a que "Mi Bodeguita" en un inicio contara con un pequeño grupo de colaboradores se ha dispuesto tener un sistema de remuneración ordenado, equitativo para la empresa y para los colaboradores, que motive eficazmente el trabajo y el cumplimiento de los objetivos y metas de la empresa. Para ello se ha determinado lo siguiente:

- El sistema de remuneración de la empresa estará de acuerdo con el mercado laboral del sector.

- Se establecerá un sistema de remuneración variable en función del cumplimiento de objetivos y metas.

- Los incrementos salariales se realizarán únicamente

como consecuencia de la evaluación de desempeño y la situación financiera de la empresa, a excepción de las disposiciones del gobierno que sí sean aplicables a la empresa. 
- El requerimiento de pago de horas extras deberá obedecer a una programación de trabajo previamente establecida y en función del costo/beneficio; y deberán ser autorizados por el jefe inmediato

\section{Política de Selección y Contratación de Personal}

Las actividades de selección y contratación del recurso humano deberán permitir elegir solo las personas necesarias y capacitadas, que se ajusten a los requerimientos de la empresa y a los perfiles establecidos para alcanzar los objetivos estratégicos y asegurar su desarrollo. Para ello se realizará lo siguiente:

El proceso de selección de personal se iniciará con la elaboración del requerimiento de personal del encargado del área solicitante, el mismo que deberá estar aprobado por la Gerencia. Esto se aplicará para todos los casos (vacantes nuevas y reemplazos).

En caso de que se genere un puesto vacante, se dará preferencia al personal que se encuentre laborando en la empresa, el mismo que deberá ajustarse al perfil del cargo, mediante un concurso interno. En caso de declararse desierto el concurso debido a que no existe personal que cumpla con el perfil requerido, se iniciara la búsqueda a través de un proceso externo.

No se podrá realizar ninguna contratación de personal que no haya cumplido con el proceso de selección aprobado por la Gerencia.

\section{Política de Plan de Carrera Empresarial}

Se establecerán los criterios y normas que permitan optimizar el desarrollo del recurso humano en "Mi Bodeguita", de acuerdo con sus competencias laborales y profesionales, con relación a las necesidades y estructuras funcionales de la empresa. En ese sentido se detalla lo siguiente:

- El desarrollo y ascensos de los colaboradores será horizontal y vertical, por lo que se establecerá en primera instancia la rotación en diferentes puestos y cargos 
del mismo nivel ocupacional, para identificar las competencias aptitudinales y actitudinales del personal; y enriquecer sus competencias profesionales.

- Las promociones y ascensos se otorgarán cuando las necesidades y estructuras de la empresa se ajusten con los perfiles de los colaboradores que han demostrado alto desempeño y potencial para posiciones de mayor responsabilidad, ya que deben cumplir con los requisitos académicos y de experiencia exigidos en el nuevo cargo.

- Las promociones y ascensos incluirán la respectiva remuneración del nuevo cargo, de acuerdo con la política salarial vigente.

\section{Política de Capacitación}

"Mi Bodeguita" en su política de capacitación impulsará el desarrollo y competencias laborales a sus colaboradores que contribuyan a conseguir los objetivos organizacionales y la satisfacción de los clientes:

- Los colaboradores contratados o ascendidos deberán participar del proceso de inducción del cargo a desempeñar.

- Se gestionará y capacitará a la mayor cantidad posible de colaboradores, de esta manera se logrará alcanzar los objetivos estratégicos de la empresa, esto con el fin de conseguir empleados comprometidos y motivados, los cuales incrementarán su rendimiento.

\subsection{Gestión Humana}

El área de Recursos Humanos estará cargo de la Gerencia en esta primera etapa y tiene como finalidad principal fomentar un adecuado clima laboral, esto con el fin de obtener el máximo potencial de los colaboradores, estableciendo así un gran trabajo en equipo, retroalimentación y coordinación en los momentos necesarios. 


\subsubsection{Reclutamiento}

Desde un principio el cubrimiento de las posiciones no será necesaria, debido a que los puestos serán cubiertos con los integrantes del proyecto. En el momento que la empresa se encuentre en la etapa de crecimiento y las necesidades de personal así lo ameriten, se emplearan los mismos mecanismos anteriormente mencionados.

Debido al modelo de negocio que se maneja, la idea principal es poder tercerizar todos los procesos de reclutamiento a través de consultoras especializadas esto solo para el tema de posiciones directas que vayan a la planilla de la empresa. Para otro tipo posiciones se usará consultora que brinde el servicio también de tercerización de planillas.

\subsubsection{Selección, contratación e inducción}

Todo personal seleccionado (directo o indirecto) deberá haber pasado y aprobado las pruebas psico métricas y proyectivas que exige el perfil del puesto y, adicionalmente, para los puestos de dirección se realizarán pruebas situacionales para determinar aquellas habilidades o competencias que deben poseer para manejar situacional del cargo al que se postula. Todas estas pruebas estarán a cargo del proveedor (consultora) seleccionado.

Después de las pruebas, los postulantes preseleccionados pasaran una entrevista con el encargado de del área quien recolectara los documentos solicitados y solicitara los resultados del análisis de la evaluación. Posteriormente, solo si se amerita se aplicará un filtro adicional solo con una terna no mayor de 3 candidatos los cuales pasaran por una entrevista con la Gerencia.

El postulante elegido será convocado a más tardar al cuarto día de tomada la decisión para firmar su contrato de trabajo, aplicando la modalidad contractual según el puesto al que postulo. Para el personal que trabajara con dependencia 
directa en la empresa, se empleara la modalidad contractual de "Inicio de Actividad" por un periodo determinado de 1 año; posteriormente, su contrato será modificado a la modalidad de "contrato indeterminado" para brindar una mayor estabilidad laboral. Por otra parte, la modalidad contractual para los asociados estratégicos será de "Locación de Servicio", debido a que ellos no prestan servicios directos de subordinación y no cuentan con horarios de trabajo establecido.

Finalmente, todo nuevo integrante de la organización pasará una inducción donde se dará a conocer la cultura organizacional de la empresa y las políticas y objetivos que se desean alcanzar; para ello, se deberá explicar la misión, visión, valores, objetivos a corto y largo plazo, beneficios laborales, etc.

\subsubsection{Capacitación, desarrollo y evaluación del desempeño}

Como principal actividad en la etapa de introducción del negocio se realizará solo las capacitaciones necesarias a los promotores y socios de $\mathrm{Mi}$ Bodeguita, tanto del manejo de negocio, sus políticas, objetivo y demás, incluyendo el servicio al cliente.

Posteriormente que la empresa este en crecimiento, se implementaran programas de capacitación para desarrollar el potencial del cliente interno; con el objetivo de explotar al máximo los talentos del personal. Se hará seguimiento a los requerimientos de capacitación que las áreas soliciten, pero solo se desarrollaran aquellos que estén aprobados por la Gerencia.

En cuanto a la evaluación de desempeño, el personal interno será evaluado trimestral en base a su productividad y finalizada la evaluación recibirá el feedback respectivo. 


\subsubsection{Motivación}

La motivación en "Mi Bodeguita" y en conjunto con el área de recursos humanos será unos de los objetivos organizacionales primordiales, esto con la idea obtener un agradable clima y ambiente de trabajo. Con ello, se implementarán las siguientes políticas y actividades para cumplir con tal objetivo:

- Se realizará trimestralmente el reconocimiento y premiación al colaborador que obtenga una sobresaliente evaluación de desempeño.

- Se realizará eventos deportivos para fomentar la buena salud y la confraternidad.

- Se otorgará días libres para el personal que se encuentre de onomástico.

- Se realizará una vez al año un paseo de confraternidad para integrar al equipo de trabajo asumido por la empresa.

- Se obsequiarán presente por días especiales; tales como, día del trabajador, día de la madre, día del padre y navidad.

\subsubsection{Sistema de remuneración}

Para empezar y resaltando el hecho de que es una microempresa las remuneraciones estarán establecidas a los beneficios vigentes en el Perú (Essalud, CTS, gratificaciones); por otro lado, los sueldos estarán basado en niveles de responsabilidad y productividad laboral, alineados a los objetivos y prioridades del negocio. El pago se realizará de manera mensual y todos los 30 de cada mes. 


\subsection{Estructura de gastos de RRHH}

PROYECTADO AÑO 1:

\begin{tabular}{|c|c|c|c|c|c|c|c|c|c|c|}
\hline Puesto & & $\begin{array}{l}\text { neració } \\
\text { ca S/. }\end{array}$ & Anualizado & Vacaciones & $\begin{array}{l}\text { Gratifica } \\
\text { ción Julio }\end{array}$ & $\begin{array}{l}\text { Gratificación } \\
\text { Diciembre }\end{array}$ & $\begin{array}{l}\text { Es Salud } \\
(\mathbf{9 \% )} \\
\text { anualizado }\end{array}$ & CTS Mayo & $\begin{array}{c}\text { CTS } \\
\text { Noviembre }\end{array}$ & $\begin{array}{c}\text { Total S/. } \\
\text { Anual }\end{array}$ \\
\hline $\begin{array}{l}\text { GERENTE } \\
\text { GENERAL } \\
\end{array}$ & $\mathrm{S} /$. & 9,500 & $\begin{array}{cc}\text { S/. } & 133,00 \\
0\end{array}$ & 9,500 & $\begin{array}{r}10,3 \\
55 \\
\end{array}$ & 10,355 & 11,970 & $\mathrm{~S} / . \quad 4,750$ & S/. $\quad 4,750$ & S/. $\quad 184,680$ \\
\hline $\begin{array}{l}\text { ASISTENTE } \\
\text { ADMNISTRATIVO }\end{array}$ & S/. & 2,000 & $\mathrm{~S} / . \quad 28,000$ & 2,000 & $\begin{array}{r}2,18 \\
0\end{array}$ & 2,180 & 2,520 & $\mathrm{~S} / . \quad 1,000$ & 1,000 & S/. $\quad 38,880$ \\
\hline $\begin{array}{l}\text { COORDINADOR } \\
\text { LOGÍSTICO }\end{array}$ & S/. & 8,000 & $\mathrm{~S} / . \quad 112,00$ & 8,000 & $\begin{array}{r}8,72 \\
0\end{array}$ & 8,720 & 10,080 & S/. $\quad 4,000$ & S/. $\quad 4,000$ & $\mathrm{~S} / . \quad 155,520$ \\
\hline $\begin{array}{l}\text { COORDINADOR } \\
\text { COMERCIAL }\end{array}$ & S/. & 8,000 & $\begin{array}{l}\text { S/. } \\
112,00 \\
0\end{array}$ & 8,000 & $\begin{array}{r}8,72 \\
0\end{array}$ & 8,720 & 10,080 & S/. $\quad 4,000$ & $\mathrm{~S} / . \quad 4,000$ & S/. $\quad 155,520$ \\
\hline $\begin{array}{l}\text { ASISTENTE } \\
\text { COMERCIAL }\end{array}$ & S/. & 2,000 & $\begin{array}{ll} & 28,000 \\
\mathrm{~S} / . & \end{array}$ & 2,000 & $\begin{array}{r}2,18 \\
0\end{array}$ & 2,180 & 18,900 & 1000 & 1000 & S/. $\quad 55,260$ \\
\hline $\begin{array}{l}\text { COORDINADOR } \\
\text { DE MARKETING }\end{array}$ & & 8,000 & $\begin{array}{l}\text { S/. } \\
112,00 \\
0\end{array}$ & S/. $\quad 8,000$ & $\begin{array}{r}8,72 \\
0\end{array}$ & 8,720 & 10,080 & $\mathrm{~S} / . \quad 4,000$ & $\mathrm{~S} / . \quad 4,000$ & S/. $\quad 155,520$ \\
\hline Total S/. & S/. & $\mathbf{3 7 , 5 0 0}$ & $\begin{array}{lc}\mathbf{5 2 5 , 0 0} \\
\mathrm{S} / .\end{array}$ & $\begin{array}{c}37,50 \\
0\end{array}$ & $\begin{array}{c}40,8 \\
75\end{array}$ & 40,875 & 63,630 & S/. $\quad 18,750$ & $\begin{array}{r}\text { S/. } \\
18,750\end{array}$ & $\begin{array}{r}\text { S/. } \\
745,380\end{array}$ \\
\hline
\end{tabular}


RESUMEN DE PLANILLA

\begin{tabular}{|l|lr|}
\hline \multicolumn{1}{|c|}{ Puesto } & \multicolumn{2}{r|}{2017} \\
\hline Gastos de administración & S/. & 534,600 \\
\hline Gastos de ventas & S/. & 36,780 \\
\hline Contador Externo & & 781,380 \\
\hline Total S/. & S/. & \\
\hline
\end{tabular}




\section{CAPÍTULO 7. PLAN ECONÓMICO - FINANCIERO}

El presente plan permitirá determinar la viabilidad del proyecto en términos económicos y financieros. Cabe señalar que los mismos, se evaluarán bajo un horizonte de cinco años.

\subsection{Supuestos}

Para el análisis respectivo, se han considerado, los siguientes supuestos fundamentales que sustentarán el plan económico - financiero del proyecto $\mathrm{Mi}$ Bodeguita:

- Horizonte de evaluación del proyecto: cinco años.

- Flujo de caja: Expresado en valores nominales y en moneda nacional.

- Tipo de cambio referencial: S/.3.2 flat.

- Política de cobro del proyecto: $100 \%$ en efectivo y la de pago a proveedores es contra factura a 30 días.

- Financiamiento total: Se realizará con los accionistas, a través de un capital propio de un total de S/ 122,896.26 (diferentes porcentajes de aportes por accionista).

- Impuesto a la renta fijado para el proyecto: $29.5 \%^{5}$

\footnotetext{
${ }^{5}$ Renta fijada por Sunat: fuente:http://orientacion.sunat.gob.pe/index.php/empresas-menu/impuesto-a-larenta-empresas/regimen-general-del-impuesto-a-la-renta-empresas/calculo-anual-del-impuesto-a-la-rentaempresas/2900-03-tasas-para-la-determinacion-del-impuesto-a-la-renta-anual
} 
- Tasa de crecimiento: Se proyecta que para el segundo año la tasa de crecimiento será de $8.00 \%$, en el tercer año de $10.00 \%$, en el cuarto año de $11.50 \%$, en el quinto año de $14 \%$.

- Distribución de los ingresos: 50\% mediante tarjeta de crédito y un 50\% al contado.

- Comisiones por servicio: Equivalen a un 17\% sobre los ingresos en tarjeta de crédito.

- Planeamiento de ventas mensual mediante bodegas: Se realizará, a través de una campaña de pre venta antes del inicio de operaciones que garantiza el comienzo con un total de 50 bodegas. Posteriormente, con la fuerza de venta indirecta, se planea ampliar la cobertura a 10 bodegas por mes y terminar el último trimestre del año manteniendo un promedio no menor de 145 bodegas.

- Transacciones mensuales: Varían de acuerdo las campañas que surgen durante el año (día de la madre, fiestas patrias, navidad, regreso al colegio, etc.). 


\subsection{Inversión en activos (fijos, costos y gastos)}

El proyecto Mi Bodeguita considera parte de la inversión en activos fijos, tangibles e intangibles, costos y gastos.

El monto total para la inversión en activo fijo S/15,000 de los cuales están destinados para 6 laptops de S/2500.00 cada activo que será usado por los propios trabajadores. Los mismos, se deprecian con una tasa del $20 \%{ }^{6}$ anual.

Los costos identificados en el proyecto Mi Bodeguita son:

\begin{tabular}{|c|r|r|r|}
\hline ACTIVO FIJO TANGIBLE & PRECIO (SIN IGV) & TASA DE DEPRECIACION & TASA DE DEPRECIACION \\
\hline LAPTOP & S/15,000.00 & $20 \%$ & S/3,000.00 \\
\hline TOTAL & S/15,000.00 & & S/3,000.00 \\
\hline ACTIVO FIJO INTANGIBLE & PRECIO (SIN IGV) & TASA DE AMORTIZACION ${ }^{-15}$ & TASA DE AMORTIZACION \\
\hline APP & S/15,000.00 & $10 \%$ & S/1,500.00 \\
\hline TOTAL & S/15,000.00 & & S/1,500.00 \\
\hline
\end{tabular}

Los costos y gastos identificados en el proyecto Mi Bodeguita, que permitirá sostener el negocio son:

Agente de BTL: Presupuesto que se trabajará con Doctor BTL

${ }^{6}$ Tratándose de maquinaria que es arrendada exclusivamente para su uso en la actividad de construcción, el propietario de dicha maquinaria, para los fines de la determinación del Impuesto a la Renta de su cargo debe aplicar como porcentaje anual máximo de depreciación el $20 \%$

7 http://www.sunat.gob.pe/legislacion/oficios/2009/oficios/i118-2009.htm 


\begin{tabular}{|c|c|c|}
\hline Numero de Promotores & $\begin{array}{c}\text { Costos mensual } \\
\text { (Incluido Igv) }\end{array}$ & $\begin{array}{c}\text { Costos anual (Incluido } \\
\text { Igv) y bonificación (J/D) }\end{array}$ \\
\hline 4 & 4200 & S/. 68,800.00 \\
\hline Numero de Promotores & $\begin{array}{c}\text { Costos mensuales } \\
\text { (Sin Igv) }\end{array}$ & $\begin{array}{c}\text { Costos anuales (Sin Igv) y } \\
\text { bonificación (J/D) }\end{array}$ \\
\hline 4 & S/.3,559.32 & S/. 58,305.08 \\
\hline
\end{tabular}

\begin{tabular}{|c|r|}
\hline Meses & 12 \\
\hline $\begin{array}{c}\text { Gratificaciones } \\
\text { totales } \\
\text { anual }\end{array}$ & 18400 \\
\hline
\end{tabular}

\section{ALQUILER DE OFICINA}

MENSUAL

1800 DOLARES 6 POSICIONES DE TRABAJO

EMPRESA COMUNAL COWORKING

INCLUYE:

RECEPCION

INTERNET FIBRA OPTICA

LOCKERS

ESCRITORIOS

CAFETERIA

ESPACIOS LIBRES

\begin{tabular}{|l|c|}
\hline \multicolumn{1}{|c|}{ Gastos en Suministros } & Mensual \\
\hline Lapiceros & $\mathrm{S} / 35.00$ \\
\hline Folder & $\mathrm{S} / 25.00$ \\
\hline Alquiler coworking & $\mathrm{S} / 5,850.00$ \\
\hline Total & $\mathrm{S} / 5,910.00$ \\
\hline
\end{tabular}

\section{GASTOS DE DESARROLLO DE APLICACIÓN}

CREACION DEL APP

15000 SOLES

$\mathrm{UN}$

SOLO

MANTENIMIENTO DE LA APP

PAGO

200 DOLARES CADA DOS MESES

EMPRESA:

MCL Proyecto 


\begin{tabular}{|l|c|}
\hline \multicolumn{2}{l}{ Bimensual } \\
\hline Mantenimiento mensual de servidor & S/325.00 \\
\hline Actualización del APP & Anual \\
\hline
\end{tabular}

\begin{tabular}{|l|c|c|c|c|c|c|c|c|c|c|c|c|c|}
\hline Flujo de Gastos & Mes 1 & Mes 2 & Mes 3 & Mes 4 & Mes 5 & Mes 6 & Mes 7 & Mes 8 & Mes 9 & Mes 10 & Mes 11 & Mes 12 & Anual \\
\hline Lapiceros & $\mathrm{S} / 35.00$ & $\mathrm{~S} / 35.00$ & $\mathrm{~S} / 35.00$ & $\mathrm{~S} / 35.00$ & $\mathrm{~S} / 35.00$ & $\mathrm{~S} / 35.00$ & $\mathrm{~S} / 35.00$ & $\mathrm{~S} / 35.00$ & $\mathrm{~S} / 35.00$ & $\mathrm{~S} / 35.00$ & $\mathrm{~S} / 35.00$ & $\mathrm{~S} / 35.00$ & $\mathrm{~S} / 420.00$ \\
\hline Folder & $\mathrm{S} / 25.00$ & $\mathrm{~S} / 25.00$ & $\mathrm{~S} / 25.00$ & $\mathrm{~S} / 25.00$ & $\mathrm{~S} / 25.00$ & $\mathrm{~S} / 25.00$ & $\mathrm{~S} / 25.00$ & $\mathrm{~S} / 25.00$ & $\mathrm{~S} / 25.00$ & $\mathrm{~S} / 25.00$ & $\mathrm{~S} / 25.00$ & $\mathrm{~S} / 25.00$ & $\mathrm{~S} / 300.00$ \\
\hline $\begin{array}{l}\text { Alquiler } \\
\text { coworking }\end{array}$ & $\mathrm{S} / 5,850.00$ & $\mathrm{~S} / 5,850.00$ & $\mathrm{~S} / 5,850.00$ & $\mathrm{~S} / 5,850.00$ & $\mathrm{~S} / 5,850.00$ & $\mathrm{~S} / 5,850.00$ & $\mathrm{~S} / 5,850.00$ & $\mathrm{~S} / 5,850.00$ & $\mathrm{~S} / 5,850.00$ & $\mathrm{~S} / 5,850.00$ & $\mathrm{~S} / 5,850.00$ & $\mathrm{~S} / 5,850.00$ & $\mathrm{~S} / 70,200.00$ \\
\hline $\begin{array}{l}\text { Mantenimiento } \\
\text { mensual } \\
\text { servidor de }\end{array}$ & & & & & & & & & & & & & \\
\hline $\begin{array}{l}\text { Actualización } \\
\text { del APP }\end{array}$ & & $\mathrm{S} / 1,000.00$ & & $\mathrm{~S} / 1,000.00$ & & $\mathrm{~S} / 1,000.00$ & & $\mathrm{~S} / 1,000.00$ & & $\mathrm{~S} / 1,000.00$ & & $\mathrm{~S} / 1,000.00$ & $\mathrm{~S} / 6,000.00$ \\
\hline
\end{tabular}

\begin{tabular}{|c|c|c|c|c|c|c|c|c|c|c|c|c|c|}
\hline & es 1 & es 2 & es 3 & es 4 & es 5 & nes 6 & es 7 & es 8 & ees 9 & nes 10 & es 11 & es 12 & Anual \\
\hline $\begin{array}{ll}\mathrm{s} & \mathrm{de} \\
\end{array}$ & & & & & & & & & & & & & \\
\hline & 000.00 &, 000.00 & $3,000.00$ & $3,000.00$ & $3,000.00$ & 0 & 00 & $3,000.00$ & 00 & 00 & 00 & & \\
\hline $\begin{array}{ll}\text { os } & \text { de } \\
\text { na }\end{array}$ & & 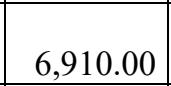 & & & & & & & & & & & 0.00 \\
\hline $\begin{array}{lr}\text { tos } & \mathrm{de} \\
\text { hinistración }\end{array}$ & 460.00 & ,460.00 & $3,460.00$ & $4,460.00$ & $53,460.00$ & $54,460.00$ & $53,460.00$ & $54,460.00$ & $53,460.00$ & $54,460.00$ & $53,460.00$ & $59,460.00$ & $652,520.00$ \\
\hline
\end{tabular}

\begin{tabular}{|c|c|c|c|c|c|c|c|c|c|c|c|c|c|}
\hline & mes 1 & es 2 & mes 3 & mes 4 & mes 5 & mes 6 & mes 7 & mes 8 & mes 9 & mes 10 & mes 11 & mes 12 & Anual \\
\hline $\begin{array}{ll}\mathrm{s} & \mathrm{de} \\
\mathrm{os} & \\
\end{array}$ & 03.00 & ,565.00 & 00 & 565.00 & $17,565.00$ & $17,565.00$ & $17,565.00$ & $17,565.00$ & $17,565.00$ & $17,565.00$ & $17,565.00$ & $17,565.00$ & 210, \\
\hline
\end{tabular}




\subsection{Proyección de ventas}

Para la proyección de ventas hemos considerado como base actualizada, lo siguiente:

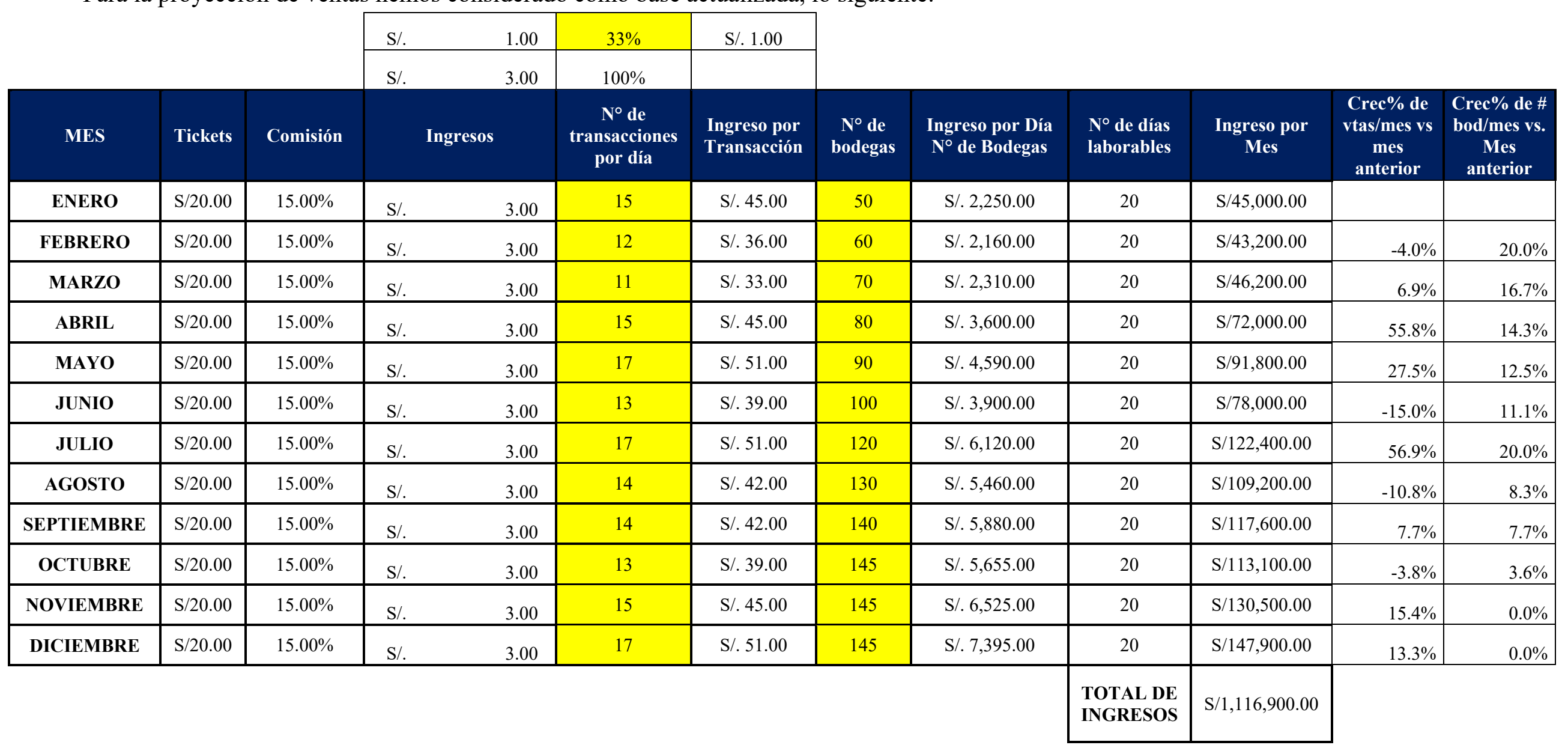


Observación: Se determinó que el crecimiento de afiliación de bodegas por mes es de manera porcentual. Esto, según se detalla en la tabla. Por ello, se verifica el crecimiento mensual del $\mathrm{N}^{\circ}$ de bodegas afiliadas de manera incremental. Cabe señalar que se mantiene un total de 145 bodegas afiliadas al final del primer año. Asimismo, se señala que el $\mathrm{N}^{\circ}$ de transacciones por mes, será determinado por fechas festivas, regulares, etc.

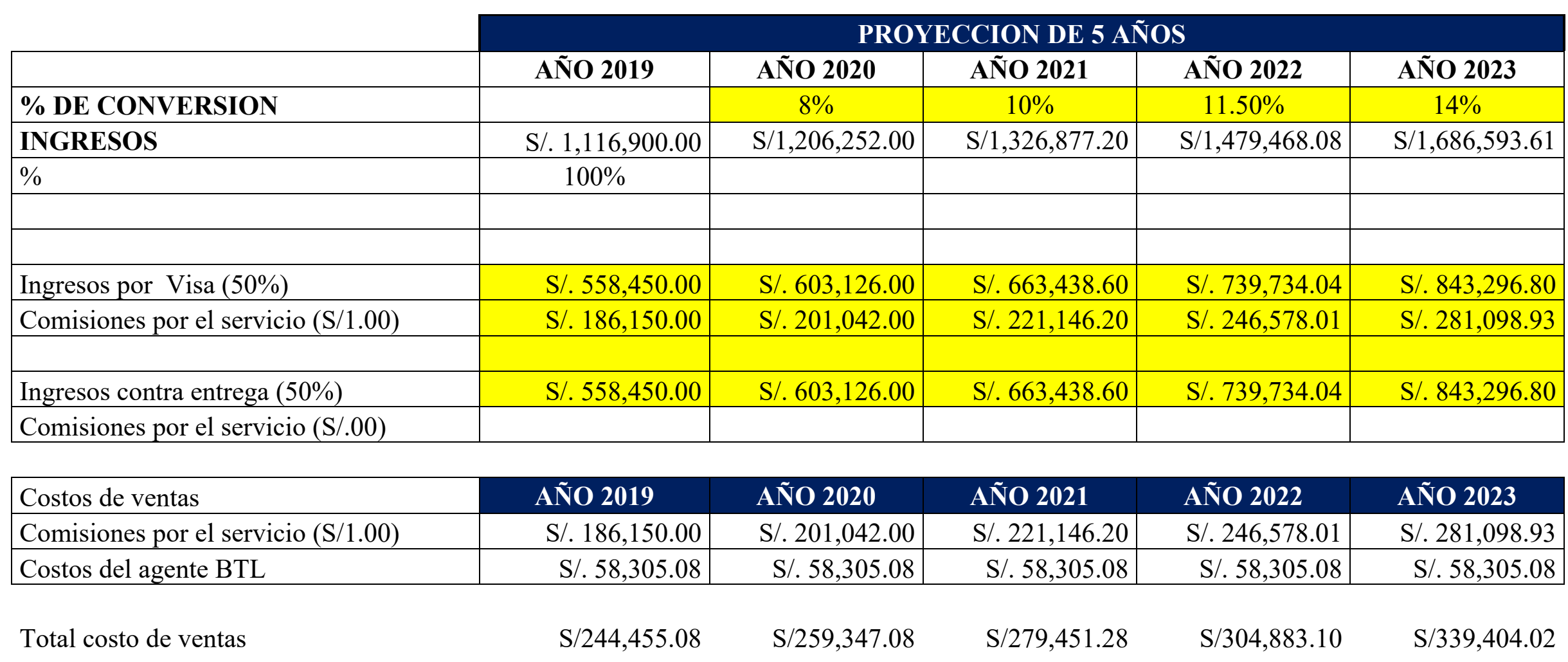




\subsection{Cálculo del capital de trabajo}

Para la determinación del capital de trabajo hemos considerado sustentarlo en base al método del presupuesto de efectivo.

\begin{tabular}{|c|c|c|c|c|c|c|c|c|c|c|c|c|}
\hline & MES 1 & MES 2 & MES 3 & MES 4 & MES 5 & MES 6 & MES 7 & MES 8 & MES 9 & MES 10 & MES 11 & MES 12 \\
\hline Ingresos & 45,000 & 43,200 & 46,200 & 72,000 & 91,800 & 78,000 & 122,400 & 109,200 & 117,600 & 113,100 & 130,500 & 147,900 \\
\hline Costo de ventas & $-20,371$ & $-20,371$ & $-20,371$ & $-20,371$ & $-20,371$ & $-20,371$ & $-20,371$ & $-20,371$ & $-20,371$ & $-20,371$ & $-20,371$ & $-20,371$ \\
\hline Gastos de administración & $-53,460$ & $-53,460$ & $-53,460$ & $-53,460$ & $-53,460$ & $-53,460$ & $-53,460$ & $-53,460$ & $-53,460$ & $-53,460$ & $-53,460$ & $-53,460$ \\
\hline Gastos de ventas & $-17,565$ & $-17,565$ & $-17,565$ & $-17,565$ & $-17,565$ & $-17,565$ & $-17,565$ & $-17,565$ & $-17,565$ & $-17,565$ & $-17,565$ & $-17,565$ \\
\hline Total gastos & $-91,396$ & $-91,396$ & $-91,396$ & $-91,396$ & $-91,396$ & $-91,396$ & $-91,396$ & $-91,396$ & $-91,396$ & $-91,396$ & $-91,396$ & $-91,396$ \\
\hline
\end{tabular}

\begin{tabular}{|l|c|c|c|c|c|c|c|c|c|c|c|c|}
\hline Saldo de caja & $-46,396$ & $-48,196$ & $-45,196$ & $-19,396$ & $\mathbf{4 0 4}$ & $-13,396$ & $\mathbf{3 1 , 0 0 4}$ & $\mathbf{1 7 , 8 0 4}$ & $\mathbf{2 6 , 2 0 4}$ & $\mathbf{2 1 , 7 0 4}$ & $\mathbf{3 9 , 1 0 4}$ & $\mathbf{5 6 , 5 0 4}$ \\
\hline Caja inicial & 91,396 & 45,000 & $-3,196$ & $-48,393$ & $-67,789$ & $-67,385$ & $-80,781$ & $-49,778$ & $-31,974$ & $-5,770$ & 15,934 & 55,037 \\
\hline Saldo final caja & 45,000 & $-3,196$ & $-48,393$ & $-67,789$ & $-67,385$ & $-80,781$ & $-49,778$ & $-31,974$ & $-5,770$ & 15,934 & 55,037 & 111,541 \\
\hline
\end{tabular}

\begin{tabular}{|c|c|}
\hline $\begin{array}{c}\text { Necesidad de capital de } \\
\text { trabajo }\end{array}$ & $91,396.26$ \\
\hline
\end{tabular}

Mi bodeguita App tendrá un Capital de trabajo de un importe de S/91,396.26 para poder sostener nuestro proyecto por un periodo de 12 meses, dicho importe será cubierto por capital propio de los 4 accionistas que tiene nuestro proyecto según participación de cada uno lo cual no se estaría financiando con recursos de terceros.

\begin{tabular}{|l|}
\hline Karina Orosco \\
\hline Tania Domínguez \\
\hline Enrique Chávez \\
\hline Abel Condori \\
\hline
\end{tabular}

\begin{tabular}{|r|r|}
\hline $20 \%$ & $\mathrm{~S} / .24,579.25$ \\
\hline $20 \%$ & $\mathrm{~S} / .24,579.25$ \\
\hline $20 \%$ & $\mathrm{~S} / .24,579.25$ \\
\hline $40 \%$ & $\mathrm{~S} / .49,158.50$ \\
\hline $100 \%$ & $\mathrm{~S} / .122,896.26$ \\
\cline { 2 - 3 }
\end{tabular}




\subsection{Estructura de financiamiento: Tradicional y no tradicional}

Para determinar el financiamiento, se ha estructurado dos propuestas: En la tradicional, se ha considerado financiarnos con el BCP y Accionistas. Así, como aplicaremos el modelo del CAPM Modificado para determinar el costo de oportunidad.

Inversión total
\begin{tabular}{|l|r|}
\hline Activo fijo & $30,000.00$ \\
\hline Inversión en Capital de trabajo & $91,396.26$ \\
\hline Gastos pre operativos & $\underline{1,500.00}$ \\
\hline Total & $\mathbf{1 2 2 , 8 9 6 . 2 6}$ \\
\hline
\end{tabular}

Metodología del cálculo del CAPM Modificado

\begin{tabular}{|l|c|}
\hline Sector: & Software (System \& Application) \\
\hline Beta desapalancado & $0.98^{8}$ \\
\hline Beta apalancado & 2.02 \\
\hline Rf & $5.15 \%^{9}$ \\
\hline Rm-Rf & $6.38 \%^{10}$ \\
\hline Rp & $1.45 \%^{11}$ \\
\hline & \\
\hline D/E & 1.50 \\
\hline Beta apalancado & 2.02 \\
\hline & \\
\hline Cok & $19.46 \%$ \\
\hline
\end{tabular}

${ }^{8}$ fuente: http://pages.stern.nyu.edu/ adamodar/New_Home_Page/datafile/Betas.html

${ }^{9}$ fuente: http://pages.stern.nyu.edu/ adamodar/New_Home_Page/datacurrent.html

${ }^{10} \mathrm{http}: / /$ pages.stern.nyu.edu/ adamodar/New_Home_Page/datacurrent.html

${ }^{11} \mathrm{https} / /$ gestion.pe/economia/riesgo-pais-peru-subio-seis-puntos-basicos-1-45-puntos-porcentuales-237052 
Estructura de financiamiento tradicional:

\begin{tabular}{|c|c|c|c|}
\hline & Monto & $\%$ & Costo \\
\hline BCP $^{\mathbf{1 2}}$ & $\mathrm{S} / .73,737.75$ & $60.00 \%$ & $14.38 \%$ \\
\hline Accionistas & $\mathrm{S} / .49,158.50$ & $40.00 \%$ & $19.46 \%$ \\
\hline Inversión Total & $\mathrm{S} / .122,896.26$ & $100.00 \%$ & \\
\hline
\end{tabular}

\begin{tabular}{|c|c|c|}
\hline Préstamo & $14.38 \%$ & TEA \\
\hline Plazo & 5 & Años \\
\hline Cuotas & Anuales & \\
\hline
\end{tabular}

\begin{tabular}{|c|c|c|c|c|c|c|}
\hline & 0 & 1 & 2 & 3 & 4 & 5 \\
\hline Saldo & S/. $73,737.75$ & S/. $62,666.15$ & $\mathrm{~S} / . \quad 50,002.45$ & S/. $\quad 35,517.71$ & S/. $\quad 18,950.07$ & $\mathrm{~S} /$. \\
\hline Interés & & S/. $\quad 10,603.49$ & S/. $\quad 9,011.39$ & S/. $\quad 7,190.35$ & S/. $\quad 5,107.45$ & $2,725.02$ \\
\hline
\end{tabular}

\section{Estructura de financiamiento no tradicional:}

\begin{tabular}{|l|c|c|c|}
\hline & Monto & $\%$ & COK \\
\hline Accionistas & $\mathrm{S} / .122,896.26$ & $100 \%$ & $19.46 \%$ \\
\hline Inversión Total & $\mathrm{S} / .122,896.26$ & $100.00 \%$ & \\
\hline
\end{tabular}

Karina Orosco

Tania Domínguez

Enrique Chávez

Abel Condori

\begin{tabular}{|r|c|}
\hline $20 \%$ & S/. 24,579.25 \\
\hline $20 \%$ & S/. $24,579.25$ \\
\hline $20 \%$ & S/.24,579.25 \\
\hline $40 \%$ & S/.49,158.50 \\
\hline $100 \%$ & S/. $122,896.26$ \\
\cline { 2 - 2 }
\end{tabular}

Observación: Como se detalla, los accionistas invertirán capital propio por un total de S/ 122,896.26 (según el porcentaje de inversión

${ }^{12}$ Fuente: http://www.sbs.gob.pe/app/pp/EstadisticasSAEEPortal/Paginas/TIActivaTipoCreditoEmpresa.aspx?tip=B 


\subsection{Estados Financieros (Balance General, Estado de GGPP, Flujo de Caja)}

Para la determinación de los Estados financieros tenemos el BBGG para los 5 años proyectados:

\section{BALANCE GENERAL PROYECTADO}

\section{ACTIVO}

\section{ACTIVO CORRIENTE}

Caja y Bancos

Inventarios

TOTAL ACTIVO CORRIENTE

ACTIVO NO CORRIENTE

Inmuebles, Maquinaria y Equipo

Depreciación acumulada

Activos Intangibles

Amortización acumulada

TOTAL ACTIVO NO CORRIENTE

TOTAL ACTIVO

PASIVO Y PATRIMONIO

PASIVO CORRIENTE

Tributo por pagar (IR)

Divdendos por pagar

TOTAL PASIVO CORRIENTE

PASIVO NO CORRIENTE

Deudas a Largo Plazo

TOTAL PASIVO NO CORRIENTE

TOTAL PASIVO

PATRIMONIO NETO

Capital

Resultados del Ejercicio (retenidas)

Reserva Legal (20\%)

Resultados Acumulados

TOTAL PATRIMONIO NETO

TOTAL PASIVO Y PATRIMONIO

NETO
Año 0

Año 1

$92,896.26$

$92,896.26$

$15,000.00$

0.00
$15,000.00$

0.00

$30,000.00$

22,896.26

0.00

0.00

0.00

0.00

0.00

0.00

$122,896.26$

$122,896.26$

$122,896.26$
Año 2

$183,620.90$
0.00

$183,620.90$

$15,000.00$

$-6,000.00$

$15,000.00$

$-3,000.00$

$21,000.00$
$204,620.90$

23,335.95

$11,153.79$

$34,489.74$

0.00
0.00

$34,489.74$

$122,896.26$

$20,035.92$

24,579.25

$2,619.73$

$170,131.16$

$204,620.90$
Año 3

$308,677.83$

$308,677.83$

$15,000.00$

$-9,000.00$

$15,000.00$

$-4,500.00$

$16,500.00$
$325,177.83$

$52,989.65$

$25,327.25$

$78,316.90$

0.00
0.00

$78,316.90$

$122,896.26$

$76,729.76$

$24,579.25$

$22,655.65$

$246,860.93$

$325,177.83$
Año 4

Año 5

$517,066.66$
0.00

$517,066.66$

$15,000.00$

$-12,000.00$
$-15,000.00$

$15,000.00$

$-6,000.00$

$12,000.00$

$29,066.66$

$90,501.57$

$43,256.68$

$133,758.25$

0.00
0.00

133,758.25

$122,896.26$

$148,447.48$

$24,579.25$

$99,385.42$

$395,308.40$

$529,066.66$
$842,618.74$ 0.00 $842,618.74$

$15,000.00$

$-15,000.00$

$15,000.00$

$-7,500.00$

$7,500.00$

141,419.93

$67,593.93$

$209,013.86$

0.00
0.00

209,013.86

$122,896.26$

$245,796.48$

$24,579.25$

$247,832.90$

$641,104.88$

$850,118.74$ 
Para la preparación del Estado de Resultados, se tiene el siguiente proyectado a 5 años:

\section{ESTADO DE GANANCIAS Y}

PÉRDIDAS

Anual

$\underline{\text { Año } 1}$

Años

Ingresos

TOTAL INGRESOS

Costo de ventas

Utilidad Bruta

Gastos de administración

Gastos de ventas

Gastos de depreciación

Gastos de amortización

Utilidad Operativa

Gastos financieros

Utilidad antes de

Impuestos

Impuesto a la Renta

(29.5\%)

Utilidad Neta

Dividendos

Utilidades Retenidas

\begin{tabular}{rr}
$100 \%$ & $1,116,900.00$ \\
\hline$-244,455.08$ \\
$872,444.92$ \\
$-652,520.00$ \\
$-210,780.00$ \\
$-3,000.00$ \\
$-1,500.00$ \\
$4,644.92$ \\
$\underline{0.00}$ \\
$4,644.92$ \\
\\
\end{tabular}

$\underline{\text { Año } 2}$

$\underline{\text { Año } 3}$

\begin{tabular}{rr}
$1,206,252.00$ & $1,326,877.20$ \\
\hline$\underline{-259,347.08}$ & $\frac{-279,451.28}{1,047,425.92}$ \\
$946,904.92$ & $-652,520.00$ \\
$-652,520.00$ & $-210,780.00$ \\
$-210,780.00$ & $-3,000.00$ \\
$-3,000.00$ & $\underline{-1,500.00}$ \\
$\underline{-1,500.00}$ & $179,625.92$ \\
$79,104.92$ & $\underline{0.00}$ \\
$\underline{0.00}$ &
\end{tabular}

$79,104.92$

$\underline{-23,335.95}$

$55,768.97$

$11,153.79$

$44,615.17$
$179,625.92$

$\underline{-52,989.65}$

$126,636.27$

$25,327.25$

$101,309.02$
Año 4

$\underline{\text { Año } 5}$

$1,479,468.08$
$-304,883.10$
$1,174,584.98$
$-652,520.00$
$-210,780.00$
$-3,000.00$
$\underline{-1,500.00}$
$306,784.98$
$\underline{0.00}$
$306,784.98$
$\underline{-90,501.57}$
$216,283.41$
$43,256.68$
$173,026.73$

$173,026.73$
$1,686,593.61$

$-339,404.02$

$1,347,189.59$

$-652,520.00$

$-210,780.00$

$-3,000.00$

$\underline{-1,500.00}$

$479,389.59$

$\underline{0.00}$

$479,389.59$

$\underline{-141,419.93}$

$337,969.66$

$67,593.93$

$270,375.73$

Para la determinación de la caja al inicio de cada periodo, se determinó el presupuesto de caja: 


\section{ESTADO DE FLUJO DE EFECTIVO}

\begin{tabular}{|c|c|c|c|c|c|c|}
\hline Cobros & $\underline{\text { Año } 0}$ & $\frac{\text { Añ } \mathbf{0} 1}{1,116,900}$ & $\frac{\text { Año 2 }}{1,206,252}$ & $\frac{\text { Año } \mathbf{3}}{1,326,877}$ & $\frac{\text { Año 4 }}{1,479,468}$ & $\frac{\text { Año 5 }}{1,686,594}$ \\
\hline \multicolumn{7}{|l|}{ Egresos } \\
\hline Pagos por comisiones & & 244,455 & 259,347 & 279,451 & 304,883 & 339,404 \\
\hline Pagos por administración & & 652,520 & 652,520 & 652,520 & 652,520 & 652,520 \\
\hline pagos por ventas & & 210,780 & 210,780 & 210,780 & 210,780 & 210,780 \\
\hline Pagos de tributos & & 0 & 1,370 & 23,336 & 52,990 & 90,502 \\
\hline pagos de dividendos & & & 655 & 11,154 & 25,327 & 43,257 \\
\hline Reserva legal & & & & 24,579 & 24,579 & 24,579 \\
\hline Total de egresos & & $1,107,755$ & $1,124,672$ & $1,201,820$ & $1,271,079$ & $1,361,042$ \\
\hline Saldo de caja & $\mathbf{0}$ & 9,145 & 81,580 & 125,057 & 208,389 & 325,552 \\
\hline Caja inicial & 92,896 & 92,896 & 102,041 & 183,621 & 308,678 & 517,067 \\
\hline Caja final & 92,896 & 102,041 & 183,621 & 308,678 & 517,067 & 842,619 \\
\hline
\end{tabular}

Posteriormente, se preparó el flujo de caja del negocio proyectado a 5 años: 
Ingresos

\section{TOTAL INGRESOS}

\section{Costo de ventas}

Utilidad Bruta

Gastos

de

administración

Gastos de ventas

Gastos de depreciación

Gastos de amortización -

Utilidad Operativa

Impuesto a la Renta

(29.5\%)

Gastos de depreciación

Gastos de amortización

Utilidad Neta

Inversión Activo fijo

Inversión en CTN

Gastos pre operativos

FCLD

Financiamiento

Amortización

Interés

EFI

FCF

FCNI $\underline{\text { Año } 1}$

\begin{tabular}{r}
$1,116,900.00$ \\
$-244,455.08$ \\
\hline $872,444.92$ \\
$-652,520.00$ \\
$-210,780.00$ \\
$-3,000.00$ \\
$-1,500.00$ \\
\hline $4,644.92$ \\
0.00 \\
$3,000.00$ \\
$1,500.00$ \\
$9,144.92$ \\
0.00 \\
0.00 \\
$\underline{0.00}$ \\
$9,144.92$ \\
0.00 \\
0.00 \\
0.00 \\
0.00 \\
$9,144.92$
\end{tabular}

$\underline{\text { Año } 2}$

$\begin{array}{r}1,206,252.00 \\ -259,347.08 \\ \hline 946,904.92 \\ -652,520.00 \\ -210,780.00 \\ -3,000.00 \\ \underline{-1,500.00} \\ 79,104.92 \\ -1,370.25 \\ 3,000.00 \\ 1,500.00 \\ 82,234.67 \\ 0.00 \\ 0.00 \\ \underline{0.00} \\ 82,234.67 \\ 0.00 \\ 0.00 \\ 0.00 \\ 0.00 \\ \hline 2,234.67\end{array}$

$$
\begin{array}{r}
1,326,877.20 \\
-279,451.28 \\
\hline 1,047,425.92 \\
-652,520.00 \\
-210,780.00 \\
-3,000.00 \\
-1,500.00 \\
179,625.92 \\
-23,335.95 \\
3,000.00 \\
1,500.00 \\
160,789.97 \\
0.00 \\
0.00 \\
\underline{0.00} \\
160,789.97 \\
0.00 \\
0.00 \\
0.00 \\
\underline{0.00} \\
160,789.97
\end{array}
$$$$
-30,000.00
$$$$
-91,396.26
$$$$
-1,500.00
$$$$
-122,896.26
$$$$
0.00
$$

$-122,896.26$
$9,144.92$ $\underline{\text { Año } 3}$

$\underline{\text { Año } 4}$

$\underline{\text { Año } 5}$

\begin{tabular}{rr}
$1,479,468.08$ & $1,686,593.61$ \\
$\underline{-304,883.10}$ & $\underline{-339,404.02}$ \\
\hline $1,174,584.98$ & $1,347,189.59$ \\
$-652,520.00$ & $-652,520.00$ \\
$-210,780.00$ & $-210,780.00$ \\
$-3,000.00$ & $-3,000.00$ \\
$-1,500.00$ & $\underline{-1,500.00}$ \\
$306,784.98$ & $479,389.59$ \\
$-52,989.65$ & $-90,501.57$ \\
$3,000.00$ & $3,000.00$ \\
$\underline{1,500.00}$ & $\underline{1,500.00}$ \\
$258,295.34$ & $393,388.02$ \\
0.00 & 0.00 \\
0.00 & 0.00 \\
$\underline{0.00}$ & $\underline{0.00}$ \\
$258,295.34$ & $393,388.02$ \\
0.00 & 0.00 \\
0.00 & 0.00 \\
0.00 & 0.00 \\
$\underline{0.00}$ & $\underline{0.00}$ \\
$258,295.34$ & $393,388.02$
\end{tabular}

$258,295.34$

$393,388.02$ 


\subsection{Flujo Financiero}

El flujo de caja financiero para el accionista se basa del flujo de caja libre descontado a 5 años, siendo el siguiente:

\begin{tabular}{|l|}
\hline FCLD \\
\hline Financiamiento \\
\hline Amortización \\
\hline Interés \\
\hline EFI \\
\hline FCF \\
\hline FCNI \\
\hline
\end{tabular}

(1)

Año 0
$-122,896.26$
0.00
0.00
0.00
0.00
$\underline{0.00}$
$-122,896.26$

Año 1
$9,144.92$
0.00
0.00
0.00
0.00
$\underline{0.00}$
$9,144.92$

\begin{tabular}{r|} 
Año 2 \\
$82,234.67$ \\
0.00 \\
0.00 \\
0.00 \\
0.00 \\
$\underline{0.00}$ \\
$82,234.67$
\end{tabular}

\begin{tabular}{r|} 
años, siendo e \\
\hline Año 3 \\
\hline $160,789.97$ \\
0.00 \\
0.00 \\
0.00 \\
0.00 \\
$\underline{0.00}$ \\
$160,789.97$
\end{tabular}

iguiente:

$\begin{array}{rr}258,295.34 & 393,388.02 \\ 0.00 & 0.00 \\ 0.00 & 0.00 \\ 0.00 & 0.00 \\ 0.00 & 0.00 \\ \underline{0.00} & \underline{0.00} \\ 258,295.34 & 393,388.02\end{array}$




\subsection{Tasa de descuento accionistas y Wacc}

Para la determinación de la tasa de descuento del accionista se aplicó el modelo del CAPM MODIFICADO.

Metodología del cálculo del CAPM Modificado

\begin{tabular}{|l|c|}
\hline Sector: & Software (System \& Application) \\
\hline Beta desapalancado & $0.98^{13}$ \\
\hline Beta apalancado & 2.02 \\
\hline Rf & $5.15 \%^{14}$ \\
\hline Rm-Rf & $6.38 \%{ }^{15}$ \\
\hline Rp & $1.45 \%^{16}$ \\
\hline D/E & 1.50 \\
\hline Beta apalancado & 2.02 \\
\hline Cok & $19.46 \%$ \\
\hline
\end{tabular}

\section{WACC FINANCIAMIENTO TRADICIONAL:}

\begin{tabular}{|l|c|c|c|c|}
\hline & $\%$ & Costo & Tx & WACC \\
\hline BCP & $60.00 \%$ & $14.38 \%$ & $29.50 \%$ & $6.08 \%$ \\
\hline Accionistas & $40.00 \%$ & $19.46 \%$ & & $7.78 \%$ \\
\hline Inversión Total & $100.00 \%$ & & & $13.87 \%$ \\
\hline
\end{tabular}

\section{WACC FINANCIAMIENTO NO TRADICIONAL:}

\begin{tabular}{|l|c|c|c|}
\hline & $\%$ & Costo & Tx \\
\hline Accionistas & $100.00 \%$ & $19.46 \%$ & \\
\hline Inversión Total & $100.00 \%$ & & $19.46 \%$ \\
\hline
\end{tabular}

${ }^{13}$ Fuente: http://pages.stern.nyu.edu/ adamodar/New Home Page/datafile/Betas.html

${ }^{14}$ Fuente: http://pages.stern.nyu.edu/ adamodar/New_Home_Page/datacurrent.html

${ }^{15}$ Fuente: http://pages.stern.nyu.edu/ adamodar/New Home Page/datacurrent.html

${ }^{16}$ Fuente: https://gestion.pe/economia/riesgo-pais-peru-subio-seis-puntos-basicos-1-45-puntos-porcentuales-237052 


\subsection{Indicadores de rentabilidad}

Los indicadores se basan en el análisis Dupont vitales para conocer el giro del negocio:

\begin{tabular}{|c|c|c|c|c|c|c|}
\hline INDICADORES & $\underline{\text { Año } 0}$ & Año 1 & $\underline{\text { Año } 2}$ & Año 3 & Año 4 & $\underline{\text { Año } 5}$ \\
\hline MARGEN NETO & & $0 \%$ & $5 \%$ & $10 \%$ & $15 \%$ & $20 \%$ \\
\hline EFICIENCIA EN ACTIVOS & & 8.76 & 5.90 & 4.08 & 2.80 & 1.98 \\
\hline ENDEUDAMIENTO ( total activo / patrimonio) & & 1.02 & 1.20 & 1.32 & 1.34 & 1.33 \\
\hline RENTABILIDAD SOBRE LOS ACTIVOS & & $3 \%$ & $27 \%$ & $39 \%$ & $41 \%$ & $40 \%$ \\
\hline RENTABILIDAD SOBRE EL PATRIMONIO & & $3 \%$ & $33 \%$ & $51 \%$ & $55 \%$ & $53 \%$ \\
\hline
\end{tabular}

Notas:

- El margen neto del negocio se ha ido incrementando porque la depreciación genera un benefício sobre la utilidad y los gastos del negocio van disminuyendo

- El ratio disminuye porque no se está reinvirtiendo

- El apalancamiento va disminuyendo producto de un incremento del patrimonio total

INDICADORES - EVALUACION

\begin{tabular}{|c|r|}
\hline VANE & $325,229.64$ \\
\hline WACC & $19 \%$ \\
\hline TIRE & $71 \%$ \\
\hline
\end{tabular}

\begin{tabular}{|r|r|}
\hline VANF & $325,229.64$ \\
\hline COK & $19 \%$ \\
\hline TIR & $71 \%$ \\
\hline
\end{tabular}




\subsection{Análisis de riesgo}

Se han determinado las siguientes variables críticas en el negocio:

\subsubsection{Análisis de sensibilidad}

Análisis Multidimensional

Variables Relevantes

\begin{tabular}{|l|c|c|}
\hline Ingresos & $90 \%$ & $100 \%$ \\
\hline Número de bodegas afiliadas & $95 \%$ & $100 \%$ \\
\hline Costos operativos & $105 \%$ & $100 \%$ \\
\hline Comisión & $12 \%$ & $15 \%$ \\
\hline VPN & $-283,275.30$ & $325,229.64$ \\
\hline TIR & $-12 \%$ & $71 \%$ \\
\hline
\end{tabular}

\section{VAN VS TIR}

Análisis: En el grafico se detalla que, al haber un cambio en las variables críticas de ingreso, número de bodegas afiliadas, costos operativos y comisión por ingresos hay una perdida en el proyecto de $-283,275.30$ reflejando una TIR de $12 \%$. Sin embargo, al considerar un 15\% de comisión se puede obtener una TIR del 71\%. (Escenario cauto para el inicio de un nuevo negocio como el del proyecto Mi Bodeguita). 


\subsubsection{Análisis por escenarios (por variables)}

Se han considerado los siguientes escenarios siendo los más críticos para el negocio:

\begin{tabular}{|c|c|c|c|c|c|}
\hline ESCENARIOS & Gastos operativos & Comisión x servicio & Comisión Banco & VPN & TIR \\
\hline Pesimista & $90,112.00$ & $12.00 \%$ & S/. 1.50 & $-257,905.85$ & $-14.11 \%$ \\
\hline Esperado & $81,920.00$ & $15.00 \%$ & S/ 1.00 & $325,229.64$ & $71 \%$ \\
\hline Optimista & $77,824.00$ & $18.00 \%$ & S/. 0.50 & $1,201,174.38$ & $274.19 \%$ \\
\hline
\end{tabular}

\subsubsection{Análisis de punto de equilibrio}

\begin{tabular}{|c|c|c|c|c|c|c|}
\hline $\begin{array}{l}\text { FLUJO DE CAJA ANUAL } \\
\text { Ingresos }\end{array}$ & Año 0 & Año 1 & Año 2 & Año 3 & $\underline{\text { Año } 4}$ & Año 5 \\
\hline Costo de ventas & & $-244,455.08$ & $-259,347.08$ & $-279,451.28$ & $-304,883.10$ & $-339,404.02$ \\
\hline Gastos operativos & & $-652,520.00$ & $-652,520.00$ & $-652,520.00$ & $-652,520.00$ & $-652,520.00$ \\
\hline Gastos de RRHH & & $-210,780.00$ & $-210,780.00$ & $-210,780.00$ & $-210,780.00$ & $-210,780.00$ \\
\hline Utilidad Operativa & & $9,144.92$ & $83,604.92$ & $184,125.92$ & $311,284.98$ & $483,889.59$ \\
\hline Costo de ventas & & $244,455.08$ & $259,347.08$ & $279,451.28$ & $304,883.10$ & $339,404.02$ \\
\hline Ingresos punto equilibrio & & $1,107,755.08$ & $1,122,647.08$ & $1,142,751.28$ & $1,168,183.10$ & $1,202,704.02$ \\
\hline
\end{tabular}

\begin{tabular}{|llllll}
\hline Objetivo de ventas & $99.18 \%$ & $93.07 \%$ & $86.12 \%$ & $78.96 \%$ & $71.31 \%$ \\
\hline
\end{tabular}

Análisis: Solo alcanzó un promedio de $86 \%$ en los ingresos, que logra cubrir los gastos operativos del proyecto. 


\subsubsection{Principales riesgos del proyecto (cualitativos)}

- Variación en el precio promedio de venta con el ingreso de nuevos competidores que se enfocaran en precios bajos.

- Variación en el volumen de ventas del primer año del proyecto debido a una falta de publicidad y negociación con los clientes.

- Variación en la política de cobranza generando en algunos clientes falta de pago.

- Incremento en el presupuesto de inversiones que no esté considerado en la inversión inicial.

- Falta de financiamiento por parte de Bancos y Accionistas. 


\section{CAPÍTULO 8. CONCLUSIONES}

\subsection{Conclusiones generales}

1. El proyecto permite marginar claramente a dos tipos de clientes, uno directo (bodeguero) y otro indirecto (usuario). Las necesidades de uno respecto al otro son abismales, el "bodeguero" busca crecimiento e incluso se podría hablar de migrar su negocio a una empresa formal. Por ejemplo, en el país se cuenta la experiencia de éxito de la familia Wong, que migro del negocio de la bodega a una cadena de súper mercados. Por otro lado, el usuario busca solucionar una problemática puntual e inesperada de una manera rápida, practica y segura, su ritmo de vida tiende a ser muy acelerado, a esto le súmanos que las familias en las cuales se mueven son totalmente variadas : madres solteras, hijos independientes, etc. El proyecto apuesta por cubrir un vacío y aprovechar esta oportunidad de negocio, a través 115 e luso de tecnología de una manera muy amigable.

2. Se ha desarrollado este proyecto tecnológico, tomando en cuenta la gran cantidad de bodegas que hay en nuestro país y el nivel de importancia que tienen para los ciudadanos de a pie. Adicionalmente, se ha identificado el nivel de informalidad, desconocimiento de un correcto control de inventarios y la falta de procedimientos adecuados para el pago a proveedores que actualmente hay en este tipo de negocios.

3. Las bodegas que implementen nuestros servicios en su negocio, serán conocidas por sus usuarios como micro empresas modernas donde se aplican técnicas de marketing (trade marketing, estrategias de exposición de producto, etc.), control de sus procesos (pago a proveedores, banca virtual, etc.), y esto a su vez ayudará a mantener y acrecentar su clientela al darles la confianza de que al comprar ahí, se estarán llevando un producto al mejor precio y con un control de calidad optimo casi tanto como al nivel de un supermercado.

4. El proyecto es rentable, por el cual se obtiene una TIR positiva, que nos indica que el índice de rentabilidad, es buena al ejecutar el proyecto. 
5. El proyecto que se va a llevar acabo es muy beneficioso, ya que según los indicadores financiaros que se han evaluado, se obtiene una buena rentabilidad para los inversionistas. 


\subsection{Conclusión Individual: Administración de Empresas - Gestión Operativa}

El inicio del proyecto empresarial Mi Bodeguita, surge para ofrecer una solución innovadora, eficiente y convenientemente atractiva para los clientes (bodegueros). Por ello, se realizó una validación previa del mercado no atendido (personas que por motivos de trabajo, estudios o atención de sus familias, no tenían el suficiente tiempo para realizar sus compras de última hora en bodegas cercanas a su domicilio) y se evidenció un alto interés por parte de estos usuarios que estarían dispuestos a pagar por un servicio rápido, seguro y que les ahorraría tiempo en las compras de último minuto, al recibir sus compras y pedidos en la puerta de su casa.

Por ello, la aplicación Mi Bodeguita para uso en smartphones, atiende la necesidad de los bodegueros de los distritos de Miraflores, San Isidro y Surco, que requerian encontrar formas de generar más ingresos a sus negocios o ver alguna alternativa de mejora en los procesos de atención, inventario y financiamiento. Por ello, con la validación realizada mediante encuestas e investigación de mercado, se pudo identificar la problemática que los bodegueros presentaban al nivel de gestión operativa. Esto, debido a que no presentaban adecuados controles de stock automáticos y tecnológicos, el manejo de sus finanzas era de forma empírica, algunos se encontraban en la informalidad, no podían crecer o expandirse por falta de financiamiento bancario, así como dependian de los clientes tradicionales que se acercaban a sus negocios.

Cabe señalar que a pesar que la tecnología y el uso de un aplicativo en el celular aleja al usuario del trato directo con el bodeguero, el proceso operativo no debe perder esta importante etapa. Por ello, el modelo de negocio se enfoca a que el responsable de la entrega (repartidor) pase a ser la primera línea de contacto con el usuario y no con el bodeguero. Es decir, las bodegas contarían con una persona que trabaje como dependiente. Con ello, se pudo trabajar con los clientes (bodegas) sobre temas relacionados con la atención a sus propios clientes (usuarios de la aplicación) y buscar fidelización de los mismos. Asimismo, este sería un punto de referencia para ayudar a identificar nuevas oportunidades para ampliar la gama de 
productos que ofrecía el bodeguero (tener información directa de los usuarios sobre sus preferencias de compra y otros).

Se señala que el proyecto empresarial Mi Bodeguita permite la modernización de las bodegas de barrio de los distritos de Miraflores, San Isidro y Surco y los ayuda a encontrar nuevos canales de venta, distintos a los tradicionales de los cuales dependían al 100\%. La aplicación Mi Bodeguita brinda la solución a las bodegas de competir en el retail moderno (tiendas de conveniencia como Listo !, Tambo, etc.).

Por otro lado, el punto central del modelo de negocio está basado en buscar la mayor cantidad de transacciones y elevar el ticket promedio de compra de los clientes (bodegas). Es por esto, que el control del abastecimiento en la bodega es muy importante, con la finalidad que las bodegas cuenten con diversidad de productos que sean atractivos para más usuarios y los mismos utilicen y manejen sus propios inventarios virtuales para tener claridad de los productos en tiempo real, por encontrarse sistematizado. Con ello, se reduce el riesgo de tener pérdidas de venta por falta de stock para tener claro cual es el punto de reorden para el abastecimiento de los productos.

Cabe señalar que el resultado positivo del VAN obtenido por el monto de S/ 325,229.64 del planteamiento financiero - económico del proyecto, evidenció el valor de la inversión para los accionistas y para los clientes. Asimismo, la TIR calculada del $71 \%$ enfatizó la rentabilidad del negocio. Esto, debido a que no se ha encontrado otras variables significativas que hagan que el negocio sufra una variación de resultados durante un periodo de proyección de cinco años, lo que permite concluir que la VAN y TIR Calculada describen de manera correcta y positiva al proyecto. De igual manera, el payback del negocio se rige dentro de los límites de un escenario esperado que permite contar con márgenes de recupero a partir del tercer año con una invesrión inicial de S/ 122,896.26.

Finalmente, el proyecto empresarial Mi Bodeguita se presenta como una starup atractiva para su clientes y para una futura afiliación de nuevos inversionistas, que permitan una cobertura a nivel de todos los distritos de Lima y a nivel nacional y convertirse en la conexión o intermediario entre usuarios y bodegas de todo el Perú. 


\section{Referencias bibliográficas}

ALOBODEGA (2018) (http://www.alobodega.com/) Sitio web que contiene información de consulta sobre la empresa Aló Bodega (consulta: 11 de abril 2018)

ASOCIACIÓN DE BODEGUEROS DEL PERÚ (2018)

(http://asociaciondebodegueros.com/) Sitio web que contiene información de consulta sobre bodegueros afiliados y su comportamiento frente al crecimiento de supermercados (consulta: 16 de abril 2018)

\section{BANCO CENTRAL DE RESERVA DEL PERÚ (2018)}

(http://www.bcrp.gob.pe/estadisticas.html) Sitio web que contiene información de consulta sobre la inflación peruana del 2012-2017 (consulta: 4 de abril 2018)

BARROZ, Giannina, Renteria, Sheyra, Murillo, Iván, Yanamango, Peggy (2017) Trabajo de Suficiencia Profesional para optar el título profesional de: Bachiller en Administración o Bachiller en Marketing del negocio Bodega App

BARROZ, Giannina, Renteria, Sheyra, Murillo, Iván, Yanamango, Peggy (2017) Trabajo Final del curso de Desarrollo Negocios 1 de la idea de negocio M4rk3t

BLOG UNIDAD DE EMPRENDIMIENTO VIRTUAL DE HERNANDO PUENTES LOZANO (2018) (http://hachepe57.blogspot.pe/2010/05/l-calculo-del-tamano-de-lamuestra.html) Sitio web que contiene información de consulta sobre mercados (consulta: 30 de abril 2018)

COMUNAL COWORKING (2018) (https://comunalcoworking.com/) Sitio web que contiene información de consulta sobre mapa de oficinas de la empresa (consulta: 15 de mayo 2018) 
DEPERU (2018) (http://www.deperu.com) Sitio web que contiene información de consulta sobre la evolución oficial del tipo de cambio de dólar americano en el Perú - 2017 (consulta: 2 de abril 2018)

EL COMERCIO (2018) (https://elcomercio.pe/lima/sucesos/san-isidro-bodegassupermercados-mira-conservas-parasitos-noticia-475828) Sitio web que contiene imagen como ejemplo de contacto con bodegas (consulta: 2 de mayo 2018)

ESCAIN (2018) (https://sites.google.com/site/escaincomercial4/home/1-modulo-pricing) Sitio web que contiene información de consulta sobre la percepción de valor y sensibilidad al precio (consulta: 27 de abril 2018)

GEOBICI (2018) (http://www.geobici.com) Sitio web que contiene información de consulta sobre la empresa y uso de logo (consulta: 12 de mayo 2018)

GESTIÓN (2018) (https://gestion.pe/economia/bodegas-recuperan-espacio-perdidosupermercados-paso-229626) Sitio web que contiene información de consulta sobre bodegas que están recuperando espacio contra supermercados y uso de android (consulta: 17 de abril 2018)

INEI (2018) (https://www.inei.gob.pe) Sitio web que contiene información de consulta sobre la evolución del PBI en el Perú, hasta mediados del 2017 (consulta: 4 de abril 2018)

JPFITNESS

(https://m.facebook.com/JPFitnessPeru/? tn_ =CR\&_nodl\&ref=external\%3Awww.google.com.pe\&_rdr) Sitio web que contiene información de consulta sobre tipo de promoción utilizada por la empresa (consulta: 22 de abril 2018) 
M4RK3T (2018) (https://www.facebook.com/m4rk3tapp) Sitio web que contiene información de consulta sobre las visitas al Facebook de M4rk3t - Base de investigación de Mi Bodeguita (consulta: 10 de abril 2018)

\section{MUNICIPALIDAD DE MIRAFLORES (2018)}

(http://www.miraflores.gob.pe/_contenTempl1.php?idpadre=4951\&idhijo=4972\&idconte nido=5398) Sitio web que contiene información de consulta sobre el número de habitantes del distrito de Miraflores (consulta: 17 de abril 2018)

PERÚ REATIL (2018) (https://www.peru-retail.com/conoce-distritos-lima-concentranbodegas-tiendas-conveniencia/) Sitio web que contiene información de consulta sobre que distritos de Lima concentran más tiendas de conveniencia (consulta: 18 de abril 2018)

QUESTIONPRO

(https://www.questionpro.com/blog/wpcontent/uploads/2015/08/post12Com21.png) Sitio web que contiene información de consulta para determinar el tamaño de la muestra (consulta: 25 de abril 2018)

RPP NOTICIAS (2018) (http://rpp.pe/economia/economia/prefieren-bodegas-quesupermercados-para-compras-al-por-mayor-noticia-1078297) Sitio web que contiene información de consulta que clientes prefieren consumir en bodegas para compras al por mayor que supermercados (consulta: 17 de abril 2018)

RPP NOTICIAS (2018) (http://rpp.pe/economia/economia/dia-del-internet-este-es-elperfil-del-internauta-peruano-noticia-1051335) Sitio web que contiene información de consulta sobre economía y perfil del internauta (consulta: 14 de abril 2018)

RPP NOTICIAS (2018) (http://rpp.pe/economia/economia/abp-en-lima-existen-113-milbodegas-y-a-nivel-nacional-414-mil-noticia-933175) Sitio web que contiene información de consulta sobre cantidad de bodegas en Lima Metropolitana (consulta: 16 de abril 2018) 
UPC BLACKBOARD (2018)

(https://aulavirtual.upc.edu.pe/webapps/blackboard/execute/announcement?method=searc $\mathrm{h} \&$ context $=$ course_entry\&course_id=_143844_1\&handle=announcements_entry\&mode= view) Sitio web que contiene información de consulta sobre procesos de negocios (consulta: 23 de mayo 2018)

\section{WIKIPEDIA (2018)}

(https://es.wikipedia.org/wiki/Estrategias_gen\%C3\%A9ricas_de_Porter) Sitio web que contiene información de consulta sobre las estrategias genéricas de Porter (consulta: 6 de abril 2018) 


\section{ANEXOS}

\section{ANEXO 1 \\ ENTREVISTAS DE PROFUNDIDAD INICIALES A BODEGAS DE MIRAFLORES}

\section{BODEGA $N^{\circ}$ 1:}

Buenos días/ tardes mi nombre es Abel soy estudiante de la carrera de Administración de Empresas de la UPC- Universidad Peruana de Ciencias Aplicadas y estoy realizando una investigación sobre un proyecto empresarial. Por ello, solicito su apoyo para contestar una entrevista que será de gran utilidad y relevancia para el análisis de esta investigación. Muchas gracias.

\begin{tabular}{|l|l|}
\hline Nombre de la bodega & MINIMARKET CESIRA \\
\hline Dirección de la bodega & AV. TORIBIO PACHECO 389 - MIRAFLORES \\
Nombres y apellidos del & Ángel Fernández Huamán \\
\hline Edado & \\
\hline Foto de la Bodega & \\
\hline
\end{tabular}




\section{CUESTIONARIO - ENTREVISTA}

\section{ÁREA: TECNOLOGÍA}

- ¿Cuándo escucha el término aplicación para celular, que es lo primero que se le viene a la mente?

YouTube, Spotify, Facebook etc.

- ¿Qué utilidad le da a su Smartphone?, ¿Qué servicios utiliza y como es su experiencia con este producto?

Compro algunas cosas por la aplicación del BCP o Aliexpress.

- ¿Suele realizar operaciones on line?

Si, para pagar cuentas y no hacer cola o ir al banco.

- ¿Utiliza la tecnología en su bodega? ¿Realiza publicidad en las redes sociales? ¿Qué tipo de publicidad usa?

No utilizo tecnología y la publicidad es tener bien exhibido la fachada de las bodegas y colocar las promociones.

- ¿Tiene conocimiento que el uso de herramientas tecnológicas puede incrementar sus ingresos? De ser así, ¿Qué opina del uso de aplicativos para celulares como una alternativa para atender otro tipo de cliente al tradicional?

No tenía conocimiento.

\section{ÁREA: CLIENTES}

- ¿Dónde y quienes suelen ser sus clientes?

Las familias que viven en los edificios cercanos.

- ¿Tiene algún perfil de cliente específico? Detalle

Son padres y madres de familia y también la gente que trabaja en las oficinas cercanas.

- ¿Qué comentarios de la atención brindada a sus clientes, ha recibido por parte de ellos? Que tengo muy bien surtida la bodega.

- ¿Su nivel de ventas como ha sido? ¿Se ha incrementado o han caído a través de los años?

Las ventas han bajado un poco los últimos meses.

- Regularmente, ¿En qué momentos del día tiene más pedidos o visitas de clientes? ¿Pierde ventas por clientes no atendidos? De ser así, ¿le gustaría tener las herramientas para atender a todos sus clientes (visitantes) y potenciales clientes (virtuales)?

Mayormente en el mañana bien temprano y las tarde noches. Rara vez pierdo cliente, ya que mi bodega está bien surtida. Si el costo es minino, sí.

- ¿Qué canales de distribución utiliza para la entrega de productos?, ¿Brinda el servicio de delivery como valor agregado?, ¿Cuál es su opinión sobre el servicio de delivery?

Si hago delivery, es un servicio necesario porque la gente ya no quiere salir de sus departamentos u oficinas.

\section{ÁREA: LOGÍSTICA}

- ¿Cómo maneja el tema de sus inventarios y el stock de su bodega?

En un cuaderno llevo el registro de mis compras y así voy controlando cuando hacer mis pedidos.

- ¿Tiene planes para incrementar o expandir su negocio?

Si estoy viendo un local a unas cuadras para abrir otra bodega y usarlo como almacén.

- ¿Encontró alguna solución para incrementar o expandir su negocio?

La verdad que no. 
- ¿Cuáles son las principales actividades que lleva a cabo en su negocio? ¿Qué línea de productos maneja?

Víveres, frutas, verduras, carnes un poco de todo.

- ¿Podría detallar cual es el proceso de pedidos y entrega de productos a sus clientes?, ¿Ha pensado en otras opciones para abarcar más mercado? Detalle

Como la zona es comercial, pensado abrir otra bodega más.

- Respecto a los procesos de inventario ¿Cómo le gustaría que fuera el manejo de este para su negocio?

El que tengo me gusta, no necesito más.

- ¿Cómo realiza la reposición y exhibición de sus productos? ¿Le gustaría tener asesoría como parte de un beneficio por un servicio utilizado?

Separo por productos, carnes por lado, bebidas por otro y así.

\section{ÁREA: PROVEEDORES}

- ¿Cómo suele pagar a sus proveedores?

Efectivo y si algunos tienen cuenta les deposito, tengo crédito a 15 días.

- ¿Cómo es el manejo con sus proveedores? ¿Ud. mismo lo hace o mediante un ayudante?

Yo mismo hago lo pedidos y consulto los precios con los proveedores.

\section{ÁREA: BANCA}

- ¿Estas apto/a para una línea de crédito?

Sí, me han venido a ofrecer crédito varias financieras.

- ¿Qué políticas de venta y pago lleva a cabo para su negocio?

Ninguna en especial.

\section{ÁREA: COMPETENCIA}

- ¿Conoce a su competencia directa?

Si son las bodegas que están en mí misma cuadra.

- ¿Por qué los clientes de su competencia acuden a ellos en vez de su tienda? Puede ser por el precio.

- ¿Cuál es tu ventaja ante la competencia, que crees que deberías mejorar? Tengo una bodega bien surtida y además un agente del BCP.

\section{ÁREA: RECURSOS HUMANOS}

- ¿Tiene personal en su tienda? ¿Cuántas personas trabajan en su negocio?

Si 3 personas que me ayudan. 
BODEGA N 2: $^{\circ}$

Buenos días/ tardes mi nombre es Abel soy estudiante de la carrera de Administración de Empresas de la UPC- Universidad Peruana de Ciencias Aplicadas y estoy realizando una investigación sobre un proyecto empresarial. Por ello, solicito su apoyo para contestar una entrevista que será de gran utilidad y relevancia para el análisis de esta investigación. Muchas gracias.

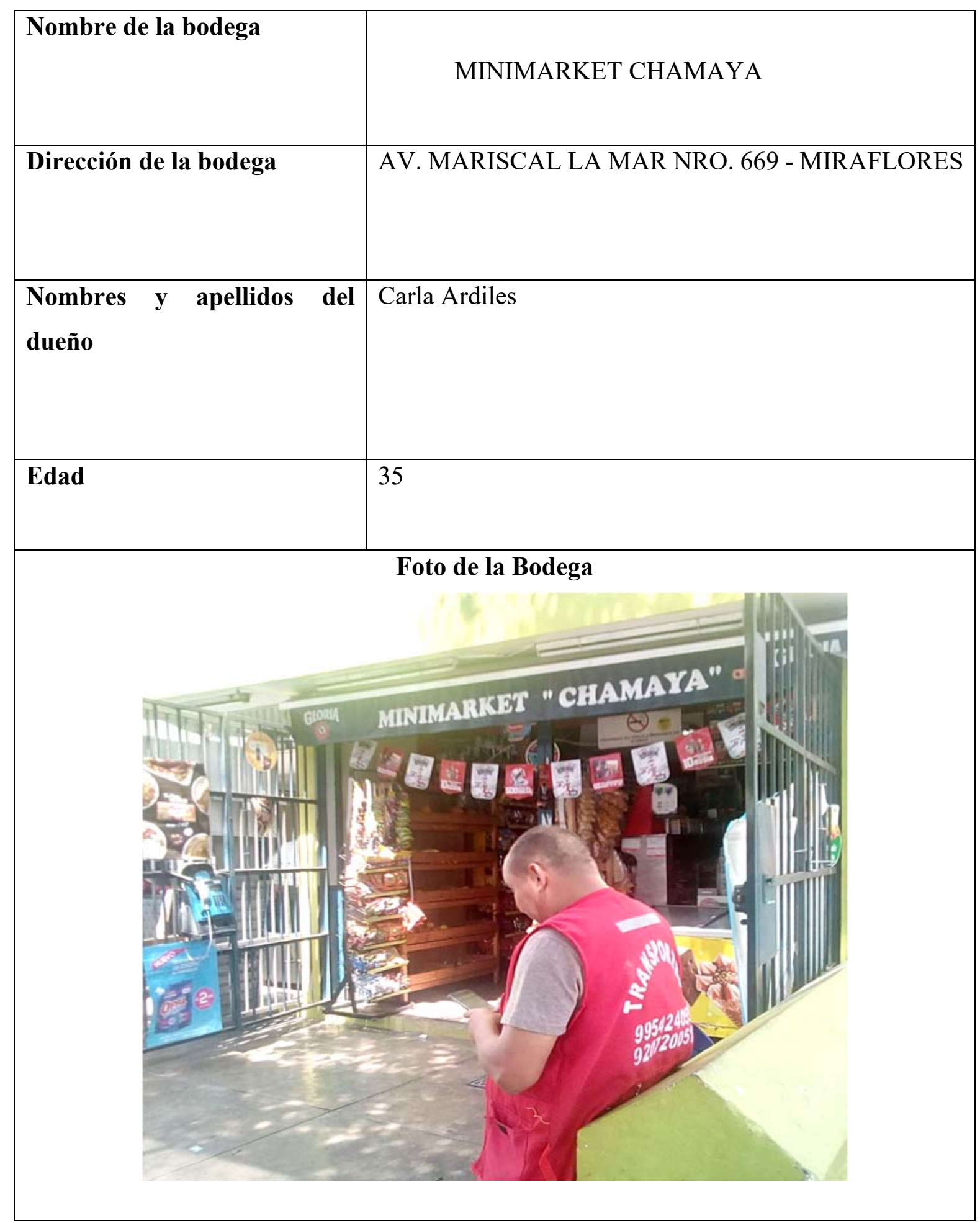




\section{CUESTIONARIO - ENTREVISTA}

\section{ÁREA: TECNOLOGÍA}

- ¿Cuándo escucha el término aplicación para celular, que es lo primero que se le viene a la mente?

Facebook, Messenger y Aliexpress.

- ¿Qué utilidad le da a su Smartphone?, ¿Qué servicios utiliza y como es su experiencia con este producto?

Para pagar recibos y comprar en internet.

- ¿Suele realizar operaciones on line?

$\mathrm{Si}$, suelo comprar en una página de fácil compra en usa.

- ¿Utiliza la tecnología en su bodega? ¿Realiza publicidad en las redes sociales? ¿Qué tipo de publicidad usa?

No hago publicidad ni uso tecnología.

- ¿Tiene conocimiento que el uso de herramientas tecnológicas puede incrementar sus ingresos? De ser así, ¿Qué opina del uso de aplicativos para celulares como una alternativa para atender otro tipo de cliente al tradicional?

Si sé que se puede vender por internet y he visto que algunas tiendas tienen aplicaciones y lo llevan a su casa.

\section{ÁREA: CLIENTES}

- ¿Dónde y quienes suelen ser sus clientes?

Las familias que viven en los departamentos de la zona y el centro empresarial que está al frente de mi bodega.

- ¿Tiene algún perfil de cliente específico? Detalle Madres y padres de familia.

- ¿Qué comentarios de la atención brindada a sus clientes, ha recibido por parte de ellos? Que tengo muy bien surtida la bodega, limpia, ordenada y en plena avenida.

- ¿Su nivel de ventas como ha sido? ¿Se ha incrementado o han caído a través de los años?

Se ha mantenido normal, ha subido ligeramente desde que comenzaron las clases.

- Regularmente, ¿En qué momentos del día tiene más pedidos o visitas de clientes? ¿Pierde ventas por clientes no atendidos? De ser así, ¿le gustaría tener las herramientas para atender a todos sus clientes (visitantes) y potenciales clientes (virtuales)?

En las mañanas y las noches óseas cuando la gente está prepara el desayuno o esta que llega a su casa. Cuando la gente está retornando del trabajo y entra un momento a hacer algunas compras.

- ¿Qué canales de distribución utiliza para la entrega de productos?, ¿Brinda el servicio de delivery como valor agregado?, ¿Cuál es su opinión sobre el servicio de delivery? $\mathrm{Si}$, llevo pedidos a los departamentos y oficinas.

\section{ÁREA: LOGÍSTICA}

- ¿Cómo maneja el tema de sus inventarios y el stock de su bodega?

Todo lo registro en un cuaderno y ahí hago seguimiento para hacer mis pedidos dos o tres veces por semana a las distribuidoras.

- ¿Tiene planes para incrementar o expandir su negocio?

Desearía abrir otra bodega por el malecón.

- ¿Encontró alguna solución para incrementar o expandir su negocio?

No 
- ¿Cuáles son las principales actividades que lleva a cabo en su negocio? ¿Qué línea de productos maneja?

Víveres y artículos de primera necesidad.

- ¿Podría detallar cual es el proceso de pedidos y entrega de productos a sus clientes?, ¿Ha pensado en otras opciones para abarcar más mercado? Detalle

Si abriendo otra tienda más en otra zona comercial.

- Respecto a los procesos de inventario ¿Cómo le gustaría que fuera el manejo de este para su negocio?

Tal vez computarizado.

- ¿Cómo realiza la reposición y exhibición de sus productos? ¿Le gustaría tener asesoría como parte de un beneficio por un servicio utilizado?

Los vendedores mayormente me visitan y preguntan si sus productos han salido y así lo reviso y si me quedan pocos los les hago el pedido.

\section{ÁREA: PROVEEDORES}

- ¿Cómo suele pagar a sus proveedores?

En efectivo semanal y quincenal, depende de la distribuidora.

- ¿Cómo es el manejo con sus proveedores? ¿Ud. mismo lo hace o mediante un ayudante?

Yo mismo trato con ellos.

\section{ÁREA: BANCA}

- ¿Estas apto/a para una línea de crédito?

Si.

- ¿Qué políticas de venta y pago lleva a cabo para su negocio?

Ninguna.

\section{ÁREA: COMPETENCIA}

- ¿Conoce a su competencia directa?

Si son las bodegas que están alrededor

- ¿Por qué los clientes de su competencia acuden a ellos en vez de su tienda?

Puede ser que por el precio y otra porque tienen agentes de BCP o Interbank.

- ¿Cuál es tu ventaja ante la competencia, que crees que deberías mejorar?

Que estoy en plena avenida y con una afluencia de público alta.

\section{ÁREA: RECURSOS HUMANOS}

- ¿Tiene personal en su tienda? ¿Cuántas personas trabajan en su negocio?

Si, 1 persona. 


\section{BODEGA N ${ }^{\circ}$ :}

Buenos días/ tardes mi nombre es Abel soy estudiante de la carrera de Administración de Empresas de la UPC- Universidad Peruana de Ciencias Aplicadas y estoy realizando una investigación sobre un proyecto empresarial. Por ello, solicito su apoyo para contestar una entrevista que será de gran utilidad y relevancia para el análisis de esta investigación. Muchas gracias.

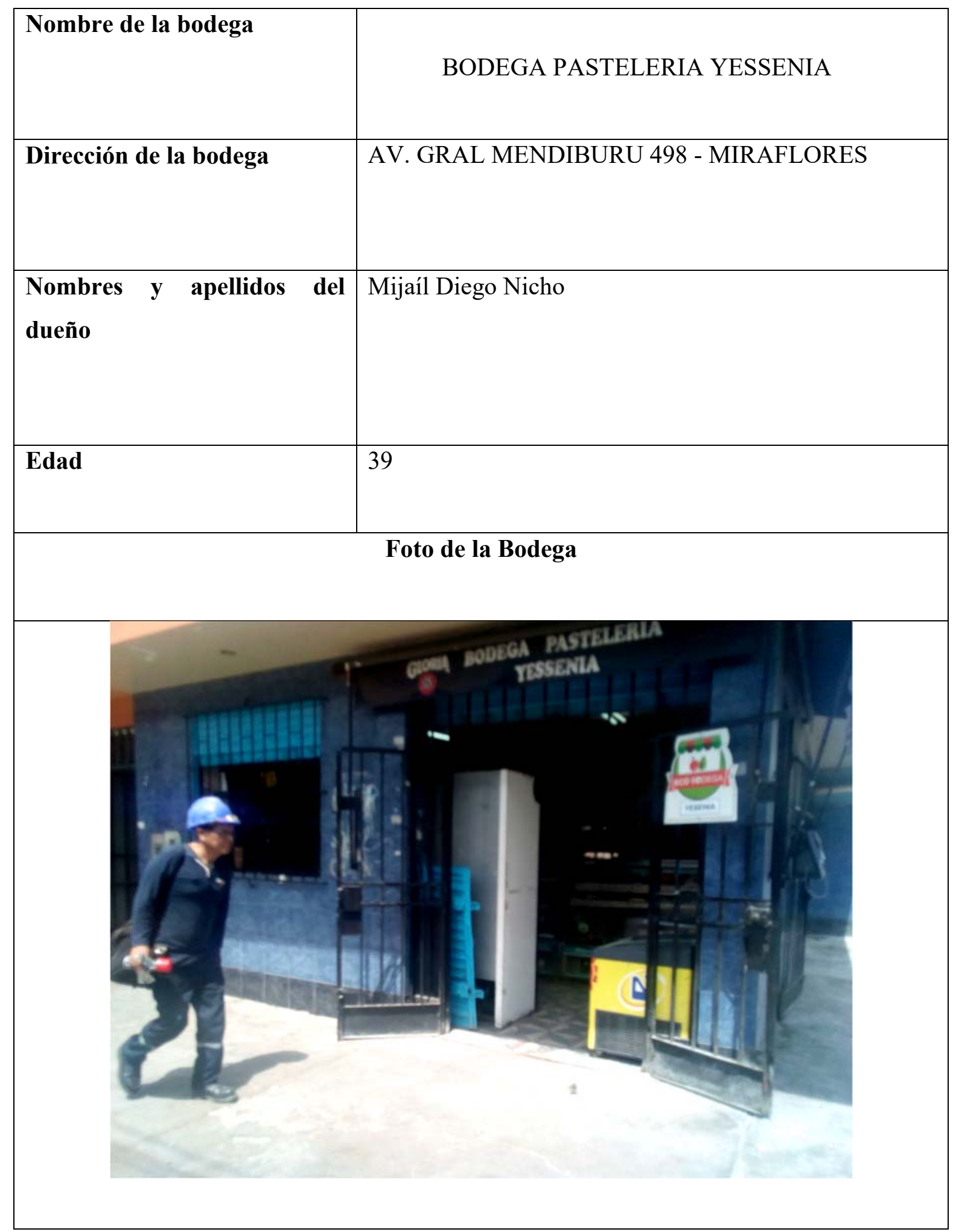




\section{CUESTIONARIO - ENTREVISTA}

\section{ÁREA: TECNOLOGÍA}

- ¿Cuándo escucha el término aplicación para celular, que es lo primero que se le viene a la mente?

Suelo asociarlo a Uber o Easy taxi que son las aplicaciones que más uso.

- ¿Qué utilidad le da a su Smartphone?, ¿Qué servicios utiliza y como es su experiencia con este producto?

La mayor utilidad es la de estar comunicados, mayormente por WhatsApp. Mas uso los servicios de taxi para ya no estar parando en la calle a cualquiera y siempre me han ido bien, no he tenido problemas.

- ¿Suele realizar operaciones on line?

No, aunque la semana pasada mis hijos me enseñaron a realizar como hacer una compra por Ali express.

- ¿Utiliza la tecnología en su bodega? ¿Realiza publicidad en las redes sociales? ¿Qué tipo de publicidad usa?

Si por tecnología te refieres al celular y la calculadora. No hago publicidad, lo vendedores se encarga de empapelarme con afiches mi tienda y los ordenas y exhiben.

- ¿Tiene conocimiento que el uso de herramientas tecnológicas puede incrementar sus ingresos? De ser así, ¿Qué opina del uso de aplicativos para celulares como una alternativa para atender otro tipo de cliente al tradicional?

No tenía conocimiento.

\section{ÁREA: CLIENTES}

- ¿Dónde y quienes suelen ser sus clientes?

Mayormente la gente los que viven en los edificios de la Av. General Córdova y las oficinas que están en la Av. La Mar.

- ¿Tiene algún perfil de cliente específico? Detalle

La mayoría son adultos, padres y madres de familia.

- ¿Qué comentarios de la atención brindada a sus clientes, ha recibido por parte de ellos? Hay de todo, desde aquellos que se quejan porque no tengo lo busco hasta los más agradecidos por la atención y rapidez.

- ¿Su nivel de ventas como ha sido? ¿Se ha incrementado o han caído a través de los años?

Los últimos meses ha bajado un poco, la gente ya no sale comprar mucho, creo que ha sido por el tema del presidente.

- Regularmente, ¿En qué momentos del día tiene más pedidos o visitas de clientes? Por la mañana plan de 6 a 9 am y por la tarde a partir de las 5 a 8 pm.

- ¿Pierde ventas por clientes no atendidos? De ser así, ¿le gustaría tener las herramientas para atender a todos sus clientes (visitantes) y potenciales clientes (virtuales)?

Algunas veces si pierdo clientes porque tengo mercadería, mayor mente en la mañana por que el pan se acaba temprano y cualquier cosa para vender más, es bien recibida.

- ¿Qué canales de distribución utiliza para la entrega de productos?, ¿Brinda el servicio de delivery como valor agregado?, ¿Cuál es su opinión sobre el servicio de delivery?

El presencial, ósea viene a mi bodega y les despacho lo que piden, algunos clientes fijos si me llaman al celular y me dictan su lista, se las preparo y las envió con hijo o sobrino que se las lleva en una bicicleta que tengo, pero solo a lugares cercanos. 


\section{ÁREA: LOGÍSTICA}

- ¿Cómo maneja el tema de sus inventarios y el stock de su bodega?

Hago los pedidos semanales, aunque los vendedores pasan 2 o 3 veces a la semana, voy viendo cuantas unidades de cada producto me quedan y hago el pedido.

- ¿Tiene planes para incrementar o expandir su negocio?

Desearía poner otra bodega más, pero necesito invertir o pedir un préstamo para eso.

- ¿Encontró alguna solución para incrementar o expandir su negocio?

Pedir préstamo a alguna caja o banco.

- ¿Cuáles son las principales actividades que lleva a cabo en su negocio? ¿Qué línea de productos maneja?

Mayor mente de consumo y panadería.

- ¿Podría detallar cual es el proceso de pedidos y entrega de productos a sus clientes?, ¿Ha pensado en otras opciones para abarcar más mercado? Detalle

El proceso es simple viene o me llama me dicen que es lo necesitan se lo doy o envió a su casa u oficinas en el caso del centro empresarial. No he pensado más opciones.

- Respecto a los procesos de inventario ¿Cómo le gustaría que fuera el manejo de este para su negocio?

Creo que el que llevo está bien.

- ¿Cómo realiza la reposición y exhibición de sus productos? ¿Le gustaría tener asesoría como parte de un beneficio por un servicio utilizado?

Mayormente quienes hacen eso o me asesoran son los vendedores o mercaderías de las distribuidoras.

\section{ÁREA: PROVEEDORES}

- ¿Cómo suele pagar a sus proveedores?

En efectivo, a algunos les pago a 15 días, dependiendo de la distribuidora.

- ¿Cómo es el manejo con sus proveedores? ¿Ud. mismo lo hace o mediante un ayudante?

Yo mismo trato y negocio con los proveedores.

\section{ÁREA: BANCA}

- ¿Estas apto/a para una línea de crédito?

En banco me piden muchas cosas, en cambio con las cajas o financieras es más fácil.

- ¿Qué políticas de venta y pago lleva a cabo para su negocio?

Tratar de que cliente este satisfecho y regrese. Para tener un negocio hay que tener mucha paciencia.

\section{ÁREA: COMPETENCIA}

- ¿Conoce a su competencia directa?

$\mathrm{Si}$, son las bodegas que están en la misma cuadra y el mercado que está en la Av. Mendiburu.

- ¿Por qué los clientes de su competencia acuden a ellos en vez de su tienda? Quizás porque en las otras bodegas tienen POS y porque la mayoría de gente de por acá no usa efectivo

- ¿Cuál es tu ventaja ante la competencia, que crees que deberías mejorar? El servicio y que bueno soy la única panadería que esta por acá.

\section{ÁREA: RECURSOS HUMANOS}

- ¿Tiene personal en su tienda? ¿Cuántas personas trabajan en su negocio? 
Yo y mi sobrino que me ayuda. 
BODEGA No 4:

Buenos días/ tardes mi nombre es Enrique y soy estudiante de la carrera de Administración de Empresas de la UPC- Universidad Peruana de Ciencias Aplicadas y estoy realizando una investigación sobre un proyecto empresarial. Por ello, solicito su apoyo para contestar una entrevista que será de gran utilidad y relevancia para el análisis de esta investigación. Muchas gracias.

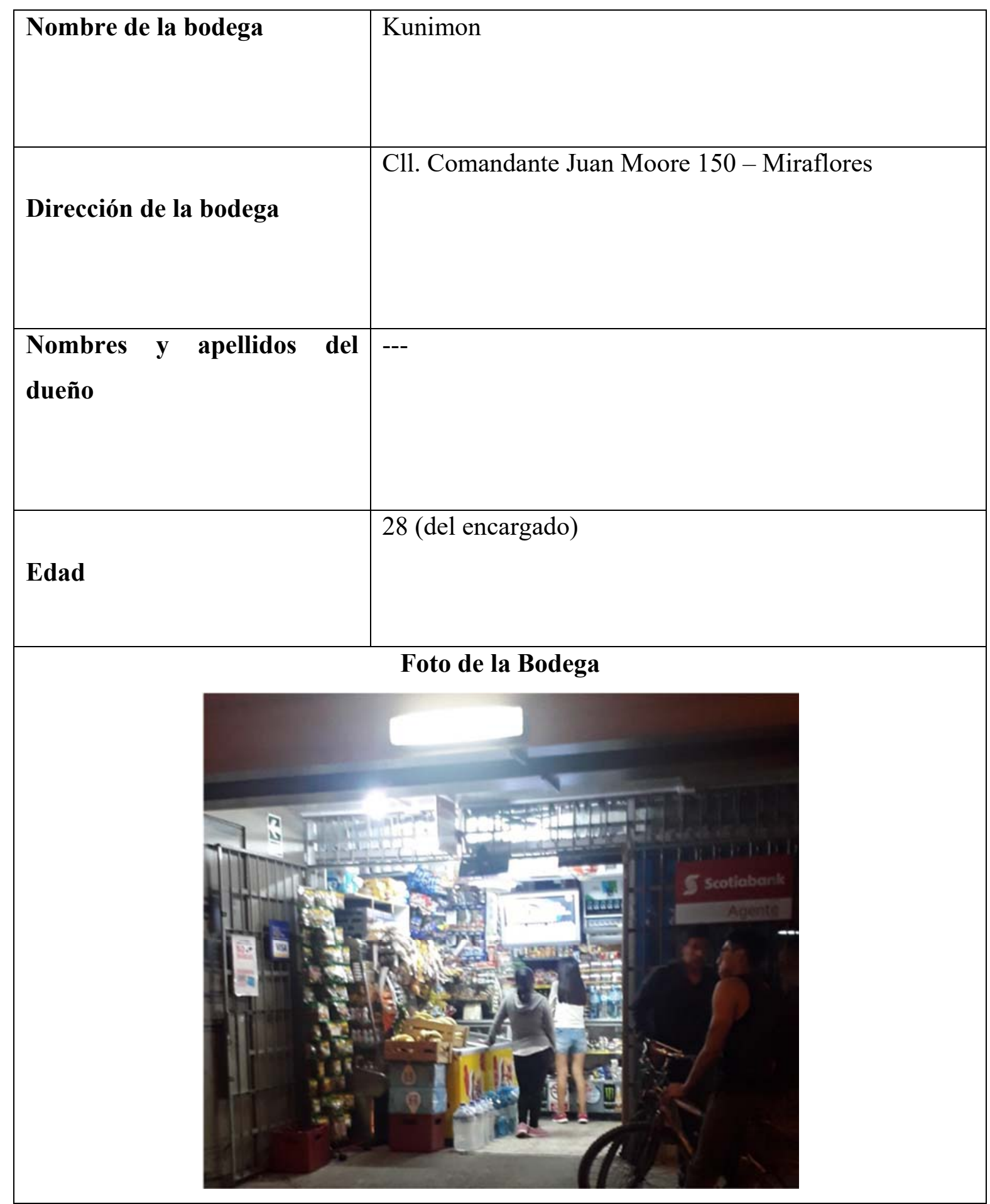




\section{CUESTIONARIO - ENTREVISTA}

\section{ÁREA: TECNOLOGÍA}

- ¿Cuándo escucha el término aplicación para celular, que es lo primero que se le viene a la mente? Internet, tecnología, etc.

- ¿Qué utilidad le da a su Smartphone?, ¿Qué servicios utiliza y como es su experiencia con este producto?

Si uso, pero poco. Llamadas más q todo.

- ¿Suele realizar operaciones on line?

$\mathrm{Si}$, compras de artículos personales.

- ¿Utiliza la tecnología en su bodega? ¿Realiza publicidad en las redes sociales? ¿Qué tipo de publicidad usa?

No, nada.

- ¿Tiene conocimiento que el uso de herramientas tecnológicas puede incrementar sus ingresos? De ser así, ¿Qué opina del uso de aplicativos para celulares como una alternativa para atender otro tipo de cliente al tradicional?

No, no nada.

\section{ÁREA: CLIENTES}

- ¿Dónde y quienes suelen ser sus clientes?

$\mathrm{Si}$, los de siempre.

- ¿Tiene algún perfil de cliente específico? Detalle

- ¿Qué comentarios de la atención brindada a sus clientes, ha recibido por parte de ellos?

- ¿Su nivel de ventas como ha sido? ¿Se ha incrementado o han caído a través de los años?

Ha incrementado.

- Regularmente, ¿En qué momentos del día tiene más pedidos o visitas de clientes? ¿Pierde ventas por clientes no atendidos? De ser así, ¿le gustaría tener las herramientas para atender a todos sus clientes (visitantes) y potenciales clientes (virtuales)?

Más vienen de noche.

- ¿Qué canales de distribución utiliza para la entrega de productos?, ¿Brinda el servicio de delivery como valor agregado?, ¿Cuál es su opinión sobre el servicio de delivery?

\section{ÁREA: LOGÍSTICA}

- ¿Cómo maneja el tema de sus inventarios y el stock de su bodega? Hay un encargado que ve esos temas.

- ¿Tiene planes para incrementar o expandir su negocio? No que yo sepa.

- ¿Encontró alguna solución para incrementar o expandir su negocio?

- ¿Cuáles son las principales actividades que lleva a cabo en su negocio? ¿Qué línea de productos maneja?

Bodega, de todo en realidad.

- ¿Podría detallar cual es el proceso de pedidos y entrega de productos a sus clientes?, ¿Ha pensado en otras opciones para abarcar más mercado? Detalle 
No está el sr que ve eso.

- Respecto a los procesos de inventario ¿Cómo le gustaría que fuera el manejo de este para su negocio?

- ¿Cómo realiza la reposición y exhibición de sus productos? ¿Le gustaría tener asesoría como parte de un beneficio por un servicio utilizado?

Sería bueno...

\section{ÁREA: PROVEEDORES}

- ¿Cómo suele pagar a sus proveedores?

En efectivo, o depósito a cuenta bancaria, depende del proveedor.

- ¿Cómo es el manejo con sus proveedores? ¿Ud. mismo lo hace o mediante un ayudante?

\section{ÁREA: BANCA}

- ¿Estas apto/a para una línea de crédito?

No han solicitado.

- ¿Qué políticas de venta y pago lleva a cabo para su negocio?

\section{ÁREA: COMPETENCIA}

- ¿Conoce a su competencia directa? Mi vecino...

- ¿Por qué los clientes de su competencia acuden a ellos en vez de su tienda? Por el espacio, quizá la atención...

- ¿Cuál es tu ventaja ante la competencia, que crees que deberías mejorar? Los precios más que todo...

\section{ÁREA: RECURSOS HUMANOS}

- ¿Tiene personal en su tienda? ¿Cuántas personas trabajan en su negocio? 4 con el dueño... 


\section{BODEGA N 5:}

Buenos días/ tardes mi nombre es Enrique y estudiante de la carrera de Administración de Empresas de la UPC- Universidad Peruana de Ciencias Aplicadas y estoy realizando una investigación sobre un proyecto empresarial. Por ello, solicito su apoyo para contestar una entrevista que será de gran utilidad y relevancia para el análisis de esta investigación. Muchas gracias.

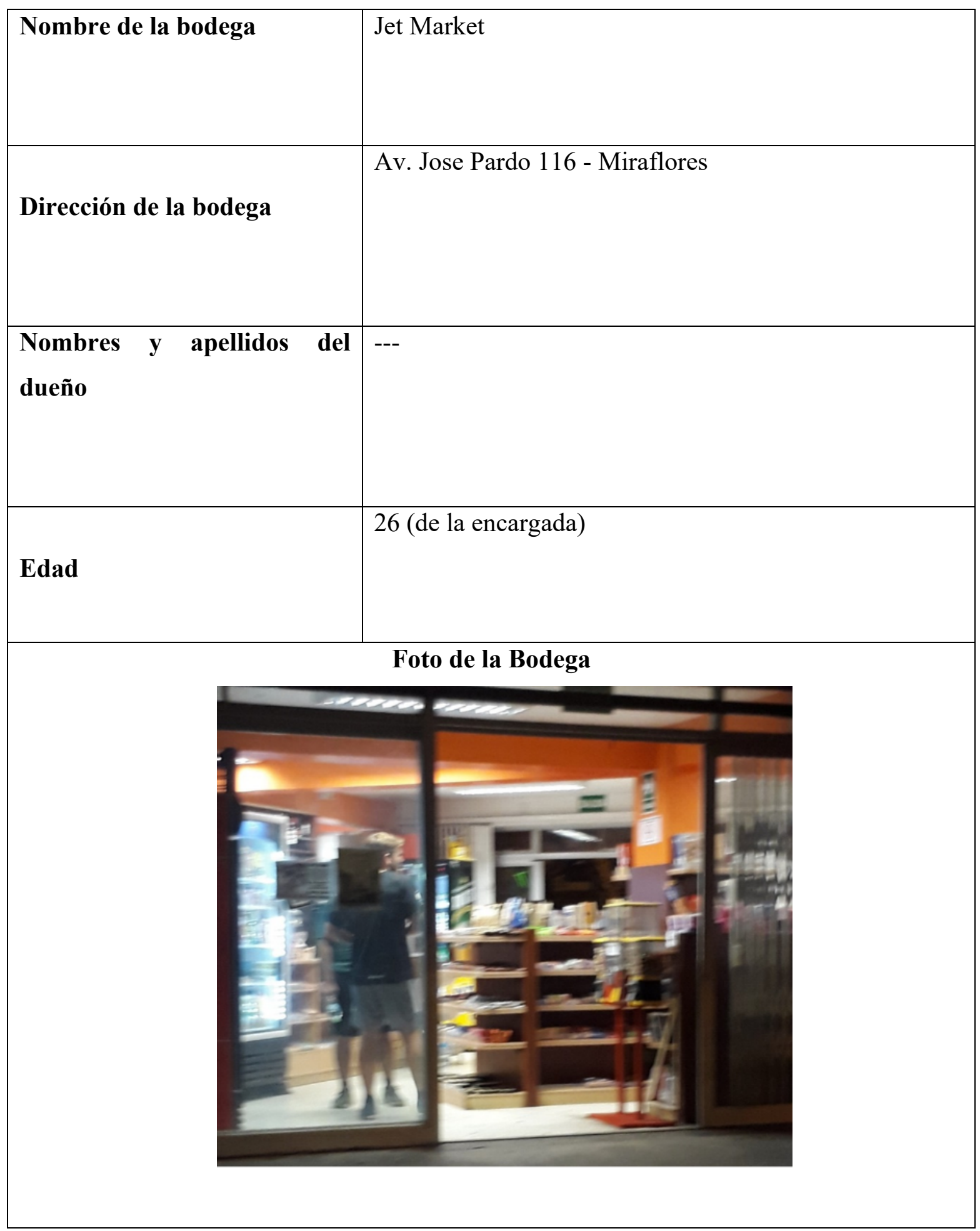




\section{CUESTIONARIO - ENTREVISTA}

\section{ÁREA: TECNOLOGÍA}

- ¿Cuándo escucha el término aplicación para celular, que es lo primero que se le viene a la mente?

Compras en línea, etc

- ¿Qué utilidad le da a su Smartphone?, ¿Qué servicios utiliza y como es su experiencia con este producto?

Bien, temas personales, aplicaciones...

- ¿Suele realizar operaciones on line?

Para temas personales sí, no de la tienda.

- ¿Utiliza la tecnología en su bodega? ¿Realiza publicidad en las redes sociales? ¿Qué tipo de publicidad usa?

No, para nada aún.

- ¿Tiene conocimiento que el uso de herramientas tecnológicas puede incrementar sus ingresos? De ser así, ¿Qué opina del uso de aplicativos para celulares como una alternativa para atender otro tipo de cliente al tradicional?

Sí, pero es inversión y el dueño aun no lo hace.

\section{ÁREA: CLIENTES}

- ¿Dónde y quienes suelen ser sus clientes?

Los vecinos y aquellos que pasan y nos ven

- ¿Tiene algún perfil de cliente específico? Detalle

Son turistas e inquilinos de los edificios aledaños.

- ¿Qué comentarios de la atención brindada a sus clientes, ha recibido por parte de ellos?

Tenemos un buzón de sugerencia y hemos recibido algunas quejas, pero en general todo bien.

- ¿Su nivel de ventas como ha sido? ¿Se ha incrementado o han caído a través de los años?

Ha aumentado.

- Regularmente, ¿En qué momentos del día tiene más pedidos o visitas de clientes? ¿Pierde ventas por clientes no atendidos? De ser así, ¿le gustaría tener las herramientas para atender a todos sus clientes (visitantes) y potenciales clientes (virtuales)?

De noche hay más movimiento. Los clientes esperan su turno para ser atendidos.

- ¿Qué canales de distribución utiliza para la entrega de productos?, ¿Brinda el servicio de delivery como valor agregado?, ¿Cuál es su opinión sobre el servicio de delivery? No tengo delivery. Es bien útil.

\section{ÁREA: LOGÍSTICA}

- ¿Cómo maneja el tema de sus inventarios y el stock de su bodega?

El dueño se encarga de eso

- ¿Tiene planes para incrementar o expandir su negocio?

Aun no

- ¿Encontró alguna solución para incrementar o expandir su negocio?

- ¿Cuáles son las principales actividades que lleva a cabo en su negocio? ¿Qué línea de productos maneja?

Bebidas, golosinas, tragos, etc. 
- ¿Podría detallar cual es el proceso de pedidos y entrega de productos a sus clientes?, ¿Ha pensado en otras opciones para abarcar más mercado? Detalle

No se encuentra el dueño, él ve eso.

- Respecto a los procesos de inventario ¿Cómo le gustaría que fuera el manejo de este para su negocio?

Mejor del actual, a veces faltan cosas y demoran en llegar los pedidos.

- ¿Cómo realiza la reposición y exhibición de sus productos? ¿Le gustaría tener asesoría como parte de un beneficio por un servicio utilizado?

Claro que sí.

\section{ÁREA: PROVEEDORES}

- ¿Cómo suele pagar a sus proveedores?

Pago a cuenta bancaria normalmente.

- ¿Cómo es el manejo con sus proveedores? ¿Ud. mismo lo hace o mediante un ayudante?

El dueño se encarga de los pagos y pedidos con los proveedores.

\section{ÁREA: BANCA}

- ¿Estas apto/a para una línea de crédito?

No han solicitado al momento.

- ¿Qué políticas de venta y pago lleva a cabo para su negocio?

No las conozco.

\section{ÁREA: COMPETENCIA}

- ¿Conoce a su competencia directa?

Las bodegas cercanas y supermercados.

- ¿Por qué los clientes de su competencia acuden a ellos en vez de su tienda? Pienso que, por los precios, quizá.

- ¿Cuál es tu ventaja ante la competencia, que crees que deberías mejorar? Pienso q renovar el local y la exposición de los productos.

\section{ÁREA: RECURSOS HUMANOS}

- ¿Tiene personal en su tienda? ¿Cuántas personas trabajan en su negocio? Somos 3 . 
BODEGA No 6:

Buenos días/ tardes mi nombre es Enrique y estudiante de la carrera de Administración de Empresas de la UPC- Universidad Peruana de Ciencias Aplicadas y estoy realizando una investigación sobre un proyecto empresarial. Por ello, solicito su apoyo para contestar una entrevista que será de gran utilidad y relevancia para el análisis de esta investigación. Muchas gracias.

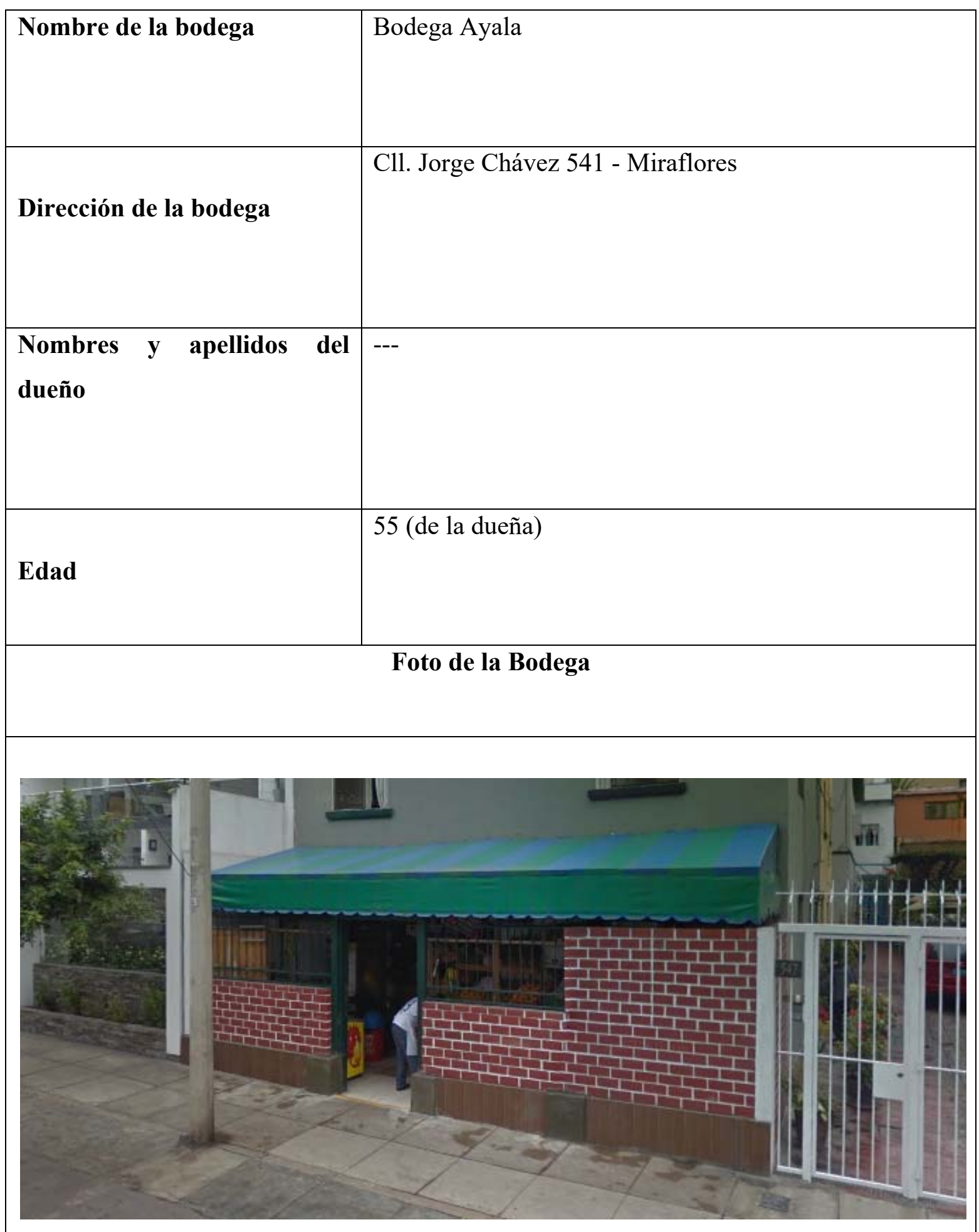




\section{CUESTIONARIO - ENTREVISTA}

\section{ÁREA: TECNOLOGÍA}

- ¿Cuándo escucha el término aplicación para celular, que es lo primero que se le viene a la mente?

Facebook, aplicación de bancos.

- ¿Qué utilidad le da a su Smartphone?, ¿Qué servicios utiliza y como es su experiencia con este producto?

Llamadas, juegos, aplicaciones...

- ¿Suele realizar operaciones online?

No, nunca

- ¿Utiliza la tecnología en su bodega? ¿Realiza publicidad en las redes sociales? ¿Qué tipo de publicidad usa?

No, para nada.

- ¿Tiene conocimiento que el uso de herramientas tecnológicas puede incrementar sus ingresos? De ser así, ¿Qué opina del uso de aplicativos para celulares como una alternativa para atender otro tipo de cliente al tradicional?

Si quizá

\section{ÁREA: CLIENTES}

- ¿Quiénes suelen ser sus clientes?

Los vecinos habituales y aquellos que circulan cerca.

- ¿Tiene algún perfil de cliente específico? Detalle Mayores más que todo.

- ¿Qué comentarios de la atención brindada a sus clientes, ha recibido por parte de ellos? Todo bien

- ¿Su nivel de ventas como ha sido? ¿Se ha incrementado o han caído a través de los años?

Al cambiar la exposición de los productos se incrementó la venta.

- Regularmente, ¿En qué momentos del día tiene más pedidos o visitas de clientes? ¿Pierde ventas por clientes no atendidos? De ser así, ¿le gustaría tener las herramientas para atender a todos sus clientes (visitantes) y potenciales clientes (virtuales)?

Tarde y noche hay más movimiento.

- ¿Qué canales de distribución utiliza para la entrega de productos?, ¿Brinda el servicio de delivery como valor agregado?, ¿Cuál es su opinión sobre el servicio de delivery? Actualmente no uso delivery, pero lo he pensado.

\section{ÁREA: LOGÍSTICA}

- ¿Cómo maneja el tema de sus inventarios y el stock de su bodega?

Nos encargamos con mi esposo

- ¿Tiene planes para incrementar o expandir su negocio?

No por el momento

- ¿Encontró alguna solución para incrementar o expandir su negocio?

- ¿Cuáles son las principales actividades que lleva a cabo en su negocio? ¿Qué línea de productos maneja?

Verduras, golosinas, bebidas, helados, etc. 
- ¿Podría detallar cual es el proceso de pedidos y entrega de productos a sus clientes?, ¿Ha pensado en otras opciones para abarcar más mercado? Detalle

Viene el proveedor con su lista y elegimos los productos q más nos sale

- Respecto a los procesos de inventario ¿Cómo le gustaría que fuera el manejo de este para su negocio?

Algunos proveedores nos ayudan en eso sino nosotros mismos

- ¿Cómo realiza la reposición y exhibición de sus productos? ¿Le gustaría tener asesoría como parte de un beneficio por un servicio utilizado?

Vamos viendo que productos salen más y que tienen más rotación

\section{ÁREA: PROVEEDORES}

- ¿Cómo suele pagar a sus proveedores?

Cuenta bancaria normalmente o también en efectivo si el proveedor viene seguido.

- ¿Cómo es el manejo con sus proveedores? ¿Ud. mismo lo hace o mediante un ayudante?

Nos encargamos nosotros mismos o a quien le toque.

\section{ÁREA: BANCA}

- ¿Estas apto/a para una línea de crédito?

Sí, pero ya estoy saliendo de un préstamo, quizá pida otro más adelante

- ¿Qué políticas de venta y pago lleva a cabo para su negocio?

No tenemos por el momento

\section{ÁREA: COMPETENCIA}

- ¿Conoce a su competencia directa?

Hay poca competencia como bodegas, pero si mucho supermercado.

- ¿Por qué los clientes de su competencia acuden a ellos en vez de su tienda?

Tal vez por la distancia q les queda o los stocks

- ¿Cuál es tu ventaja ante la competencia, que crees que deberías mejorar?

Muchas cosas, como el local y las vitrinas, pero es inversión, por el momento no

\section{ÁREA: RECURSOS HUMANOS}

- ¿Tiene personal en su tienda? ¿Cuántas personas trabajan en su negocio?

Somos 3. Y rotamos 
BODEGA No 7:

Buenas tardes mi nombre es Karina Orosco Calero y soy estudiante de la carrera de Administración de Empresas de la UPC- Universidad Peruana de Ciencias Aplicadas y estoy realizando una investigación sobre un proyecto empresarial. Por ello, solicito su apoyo para contestar una entrevista que será de gran utilidad y relevancia para el análisis de esta investigación. Muchas gracias.

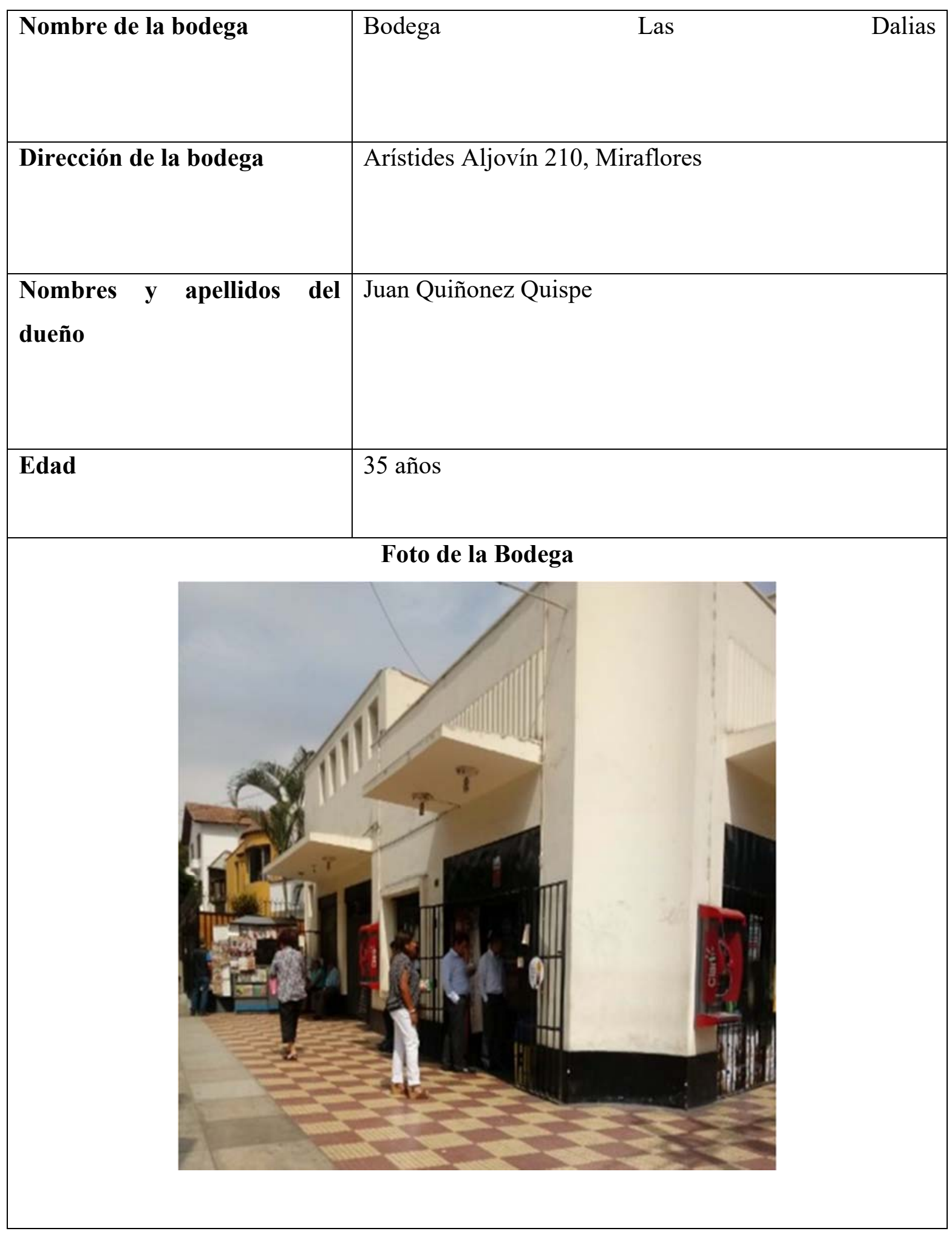




\section{CUESTIONARIO - ENTREVISTA}

\section{ÁREA: TECNOLOGÍA}

- ¿Cuándo escucha el término aplicación para celular, que es lo primero que se le viene a la mente?

- Lo primero que pienso es en que servicios ofrece la aplicación, cuanto de espacio utiliza en el celular y si tiene algún tipo de costo el mantenerlo en mi equipo. En mi caso utilizo aplicaciones de entretenimiento como WhatsApp, Facebook, Waze, entre otros.

- ¿Qué utilidad le da a su Smartphone?, ¿Qué servicios utiliza y como es su experiencia con este producto?

- Con mi equipo puedo acceder al internet, llamadas, etc. Como te estaba comentado, utilizo el WhatsApp y Facebook con mayor frecuencia y un aplicativo de banco Continental que es en donde tengo una cuenta. En mi caso, el tránsito de equipos ha sido normal. No he tenido inconveniente, además que el servidor que uso me ofrece cambio de equipos cada vez que está por terminar mi plan.

- ¿Suele realizar operaciones on line?

- Al principio no lo hacía y siempre tenía que acercarme al banco y perder tiempo haciendo colas para los pagos, pero con la publicidad del propio banco para el uso de su aplicativo, me animé y vengo usándolo hace casi 11 meses. Ahora veo mis cuentas, pago los celulares que tengo a mi nombre y los servicios.

- ¿Utiliza la tecnología en su bodega? ¿Realiza publicidad en las redes sociales? ¿Qué tipo de publicidad usa?

- Por el momento no uso dispositivos de cobro tipo POS, solo en efectivo y para ser honesto no tengo cuenta de Facebook para mi bodega, solo una cuenta personal. Sin embargo, no hago publicidad de mi bodega por internet. Me parece que es costoso.

- ¿Tiene conocimiento que el uso de herramientas tecnológicas puede incrementar sus ingresos? De ser así, ¿Qué opina del uso de aplicativos para celulares como una alternativa para atender otro tipo de cliente al tradicional?

- La verdad no he escuchado de esos términos para generar más ingresos a mi negocio. Sería interesante conocer a detalle que me puede ofrecer el uso de aplicativos y captar más clientes.

\section{ÁREA: CLIENTES}

- ¿Dónde y quienes suelen ser sus clientes?

- En la mayoría, mis clientes son vecinos y personas que trabajan en oficinas de los edificios alrededor. Esto, debido a que la zona en donde me encuentro está cerca de Larcomar y el Hotel Marriot en Miraflores.

- ¿Tiene algún perfil de cliente específico? Detalle

- En mi caso no tengo un cliente específico, sino que trato de atender a la gran mayoría de personas que viene a mi bodega a consumir. 
- ¿Qué comentarios de la atención brindada a sus clientes, ha recibido por parte de ellos?

- Regularmente, cuento con clientes que siempre me compran y me comentan la variedad de productos que ofrezco, incluyendo productos light o naturales como galletas de maca, avena, ajonjolí, yogurt griego, etc.

- ¿Su nivel de ventas como ha sido? ¿Se ha incrementado o han caído a través de los años?

- Al inicio, las ventas eran bajas. Asumo que esto sería porque los clientes no me conocían y no ofrecía productos naturales o de dieta. Cuando observe que muchos jóvenes de oficinas venían a pedir productos más sanos y les decía que no tenía, se iban sin comprar. Así que busqué un proveedor de snacks y demás productos más sanos. Los demás productos regulares siguen vendiéndose, pero ahora mi punto de fuerza es la venta de productos más naturales. Asumo que las chicas de oficina cuidan su figura al igual que los varones.

- Regularmente, ¿En qué momentos del día tiene más pedidos o visitas de clientes? ¿Pierde ventas por clientes no atendidos? De ser así, ¿le gustaría tener las herramientas para atender a todos sus clientes (visitantes) y potenciales clientes (virtuales)?

- Regularmente, mis clientes aumentan a la hora de almuerzo entre 12:30 a 3:30 pm y a partir de las 6:30 pm. Este último es a la hora de salida de las personas que trabajan en oficinas. Asimismo, en fechas festivas, recurren a mi bodega para la compra de snacks, bebidas, etc. para sus reuniones.

- En los horarios que mencioné, me apoya mi esposa. Sin embargo, si me gustaría tener más ayuda, pero que eso no me genere costos.

- ¿Qué canales de distribución utiliza para la entrega de productos?, ¿Brinda el servicio de delivery como valor agregado?, ¿Cuál es su opinión sobre el servicio de delivery?

- Por lo general, son los mismos clientes que vienen a comprar y llevan sus pedidos. Sin embargo, a los clientes que ya conozco, les he brindado mi número de celular para que me hagan sus pedidos por teléfono, yo lo preparo y ellos vienen a recoger. No brindo delivery por el momento.

- No cuento con moto para hacer repartición de pedidos por delivery.

\section{ÁREA: LOGÍSTICA}

- ¿Cómo maneja el tema de sus inventarios y el stock de su bodega?

- Llevo un inventario manual (cuaderno) de mis productos para estar seguro de no quedarme sin mercadería y de vender según fecha de caducidad, mi esposa me ayuda con este tema. Ella está atenta a ese detalle.

- ¿Tiene planes para incrementar o expandir su negocio? 
- Por el momento, no cuento con capital para alquiler otro espacio en donde abrir otra bodega. El alquiler del espacio es un poco caro, pero si me da para generar ingresos. Sin embargo, si me gustaría tener más tiendas.

- ¿Encontró alguna solución para incrementar o expandir su negocio?

- Algunos familiares me comentaron utilizar POS para hacer cobros con tarjeta de crédito, pero aún no estoy seguro del tema. Prefiero el efectivo que es más líquido, tendría que informarme más al respecto.

- ¿Cuáles son las principales actividades que lleva a cabo en su negocio? ¿Qué línea de productos maneja?

- En general, adquiero productos de proveedores o distribuidores, los clasifico por sección, saco los porcentajes de ganancia y los ofrezco a mis clientes. Manejo todo lo relacionado a abarrotes (no verduras, ni frutas) sino alimentos embolsados, alimentos naturales, etc.

- ¿Podría detallar cual es el proceso de pedidos y entrega de productos a sus clientes?, ¿Ha pensado en otras opciones para abarcar más mercado? Detalle

- Como comenté, los clientes vienen a la tienda y comprar lo que necesitan y yo entrego una vez que cancelan, solo en algunos casos con mis clientes conocidos me piden por celular sus pedidos y luego vienen a recoger. Si me gustaría tener más clientes, pero no se me ocurre que otra forma podría atenderlos.

- Respecto a los procesos de inventario ¿Cómo le gustaría que fuera el manejo del mismo para su negocio?

- Me gustaría que fuera más rápida que solo manual o con registro en cuadernos. Quizás, podría usar más una laptop y tener información de mis productos en un archivo Excel.

- ¿Cómo realiza la reposición y exhibición de sus productos? ¿Le gustaría tener asesoría como parte de un beneficio por un servicio utilizado?

- Muchos de mis proveedores, se ofrecen a poner decoración de sus productos o me entregan ciertos paneles para colocar sus productos y así se vean mejor. Esta ayuda la recibo cuando compro cierto monto en mercadería de un proveedor.

\section{ÁREA: PROVEEDORES}

- ¿Cómo suele pagar a sus proveedores?

- A los proveedores pequeños es en efectivo y a los más grandes o medianos con crédito de 15 o 30 días.

- ¿Cómo es el manejo con sus proveedores? ¿Ud. mismo lo hace o mediante un ayudante?

- Mi esposa y yo tratamos con los proveedores, directamente. Sin embargo, los proveedores grandes tienen su vendedor o sectorista.

ÁREA: BANCA 
- ¿Estas apto/a para una línea de crédito?

- Si estoy apto, cumplo con los pagos regulares. Esto, a que en Miraflores los reglamentos son estrictos y claros para el comercio.

- ¿Qué políticas de venta y pago lleva a cabo para su negocio?

- En mi caso, todo tipo de venta es en efectivo. Esto incluyendo a mis clientes conocidos. Yo no fio.

\section{ÁREA: COMPETENCIA}

- ¿Conoce a su competencia directa?

- Si, son las tiendas que están alrededor y que son mi competencia directa, pero trato de siempre tener productos surtidos para atender a mis clientes. De cuando en cuando mi esposa va a comprar a algunas tiendas para ver si tienen otros productos que nosotros no.

- ¿Por qué los clientes de su competencia acuden a ellos en vez de su tienda?

- En la gran mayoría es por la distancia, asumo. Esto, debido a que ofrecemos productos parecidos.

- ¿Cuál es tu ventaja ante la competencia, que crees que deberías mejorar?

- En mi caso trato de ofrecer más productos light que es lo que las personas de oficina buscan. Podría mejorar mi publicidad para hacerme más conocido.

\section{ÁREA: RECURSOS HUMANOS}

- ¿Tiene personal en su tienda? ¿Cuántas personas trabajan en su negocio?

- En mi negocio, solo trabajamos mi esposa y yo. No cuento con otra persona de apoyo. 
BODEGA No 8:

Buenas tardes mi nombre es Karina Orosco Calero y soy estudiante de la carrera de Administración de Empresas de la UPC- Universidad Peruana de Ciencias Aplicadas y estoy realizando una investigación sobre un proyecto empresarial. Por ello, solicito su apoyo para contestar una entrevista que será de gran utilidad y relevancia para el análisis de esta investigación. Muchas gracias.

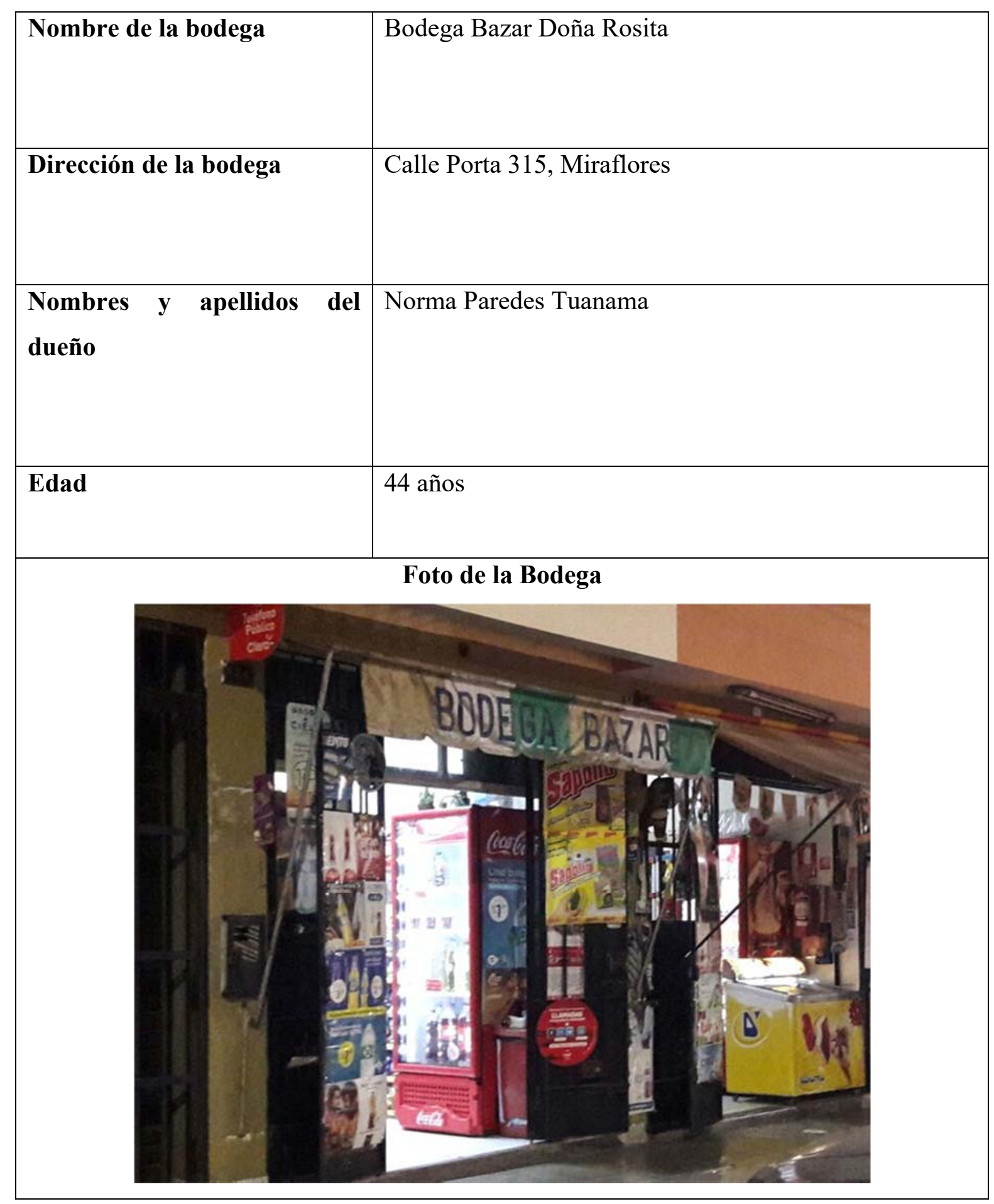




\section{CUESTIONARIO - ENTREVISTA}

\section{ÁREA: TECNOLOGÍA}

- ¿Cuándo escucha el término aplicación para celular, que es lo primero que se le viene a la mente?

Que me ofrece esta aplicación y a que juegos o entretenimiento, tengo acceso.

- ¿Qué utilidad le da a su Smartphone?, ¿Qué servicios utiliza y como es su experiencia con este producto?

En mi caso, utilizo el celular para llamadas y contacto con mis hijos. Utilizo el WhatsApp para conversar con mis hijos, amigas, etc., y el Facebook para distraerme.

- ¿Suele realizar operaciones on line?

Por el momento no realizo operaciones en internet, me da un poco de miedo que me puedan estafar o brindar información que luego puedan utilizar para robarme.

- ¿Utiliza la tecnología en su bodega? ¿Realiza publicidad en las redes sociales? ¿Qué tipo de publicidad usa?

Por el momento no utilizo tecnología para mis ventas, tampoco hago publicidad de mi tienda por Facebook por seguridad. La única publicidad que hago es en mi propia tienda, mediante afiches o banners.

- ¿Tiene conocimiento que el uso de herramientas tecnológicas puede incrementar sus ingresos? De ser así, ¿Qué opina del uso de aplicativos para celulares como una alternativa para atender otro tipo de cliente al tradicional?

No sabía que podría tener más ingresos usando tecnología, es más no había escuchado sobre ello. El usar aplicativos para el celular para incrementar mis clientes, me llama la atención, pero supongo tendrá un costo y no sé si podría pagarlo.

\section{ÁREA: CLIENTES}

- ¿Dónde y quienes suelen ser sus clientes?

Mis clientes suelen ser vecinos de la zona, las chicas que apoyan en casa de los vecinos o personas que trabajan en oficinas (asumo son de oficinas porque siempre vienen con vestimenta formal). Todos mis clientes están en Miraflores.

- ¿Tiene algún perfil de cliente específico? Detalle

No cuento con un tipo de cliente especial o definido, sino que trato de atender a toda persona que viene a comprar a mi tienda.

- ¿Qué comentarios de la atención brindada a sus clientes, ha recibido por parte de ellos?

Bueno, en el caso de mis clientes conocidos, siempre me dicen que mi manera de atenderlos con cariño. Yo soy de Iquitos y siempre les hablo con palabras alegres como ¿que busca buen caballero o jovencito? para los varones y en el caso de las damas. ¿en que la puedo atenderle señorita o cariñito? Ellos se ríen y me llaman "seño Normita".

- ¿Su nivel de ventas como ha sido? ¿Se ha incrementado o han caído a través de los años?

Bueno, como todo negocio al inicio tenía poca clientela y a manera de conseguir más, mi mamá quien fue la que inició la bodega, los atendía con palabras cariñosas. Yo 
aprendí que a los clientes les gusta que los trates bien e incluso si alguno es serio, cuando les digo esas frases que aprendí de mi mamá, los clientes se ríen y se rompe la barrera. Esto me ha permitido tener más clientes e ingresos.

- Regularmente, ¿En qué momentos del día tiene más pedidos o visitas de clientes? ¿Pierde ventas por clientes no atendidos? De ser así, ¿le gustaría tener las herramientas para atender a todos sus clientes (visitantes) y potenciales clientes (virtuales)?

En mi caso, los clientes vienen en las mañanas entre 6:30 y $7.30 \mathrm{am}, 1: 00$ y 3:00 pm y por las noches entre 5:30 y 8:00 pm. Cuando estoy sola atendiendo, si veo que algunos clientes se van porque no quieren esperar, pero cuando mis hijos me apoyan si tratamos de atender a todos. Sí, me gustaría tener más apoyos para aumentar mi número de clientes.

- ¿Qué canales de distribución utiliza para la entrega de productos?, ¿Brinda el servicio de delivery como valor agregado?, ¿Cuál es su opinión sobre el servicio de delivery?

Las entregas son en mí mismo local, no brindo servicio de delivery, debido a que no cuento con personal. Asumo este tipo de servicio serían para empresas más grandes o mini markets, mi bodega aun es pequeña.

\section{ÁREA: LOGÍSTICA}

- ¿Cómo maneja el tema de sus inventarios y el stock de su bodega?

Mis hijos me apoyan en tener un inventario en casa en su archivo Excel, pero yo controlo mi inventario con un cuaderno en la misma tienda. Siempre estoy verificando que no me falte productos y reviso las fechas de vencimiento para hacer rotar la misma y no perder productos para vender porque están vencidas. Los clientes se fijan ahora en las fechas de vencimiento.

- ¿Tiene planes para incrementar o expandir su negocio?

Si me gustaría ampliar mi bodega para ofrecer más productos y tener un espacio adecuado. Sin embargo, eso demanda dinero y no estoy tan segura de pedir préstamo a los bancos. Tendría que evaluarlo.

- ¿Encontró alguna solución para incrementar o expandir su negocio?

Por el momento no, pero mis hijos me apoyan en querer crecer y generar más ingresos para mi tienda. Estos ingresos sirven para solventar los estudios de mis hijos (uno en el colegio y uno que se está preparando para la universidad)

- ¿Cuáles son las principales actividades que lleva a cabo en su negocio? ¿Qué línea de productos maneja?

Hago mi chequeo de stock para estar segura de que tengo todo para vender, contacto a los vendedores para hacer mis pedidos, clasifico mis productos, los acomodo para la venta, calculo los incrementos de precios que requiero para obtener ganancias, etc. Manejo todo en general que se puede vender en una tienda que no sea productos perecibles. Yo no vendo verduras o frutas porque se malogran y no tiene tanta rotación.

- ¿Podría detallar cual es el proceso de pedidos y entrega de productos a sus clientes?, ¿Ha pensado en otras opciones para abarcar más mercado? Detalle 
Mis clientes vienen directamente a mi tienda piden y compran los productos que requieren. Yo les entrego de manera inmediata sus pedidos. Por el momento, no he pensado en otras opciones de atraer más cliente que el regular que uso.

- Respecto a los procesos de inventario ¿Cómo le gustaría que fuera el manejo de este para su negocio?

Mis hijos me comentaron que ahora existen programas que te ayudan a tener todo el inventario de manera virtual e inclusive uno solo pone el código del producto y el sistema lo busca para darte el número exacto de productos que uno tiene, pero asumo estos sistemas costarán mucho dinero.

- ¿Cómo realiza la reposición y exhibición de sus productos? ¿Le gustaría tener asesoría como parte de un beneficio por un servicio utilizado?

En mi caso, soy yo directamente que ordeno los productos a manera de atraer a mis clientes. Más o menos coloco de manera estratégica los productos que sé que mis clientes pueden comprar a último momento y aumentar sus compras.

\section{ÁREA: PROVEEDORES}

- ¿Cómo suele pagar a sus proveedores?

En general les pago a mis proveedores de manera quincenal y mensual.

- ¿Cómo es el manejo con sus proveedores? ¿Ud. mismo lo hace o mediante un ayudante?

En mi caso, soy yo la que hace los contactos y demás coordinaciones con los proveedores para las compras de mercadería. No tengo ayudantes.

\section{ÁREA: BANCA}

- ¿Estas apto/a para una línea de crédito?

Si me encuentro apta, pero por el momento prefiero no endeudarme para cuidar los ingresos que pagan los estudios de mis hijos.

- ¿Qué políticas de venta y pago lleva a cabo para su negocio?

Siempre mis ventas son en efectivo, prefiero hacerlo de esa manera para tener el dinero de manera más directa.

\section{ÁREA: COMPETENCIA}

- ¿Conoce a su competencia directa?

Tengo mucha competencia directa, debido a que hay tres bodegas juntas y las tres ofrecemos productos similares.

- ¿Por qué los clientes de su competencia acuden a ellos en vez de su tienda? He visto que uno de mis competidores es gente Interbank y asumo sus clientes podrán pagar con tarjeta de crédito. En cambio, yo solo cobro en efectivo.

- ¿Cuál es tu ventaja ante la competencia, que crees que deberías mejorar?

Considero que la atención personalizada que les doy a mis clientes, productos variados y la atención especial que les doy. Esto hace que pesar que solo cobro en efectivo, vienen a mi tienda y no me va mal.

\section{ÁREA: RECURSOS HUMANOS}


- ¿Tiene personal en su tienda? ¿Cuántas personas trabajan en su negocio? No cuento con personal de apoyo, en general trabajo sola. Sin embargo, mis hijos me apoyan en sus ratos libres. 


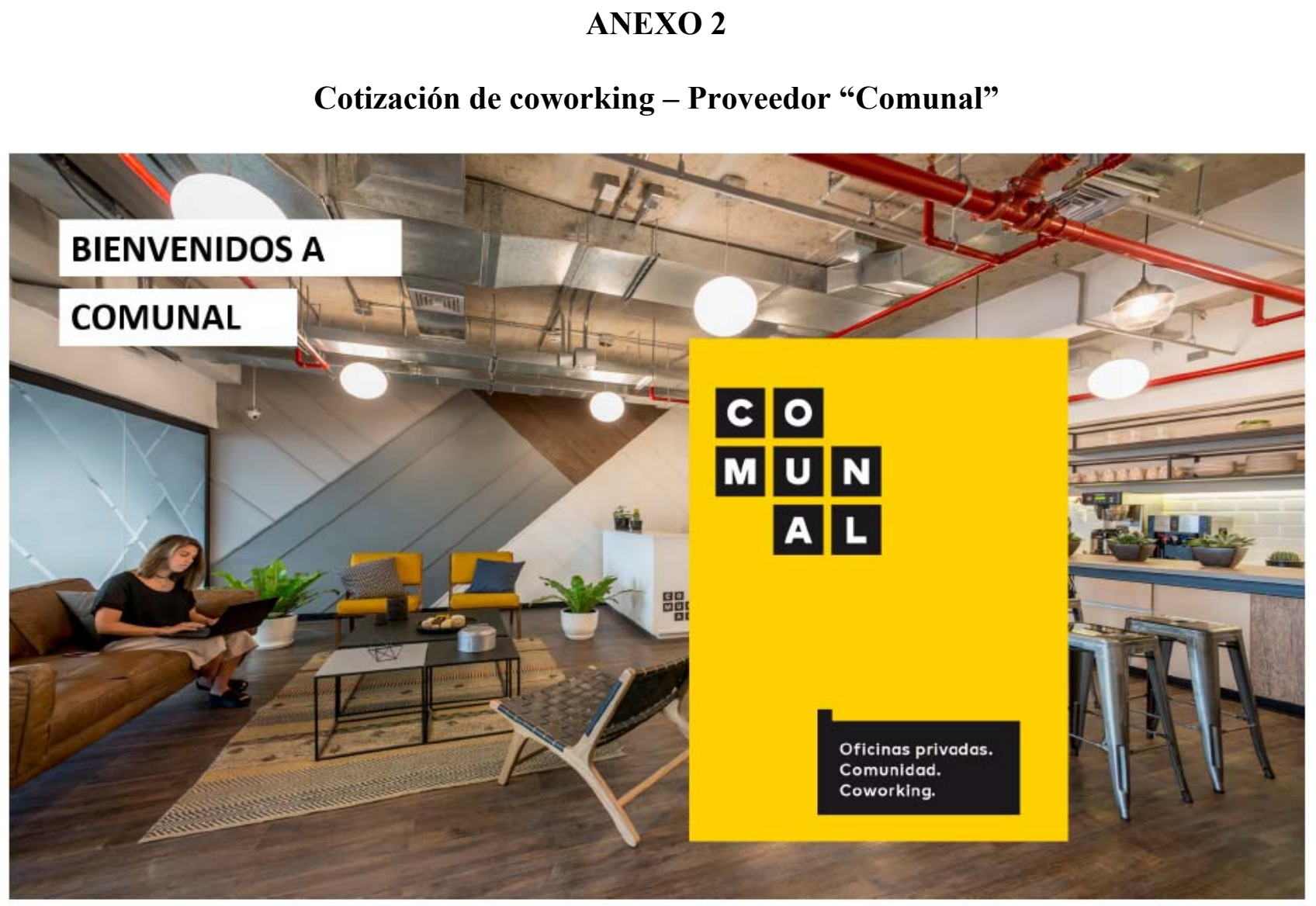

\section{Proforma}

\section{Caracteristicas del espacio}

1) Membresía Flex para 1 persona

2) Membresía Flex para 1 persona

3) Membresía Flex para 1 persona

4) Membresía Flex para 1 persona

5) Oficina Privada para 4 personas

6) Membresía Flex para 1 person

7) Membresía Flex para 1 persona

8) Membresía Flex para 1 persona

9) Membresía Flex para 1 persona

10) Oficina Privada para 4 personas

Locación: Calle Recavarren 111, Piso 7, Miraflores

\section{Precio}

1) USD $190+$ IGV al mes

2) USD $190+$ IGV al mes

3) USD $190+$ IGV al mes

4) USD $190+$ IGV al mes

5) USD $1170+$ IGV al mes

6) USD $190+$ IGV al mes

7) USD $190+$ IGV al mes

8) USD $190+$ IGV al mes

9) USD $190+$ IGV al mes

10) USD $1170+$ IGV al mes

$23 \mathrm{hrs}$. al mes de sala de reunión en nuestros 5 locales

\section{Condiciones}

- Los pagos se realizan el 1ero de cada mes

- Garantía: Correspondiente a un mes de servicios

- Impresiones: 100 en BN y 20 a color por usuario

- Medio de Pago: Transferencia bancaria

- Tiempo de Contrato: Indeterminado

- Cotización válida por 5 dias

- Espacios sujetos a disponibilidad 

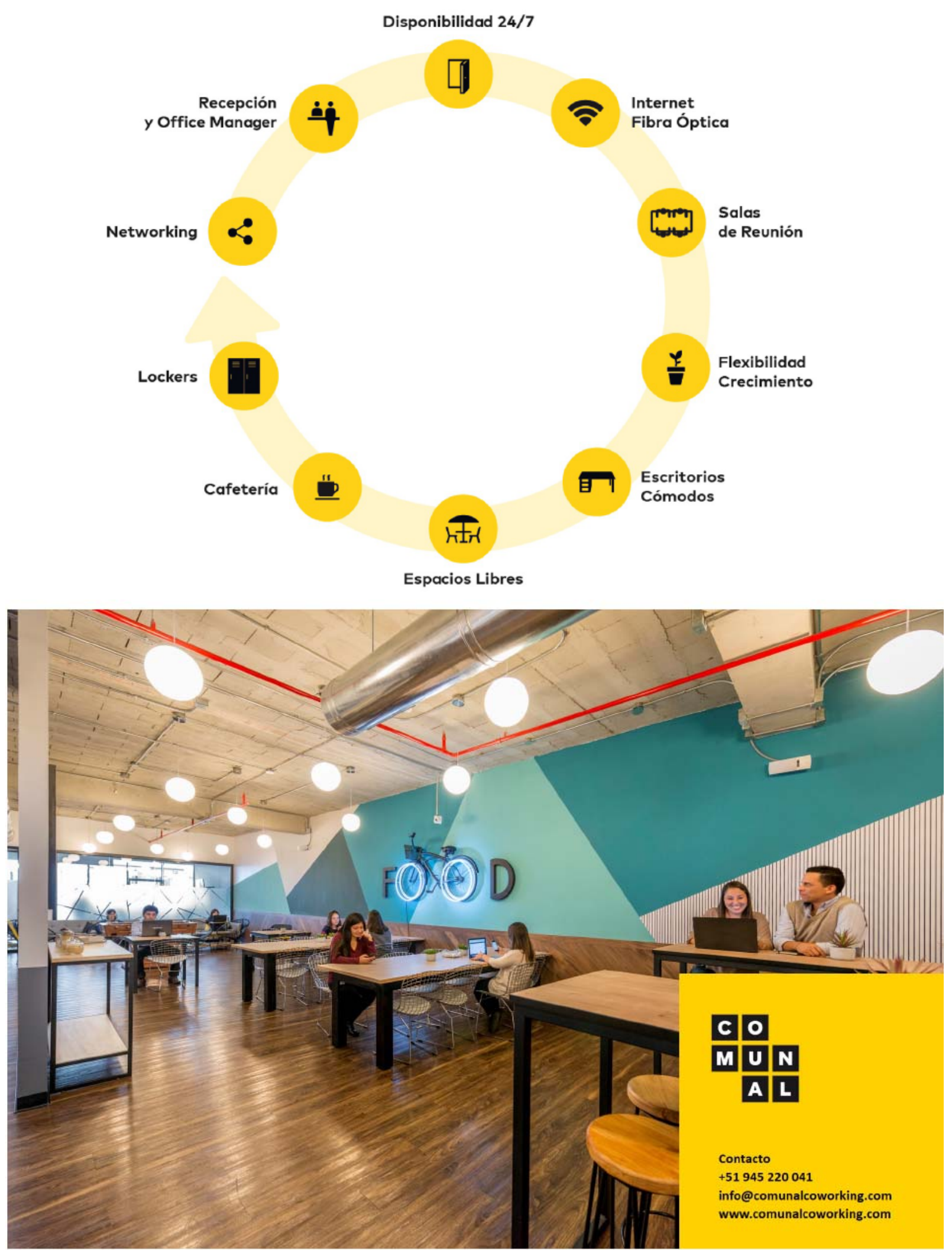